University of Louisville

ThinkIR: The University of Louisville's Institutional Repository

Electronic Theses and Dissertations

$12-2010$

\title{
Comparing pre and post-surgical self-efficacy behavior changes by introducing prehabilitation exercise.
}

Anthony Kent Brown

University of Louisville

Follow this and additional works at: https://ir.library.louisville.edu/etd

\section{Recommended Citation}

Brown, Anthony Kent, "Comparing pre and post-surgical self-efficacy behavior changes by introducing prehabilitation exercise." (2010). Electronic Theses and Dissertations. Paper 163.

https://doi.org/10.18297/etd/163

This Doctoral Dissertation is brought to you for free and open access by ThinkIR: The University of Louisville's Institutional Repository. It has been accepted for inclusion in Electronic Theses and Dissertations by an authorized administrator of ThinkIR: The University of Louisville's Institutional Repository. This title appears here courtesy of the author, who has retained all other copyrights. For more information, please contact thinkir@louisville.edu. 


\title{
COMPARING PRE AND POST- SURGICAL SELF-EFFICACY BEHAVIOR CHANGES BY INTRODUCING PREHABILITATION EXERCISE
}

\section{By}

Anthony Kent Brown

B.S. University of Louisville, 2003

M.S. University of Louisville, 2005

\author{
A Dissertation \\ Submitted to the Faculty of the \\ Graduate School of the University of Louisville \\ In Partial Fulfillment of the Requirements
}

For the Degree of

\section{Doctor of Philosophy}

Health Promotion and Behavioral Sciences Department

School of Public Health and Information Science

University of Louisville, Kentucky

December 2010 
Copyright 2010 by Anthony Kent Brown

All rights reserved 

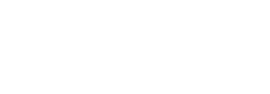

(

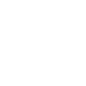

( . .

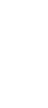

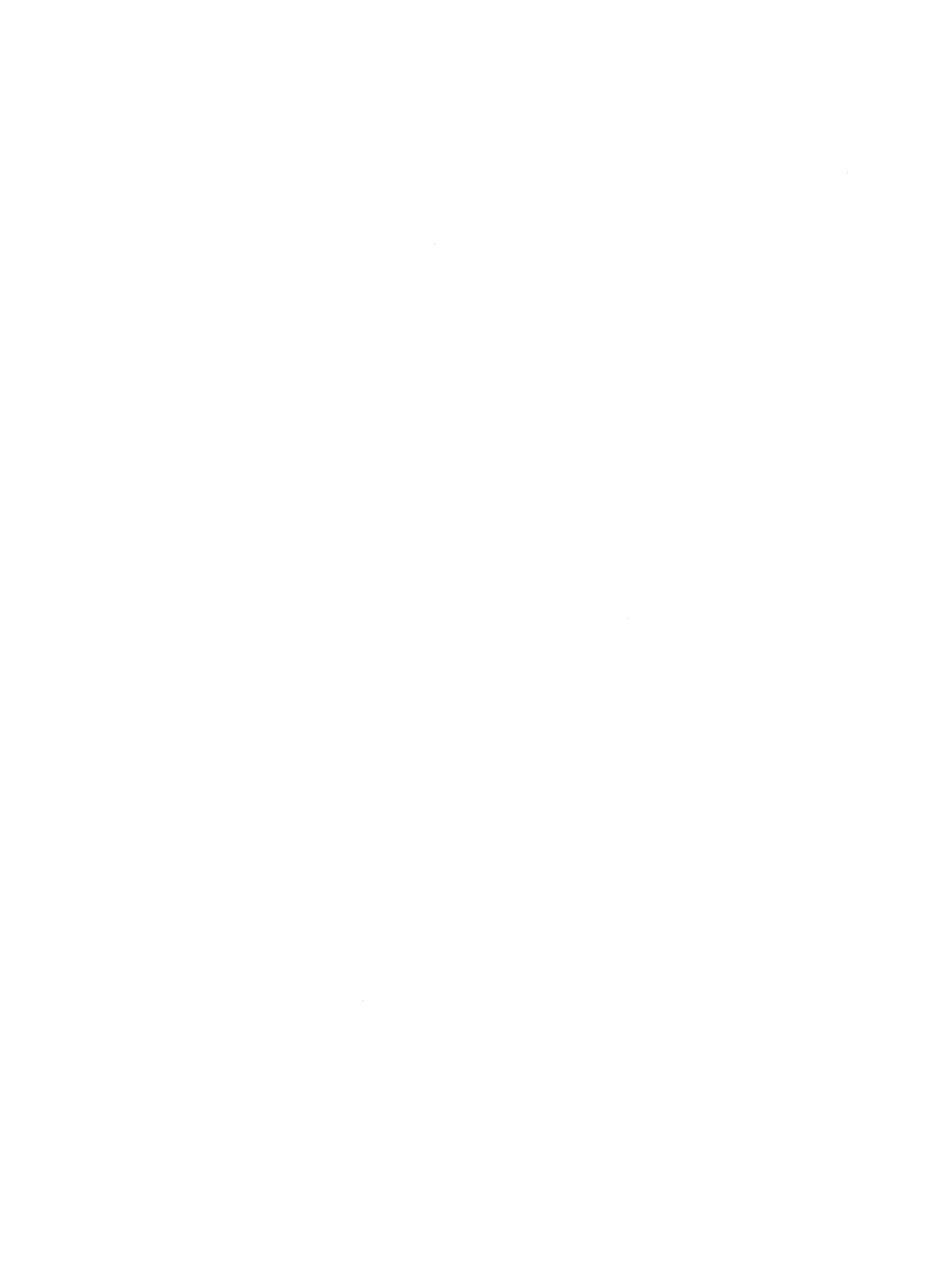

(1) 
COMPARING PRE AND POST- SURGICAL SELF-EFFICACY BEHAVIOR CHANGES BY INTRODUCING PREHABILITATION EXERCISE

\section{By}

Anthony Kent Brown

B.S. University of Louisville. 2003

M.S. University of Louisville, 2005

A Dissertation Approved on

Date: September 17, 2010

by the following Dissertation Committee:

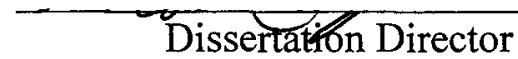

Dissertation Director 


\title{
DEDICATION
}

\author{
This dissertation is dedicated to my wife Cindy Brown \\ and my children, Mistie, Adam and Paul for their \\ support and encouragement during my graduate school years.
}

Also to my parents, James and Ina for instilling in me the desire to succeed. 


\section{ACKNOWLEDGMENTS}

First and foremost I want to start by thanking God, for surely he has laid out my path before me. It often seemed choices were made for me and all I had to do was follow his direction. It is through this following of God's direction that I have come to realize that the wonders of this world and the developments of its relationships were by design, not just by chance. Next I need to thank my wife, Cindy and daughter Mistie, for being my most ardent supporters. They always exhibited more confidence in me than I had in myself. I will always be appreciative of their never - ending encouragement for me to succeed.

I owe a special thank you to my dissertation chair and academic mentor, Dr. Scott LaJoie, for being a skilled and patient educator. I always felt compelled to work hard and to continuously improve because I knew Dr. LaJoie would not settle for anything less. This often led to many re-writes and revisions of my paper. His guidance and input during this long process resulted in me going from a "sophomoric" writing level to this completed dissertation.

My other committee members, Dr. Richard Wilson, Dr. John Myers, Dr. Ann Swank, and Dr. Robert Topp all provided me with different and unique perspectives on my topic. I would like to thank Drs. Wilson and Myers for their help on my committee and their recommendations for its improvements. 
One of the most rewarding aspects of going to school is the relationships it develops. There are some relationships I will always treasure. There are two that come to mind. This whole adventure started with Dr. Ann Swank, and her role as my teacher in graduate school. She suggested I participate in a TKA study which led to the research found in this dissertation. I am thankful for her insight and friendship. Then there is Dr. "Bob" Topp whom without his guidance and friendship, at every stage of my research, none of this would have ever happened. Dr. Topp has been invaluable in many ways. He has been a good mentor and has become a good friend to me and my family. Thank you "Bob" for all you have done to further my research knowledge.

I'd also like to thank and acknowledge Dr. Tony Brosky and Dr. Dave Pariser for their help and guidance. Without Tony letting me become part of this research I would have been at a loss for facilities and a location for all of the data collection.

Throughout this whole process Tony made it all fun and not so overwhelming. We even laughed at times.

Last but definitely not least I would like to thank all of the participants who volunteered to participate in the study. I also want to thank their family and friends that brought them to each session throughout this research.

Thank-You all 


\title{
ABSTRACT \\ COMPARING PRE AND POST- SURGICAL SELF-EFFICACY BEHAVIOR CHANGES BY INTRODUCING PREHABILITATION EXERCISE
}

\author{
Anthony Kent Brown
}

August 7, 2010

Introduction: Osteoarthritis (OA) is a clinical condition affecting over 27 million Americans. There is no known cure for OA other than replacing the diseased joint with a joint prosthesis, total knee arthroplasty (TKA).

Purpose: This study compared pre and post-surgical functional ability, exercise self efficacy and outcome expectations among total knee arthroplasty (TKA) patients who did and did not receive a prehabilitation exercise program.

Methods: 67 participants were eligible to participate in the study. Twenty-five participants indicated that they were not interested in participating in the study. As a result forty-two OA participants ( 31 female, 11 male) Of the 42,37 were interested and recruited into the study ( $\mathrm{n}=19 \mathrm{PRE}, \mathrm{n}=18 \mathrm{CON})$. The analytic sample ( $\mathrm{n}=16$ PRE, $\mathrm{n}=15 \mathrm{CON})$ included 31 subjects ( 22 female, 9 male).

Outcome Variables: self-efficacy to exercise survey (SEE), outcome expectations to exercise survey (OEE), 6-minute walk distance, number of sit-tostand repetitions in 30 seconds, the timed get up and go (TUG) test. 
Results: The effect of time was non-significant for SEE, $p=.655$ and OEE, $p=.146$. There was no significant interaction effect on SEE, $p=.590$ or OEE, $p=.933$. There was a significant effect of time on the six minute walk, $p<.001$, TUG, $p<.001$; sit-to-stand, $p$ $<.001$, ascending stair, $p<.001$ and on descending stair, $p=.001$.

Presentation: The dissertation is divided into five chapters, covering the clinical conditions of OA, treatment, impact of the problem, and the benefits of exercise. Chapter One gives an overview of the problem, impact of the problem, its history and discusses the significant health problem as a result of OA. Chapter two uses a review of the current literature to examine the conceptual framework and theory used in this study along with the introduction of the prehabilitation exercise intervention. Chapter three discusses the methodology used in the study and chapter four gives the data analysis and reports the findings of the data collected during the study. Finally chapter five gives a brief introduction of the study followed by the conclusions of the study. These conclusions include interpretations of the findings, discussions of the research hypotheses, recommendations, future research, theory application and finally future studies, limitations and a brief summary of the study. 
TABLE OF CONTENTS

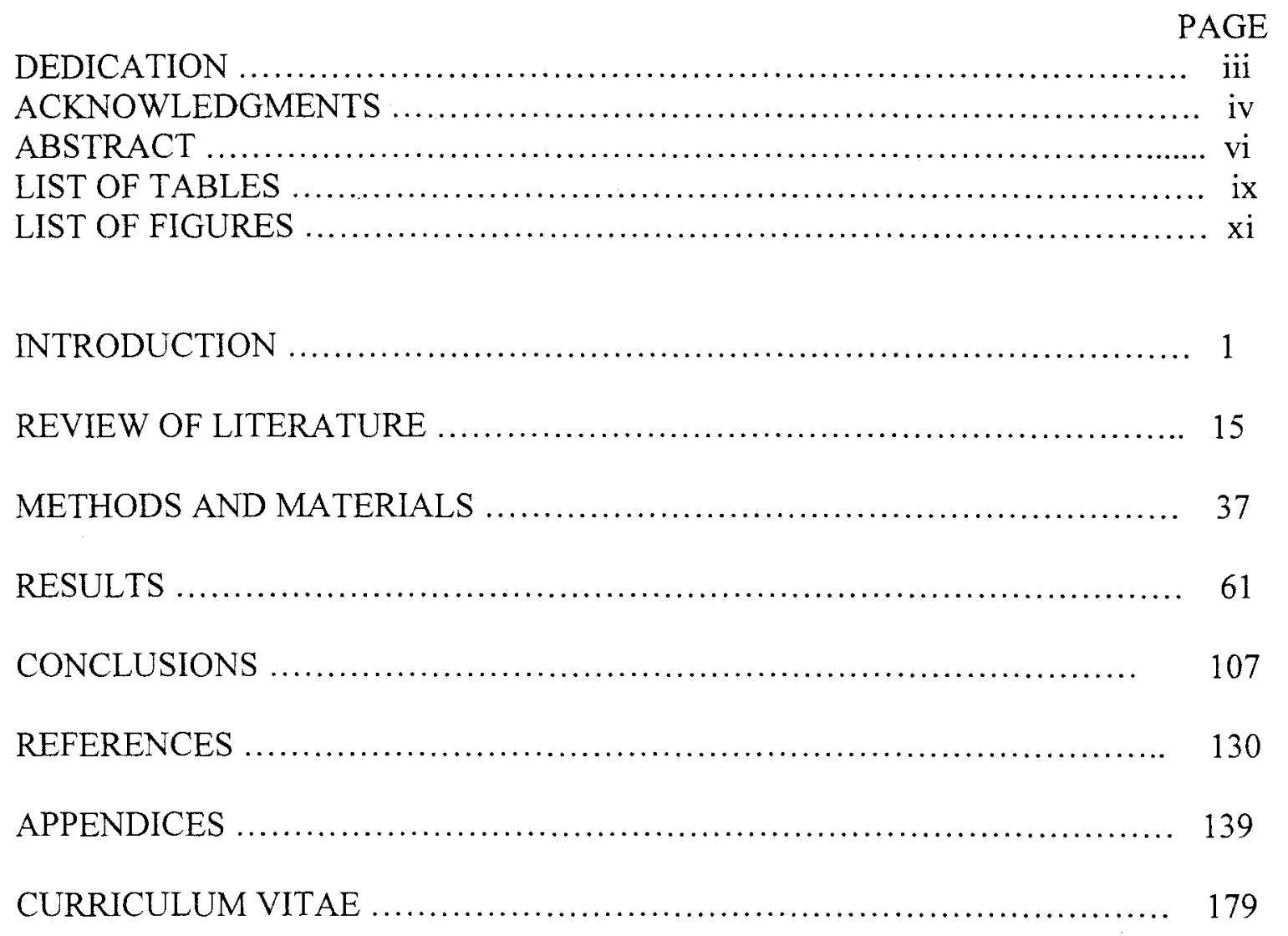




\section{LIST OF TABLES}

TABLE

PAGE

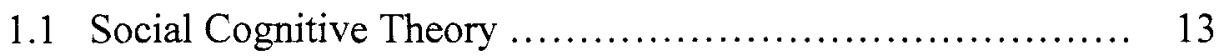

2.1 Psychosocial Determinants of Health Behavior .............. 22

2.2 Social Cognitive Theory Concepts ..................... 28

2.3 Methods for increasing self-efficacy $\ldots \ldots \ldots \ldots \ldots \ldots \ldots \ldots \ldots, 33$

3.0 Data collection timeline ............................... 46

3.1 Sample size estimates for outcome variables ............... 50

4.0 Demographic Characteristics of the Subjects $(\mathrm{N}=31) \ldots \ldots \ldots 65$

4.1 Pairwise comparison of time on OEE ..................... 69

4.2 Pairwise comparison of time on six minute walk ............ 72

4.3 Six minute walk Independent Samples T test .............. 73

4.4 PRE - Six minute walk Paired Samples T test ................. 74

4.5 CON - Six minute walk Paired Samples T test .............. 74

4.6 Pairwise comparison six minute walk .................... 75

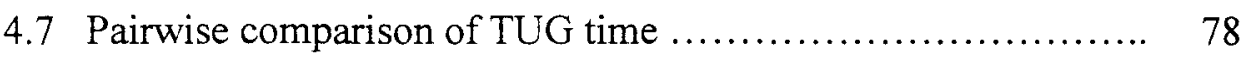

4.8 TUG Independent Samples T test ........................ 79

4.9 PRE group TUG Paired Samples T test .................... 79 
4.11 Pairwise comparison of TUG time, secondary data ........... 81

4.12 Pairwise comparison of sit to stand, initial data ............. 84

4.13 Sit to stand Independent Samples T test .................. 85

4.14 PRE group sit to stand Paired Samples T test ................ 85

4.15 CON group sit to stand Paired Samples T test .............. 86

4.16 Pairwise comparison of sit to stand, secondary data .......... 87

4.17 Pairwise comparison of Ascending stair, initial data .......... 90

4.18 Ascend stairs Independent Samples T test ................. 91

4.19 PRE group Paired Samples T test .......................... 91

4.20 CON group Paired Samples T test ........................ 92

4.21 Pairwise comparison of Ascending stair, secondary data ........ 93

4.22 Pairwise comparison of Descending stair, initial data ........... 96

4.23 Descend stairs Independent Samples T test ................ 97

4.24 PRE group descend stairs Paired Samples T test ............. 97

4.25 CON group descend stairs Paired Samples T test .............. 98

4.26 Pairwise comparison of Descending stair, secondary data ...... 99

4.27 PRE and CON means three months post TKA .............. 105

4.28 PRE and CON means three months post TKA Independent T test 106 


\section{LIST OF FIGURES}

FIGURE

PAGE

3.1 Instruments to Operationalize Variables

48

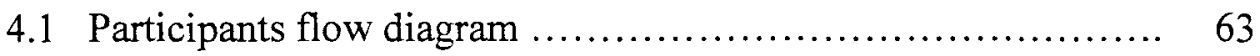

4.2 SEE Means for Group x Time 4 data points - primary data ..... 66

4.3 OEE Means for Group x Time 3 data points .................. 69

4.46 minute walk means - primary data, 4 data points ............ 71

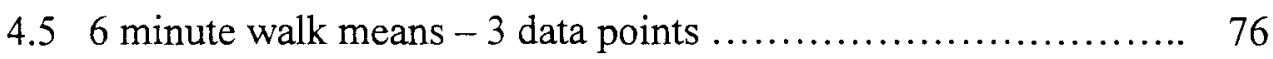

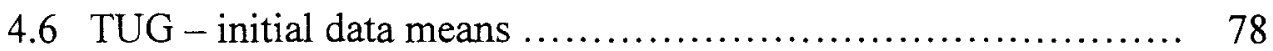

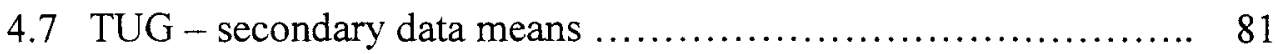

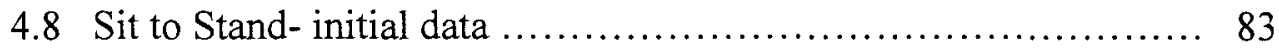

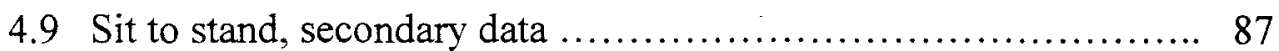

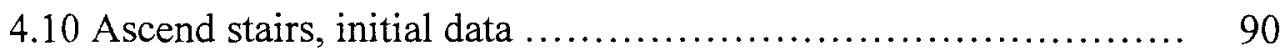

4.11 Ascend stairs, secondary data $\ldots \ldots \ldots \ldots \ldots \ldots \ldots \ldots \ldots \ldots \ldots . \ldots \ldots$

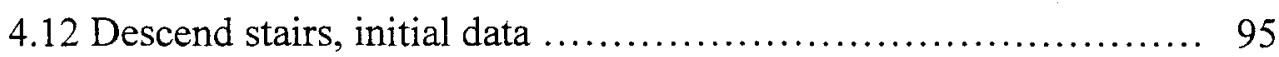

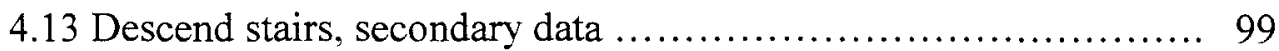

4.14 PCS mean score of population norms vs TKA ................ 102

4.15 MCS mean score of population norms vs TKA ................. 102 
4.16 PCS mean score of population norms vs TKA and CON........ 103

4.17 MCS mean score of population norms vs TKA and CON ....... 103 


\section{CHAPTER I}

Introduction to the problem

Osteoarthritis $(\mathrm{OA})$ is the clinical condition of joint pain and dysfunction caused by joint degeneration, and loss of articular cartilage (Buckwalter \& Martin, 2006). This disease is one of most common chronic health problems affecting over 27 million Americans, up from an estimate of 21 million in 1995 (Centers for Disease Control and Prevention, 2001; Lawrence, et al., 2008). With 59\% of adults over age of 65 years affected by this disease, its impact is projected to increase with the aging population of the U.S (Centers for Disease Control and Prevention, 2002). This chapter will introduce the reader to the diagnosis and categorization of $\mathrm{OA}$ along with treatment, impact of the problem, medical costs due to $\mathrm{OA}$ and the benefits of exercise.

The clinical classification of $\mathrm{OA}$ includes symptoms of persistent joint pain and stiffness along with joint degeneration (Buckwalter \& Martin, 2006). Once a patient develops OA, they suffer from the disease for the remainder of their lives, and the severity of pain and disability generally increases (Buckwalter, Saltzman, \& Brown, 2004; Osteoarthritis, 2000a, 2000b). After the age of 40 the incidence of OA increases rapidly in all joints, and in most joints the incidence is greater in women than in men (Buckwalter, et al., 2004). 
Characteristics of knee OA include decreases in strength (muscle weakness), fatigue, and functional ability and increases in joint pain (Creamer, 2004b; Hurley, 1999). Progression of these symptoms often leads to decreased mobility, deconditioning, reduced functional ability, and increased knee pain, all of which contribute to declines in the patient's quality of life.

Diagnosis and categorization of the severity of $\mathrm{OA}$ is normally made from radiographic evidence of arthritic damage of the articular cartilage and changes in the underlying subchondral bone (Hurley, 1999). However there exists a poor association between $\mathrm{x}$-ray signs of joint damage and the pain experienced by a patient with $\mathrm{OA}$ (Claessens, Schouten, van den Ouweland, \& Valkenburg, 1990).

Some patients who present with severe $\mathrm{x}$-ray joint damage may report little or no pain while others with severe pain may have very small degenerative changes in their affected joint (Claessens, et al., 1990). Whereas radiographic signs of knee OA are an unreliable predictor of joint pain, quadriceps weakness is a very common symptom reported by patients and is a better determinant of knee pain (Fisher, et al., 1993; Fisher, White, Yack, Smolinski, \& Pendergast, 1997; Slemenda, et al., 1997). In some subjects with no symptomatic signs of joint pain who have radiographic changes of $\mathrm{OA}$, quadriceps weakness predicts radiograph progression and pain (Slemenda, et al., 1997).

Hurley (1999) suggests these findings shows that muscle weakness may occur before OA damage. Slemenda (1997) states, in individuals with symptomatic OA of the knee, quadriceps muscle weakness is believed to result from disuse atrophy due to joint pain. Studies of the risk factors for the development of knee OA and/or its indicators of disease progression have taken place over the past decades. 
According to Hurley (1999) there has been limited research examining what occurs in the periarticular skeletal muscles surrounding a joint with $\mathrm{OA}$. These muscles are an integral part of the joint function. Weakness of the quadriceps muscles that surround the knee have been shown to lower the knee muscle's capacity to protect the knee joint against greater physical stress, structural damage, and joint degeneration and may play a role in disease development (Hurley, 1999; Petterson, et al., 2008; Slemenda, et al., 1997). More recent reports (Amin, et al., 2009) from longitudinal studies indicate that quadriceps strength influence on the progression of knee $\mathrm{OA}$ is unclear.

Knee OA is initially treated pharmacologically in an attempt to control the joint pain and preserve functional ability, but frequently, the disease progresses to where total knee arthroplasty TKA is indicated (Hawker, et al., 2006). Total knee arthroplasty involves removal of the knee joint, which is replaced by a prosthetic device and commonly involves prolonged rehabilitation (DeFrances \& Hall, 2004; Hawker, et al., 2006). Demand projections for the year 2016 are 1,046,000 total knee arthroplasties ( $\mathrm{O}^{\prime}$ Connor \& Fehring, 2009), and this number is predicted to increase by $600 \%$, from current levels, to over 3.4 million cases by 2030 (Kurtz, Ong, Lau, Mowat, \& Halpern, 2007). While the causes of OA are not completely known or understood, it appears that biomechanical abnormalities and/or stresses and biochemical changes in the articular cartilage and synovial membrane are both important in its pathogenesis (Hurley, 1999; Osteoarthritis, 2000b). There is no known cure for OA other than replacing the diseased joint with a joint prosthesis. Treatment designed for each individual patient can reduce pain, maintain or improve joint mobility and limit functional impairment (Osteoarthritis, 2000b). Pain from OA may increase with the changing of the weather, fluctuations in 
temperature, and increased physical activity (Buckwalter \& Martin, 2006).

Osteoarthritis is a major cause of disability among older people (Hughes, et al., 2004). Lower extremity OA has been shown to be a risk factor for disability (Hughes, et al., 2004). Patients with lower extremity OA may have limitations that impair their ability to perform activities of daily living (ADL), such as walking, bathing, dressing, use of toilet, and performing normal household chores (Osteoarthritis, 2000b).

\section{Impact of the problem}

Osteoarthritis, also known as degenerative joint disease, is one of the most common and historic forms of arthritis among U.S. adults and is a leading cause of disability (Arthritis foundation, 2009; Lawrence, et al., 2008; Osteoarthritis, 2000b; Prevention, 2006). Osteoarthritis leads to activity limitations, work disability, reduced quality of life, and higher health care costs (Petrella \& Bartha, 2000; Prevention, 2006).

Osteoarthritis affects individuals from all ethnic backgrounds and from all geographic regions across the U.S (Buckwalter \& Martin, 2006). In people over age 65, more than $75 \%$ have OA (Buckwalter, et al., 2004). Osteoarthritis accounts for $6 \%$ of all arthritis-related deaths which amounts to 500 deaths per year attributed to OA; these numbers have increased during the past 10 years (Sacks, et al., 2004).

Even though age is an overriding risk factor for OA, there are still other risk factors that can lead to this disease. Genetic predisposition, obesity, and joint laxity are also risk factors for increased risks of OA (Buckwalter \& Martin, 2006; Buckwalter, et al., 2004).

According to data from the Centers of Disease Control and Prevention, (CDC) $\mathrm{OA}$ is expected to impact the lives of an estimated 67 million adults in the United States 
by the year 2030 (Prevention, 2006). Estimates of the incidence of OA rank it as a major cause of economic loss and second only to ischemic heart disease as a cause of work disability in men over the age of 50 (Lawrence, et al., 2008).

The general public is facing a significant public health problem as a result of OA. Better health promotion and management interventions from public and private health agencies, along with disease prevention measures, have the potential to reduce the prevalence of disability among OA patients (Centers for Disease Control and Prevention, 2001; Prevention, 2006).

The incidence rates of OA, according to Buckwalter (2004), increases with each passing decade and tend to level off around the age 80 (Buckwalter, et al., 2004; Hurley, 1999). Individuals of all ethnic groups are affected by OA, and this disease develops in both men and women (Buckwalter, et al., 2004). Women have higher rates for the prevalence of $\mathrm{OA}$ than men due to the greater presence of osteophytes (outgrowths of bone at the margin of the joint) (Srikanth et al, 2005), especially after the age 50 (Buckwalter, et al., 2004). With the increase in the U.S. of an aging population, the incidence of TKA due to OA of the knee will continue to rise (Buckwalter, et al., 2004).

Osteoarthritis accounts for $55 \%$ of all arthritis-related hospitalizations; this number represents over 409,000 hospitalizations involving OA as the principal diagnosis (Lethbridge-Cejku, et al., 2003). Knee and hip replacement procedures represent $35 \%$ of all total arthritis-related procedures during hospitalization (Lethbridge-Cejku, et al., 2003). OA disables about $10 \%$ of individuals who are over the age of 60 , lowering the quality of life of more than 20 million Americans, and adds a cost of over $\$ 60$ billion per year to the U. S. economy (Buckwalter, et al., 2004). Lethbridge-Cejku et al (2003) 
estimated the costs of knee and hip replacements back in the year 1997 were close to $\$ 7.9$ billion (Lethbridge-Cejku, et al., 2003). The total costs attributable to arthritis and other rheumatic conditions in the United States in 2003 was approximately $\$ 128$ billion. Of this, $\$ 80.8$ billion were direct costs (i.e., medical expenditures) and $\$ 47$ billion were indirect costs (i.e., lost earnings). This equaled $1.2 \%$ of the 2003 U.S. gross domestic product (National Center for Chronic Disease Prevention and Health Promotion, 2007). According to Buckwalter (2004) these estimates of economic impact do not include the pain and suffering, adverse psychosocial effects, lost activities of daily living, and decreased ability to participate in regular exercise that could improve general health and lower health care costs.

Osteoarthritis is becoming a major public health problem due to its high prevalence, costs, and levels of pain and disability (Srikanth, et al., 2005). Since the most effective treatment of knee OA (TKA) is an expensive procedure, helping patients postpone the surgery and/or maximize the outcomes of surgery are necessary. Decreasing the burden of $\mathrm{OA}$ will require finding methods of preventing and slowing the joint degeneration OA causes (Buckwalter, et al., 2004).

Exercise has been shown to be beneficial for older adults with OA (American College of Sports, 2004; Hughes, et al., 2004) because it helps to decrease pain and aid in maintaining joint function (Hughes, et al., 2004). The role of therapeutic resistance exercise for increasing muscle strength in patients with knee $\mathrm{OA}$ is recommended within several guidelines (Osteoarthritis, 2000b; Panel, 2005). Studies have shown that pain is one of the leading barriers that discourage this population from participating in exercise (Der Ananian, Wilcox, Saunders, Watkins, Evans, et al., 2006; Murphy, et al., 2008; 
Wilcox, Der Ananian, Abbott, Vrazel, et al., 2006). Finding ways to increase and promote exercise participation in this population will need to include exercise intervention strategies which incorporate pain management, adaptive strategies and behavioral skills (Der Ananian, Wilcox, Saunders, Watkins, Evans, et al., 2006; Murphy, et al., 2008; Wilcox, Der Ananian, Abbott, Vrazel, et al., 2006).

One way to promote exercise behavior is to enhance exercise self-efficacy or perceived beliefs in control over one's ability to exercise (Bandura, 1997). Researchers have shown that exercise self-efficacy is an important predictor of the adoption and maintenance of exercise behaviors (Fletcher \& Banasik, 2001). To improve exercise activity in older adults, it is useful to consider self-efficacy expectations (desired results) to exercise, along with outcome expectations (expected benefits and costs of performing a behavior), because these beliefs influence motivation to exercise and actual exercise activity (Resnick \& Jenkins, 2000).

The primary assumption of this dissertation is that preoperative exercise interventions introduced to change exercise behavior prior to TKA will increase the patient's self-efficacy towards exercise participation and accelerate the rate of the patient's postoperative recovery. Post surgical rehabilitation has been the focus of most of the literature to date; however, literature dealing directly with exercise prehabilitation prior to TKA surgery appears limited in the literature.

The concept of preparing the body prior to a stressful event such as TKA surgery has been termed "prehabilitation" (Topp, Ditmyer, King, Doherty, \& Hornyak, 2002). This study addressed the problem of how to accelerate recovery and functioning after TKA. This researcher postulates that self-efficacy and expected exercise outcomes 
introduced and enhanced during the prehabilitation intervention will enhance recovery and functioning after TKA. Prehabilitation positively impacts knee strength and knee pain before surgery (Brown, et al., 2009; Ettinger, et al., 1997; Topp, Woolley, Hornyak, Khuder, \& Kahaleh, 2002) and will positively affect post surgical outcomes.

\section{Specific Aims}

The purpose of this research is to assess whether knee OA patients who engage in guided exercise prior to TKA have higher self-efficacy to exercise (SEE), higher outcome expectations for exercise (OEE) and higher post surgical functional ability than those who do not. A secondary purpose is to determine if knee OA patients who engage in guided exercise prior to TKA report higher levels of general health-related quality of life three months following their surgery compared to knee OA patients who don't engage in pre-operative guided exercise. Persons with higher SEE and OEE are expected to do better during post surgery rehab and therefore recover more fully. This purpose will be addressed through testing the following four hypotheses:

H1: Knee OA (KOA) patients who complete an eight-week prehabilitation program prior to TKA surgery will demonstrate an increase in scores as measured by the Self-Efficacy to Exercise (SEE) scale prior to surgery and at seven and 14 days post surgery compared to KOA patients who do not complete a prehabilitation program prior to their TKA surgery.

$\mathrm{H} 2$ : Knee OA (KOA) patients who complete an eight-week prehabilitation program prior to TKA surgery will demonstrate an increase in scores as measured by the Outcome Expectation for Exercise (OEE) scale prior to surgery and at seven and 14 days post surgery compared to $\mathrm{OA}$ patients who do not complete a prehabilitation program prior to their TKA surgery.

H3: Knee $\mathrm{OA}(\mathrm{KOA})$ patients who complete an eight-week prehabilitation program prior to TKA surgery will demonstrate an improved functional ability (sit to stand, walking time, stair time) at seven and 14 days post surgery compared to OA patients who do not complete a prehabilitation program prior to their TKA surgery. 
H4: Knee OA (KOA) patients who complete an eight-week prehabilitation program prior to TKA surgery will report high levels of general health-related quality of life three months following their TKA surgery compared to OA patients who do not complete a prehabilitation program prior to their TKA surgery.

\section{Exercise Intervention}

According to the best practices statement published by the American College of Sports Medicine, physical activities that include planned exercise offer great opportunities for individuals to extend their years of independence and reduce their functional limitations (Cress, et al., 2005; Murphy, et al., 2008). Crest (2005) states that regular participation in physical activities is one of the best ways for older adults, including those with disabilities, to help prevent chronic disease, promote independence, and increase quality of life in old age (Cress, et al., 2005, p. 1997). Among adults with $\mathrm{OA}$, participation in regular and vigorous physical activity has been shown to reduce the rate of functional decline (Murphy, et al., 2008). Ettinger (1997) states appropriate exercise offers benefits in treating the OA patient. Exercise by the OA patient has been shown to improve pain, function and increase self-efficacy to exercise (Ettinger, et al., 1997; Rooks, et al., 2006a) even after as little as four to eight weeks of moderate intensity training ( Brown, et al., 2009; Deyle, et al., 2000; Ries, et al., 1996). Exercise is considered by many to be a cornerstone of rehabilitation following TKA; however, there has not been much attention placed on the role of exercise in preparation prior to an individual undergoing TKA surgery. Previous research using exercise as an intervention prior to TKA indicates that preoperative knee strength is a consistent predictor of preoperative ( Brown, et al., 2009) and post operative functioning among TKA patients (Topp, Swank, Quesada, Nyland, Kachelman, et al., 2008). 
Enhancing the individual's exercise self-efficacy has been shown to be one of the most effective ways of increasing exercise participation (Bandura, 1997; Cotter, Sherman, Cotter, \& Sherman, 2008). Exercise self-efficacy instills a sense of selfconfidence in one's personal ability to become physically active (Bandura, 1997; McAuley, et al., 2003). Cotter (2008) states that exercise interventions must include methods for increasing exercise self-efficacy.

Other research indicates that an exercise intervention can improve the ability to complete functional tasks, increase knee strength and reduce knee pain among nonsurgical knee OA patients (Topp, S. Woolley, J. Hornyak, S. Khuder, \& B. Kahaleh, 2002). Based upon these studies, it is reasonable to predict that enhancing knee strength and the ability to complete functional tasks preoperatively through exercise interventions will accelerate the rate of the patient's postoperative recovery. Enhancing knee strength preoperatively should also lead to the reduction of activity limitations, less work disability, improved quality of life, and lower health care costs.

A number of studies have examined the effects of preoperative exercise interventions upon postoperative outcomes (Barbay \& Barbay, 2009; Brown, et al., 2009; D'Lima, Colwell, Morris, Hardwick, \& Kozin, 1996; Gilbey, et al., 2003; Jaggers, et al., 2007; Mizner, Petterson, Stevens, Axe, \& Snyder-Mackler, 2005; Rodgers, et al., 1998; Rooks, et al., 2006a). Data on the direct effects of prehabilitation TKA exercise interventions are scarce (Rooks, et al., 2006b), although recent case studies suggest the benefits of appropriate prehabilitation exercise interventions in treating patients with osteoarthritis (OA) prior to TKA (Brown, et al., 2009; Kachelman, et al., in review; Topp \& Page, 2009). 
According to Beaupre, it is unclear how a preoperative program combining both education and exercise will affect postoperative recovery and health service utilization following primary TKA (Beaupre, et al., 2004). Unfortunately, efforts to help patients adopt an exercise program are often unsuccessful. It may be even harder to get the patient to adopt an exercise program especially if those patients are experiencing pain.

Steinhardt and Dishman (1989) indicated that in order to understand the gaps in knowledge of the determinates of participation in physical activity, the researcher will have to increase the testing of psychological theories of behavior (Steinhardt $\&$ Dishman, 1989). Recent evidence suggests decision-making theories (like the social cognitive theory SCT) developed in the field of social psychology may be applicable to physical activities (Steinhardt \& Dishman, 1989). These theories include a role for the value a person places on the outcomes expected from a behavior and the barriers that a person perceives as obstacles to the behavior. For many older individuals, aging is associated with a loss of perceived control (Kunzmann, et al., 2002). This loss of control could be due in part to the lowering of one's confidence to participate in exercise programs without causing harm.

People are more likely to start and maintain physical activity if they feel confident about their ability to be successful and if they are given opportunities to actively participate in physical activity, which leads to enhancing their self-efficacy (Cress, et al., 2005). Positive changes in performance along with success in achieving expected outcomes are associated with exercise adherence in older adults (Cress, et al., 2005). Empowerment based exercise programs that include strength-training programs are often motivating for older adults, by creating a more meaningful physical activity experience 
for them (Katula, et al., 2006).

According to Bandura's Social Cognitive theory (SCT), self-efficacy determines whether an individual attempts to perform a given task and how persistent he or she is when difficulties are encountered (Bandura, 1977a). An example of overcoming encountered difficulties would be the OA patient exercising while experiencing knee joint pain. Bandura states that: "appropriate skills and adequate incentives" are needed for successful outcomes (Bandura, 1977a). Introducing the OA patient to a prehabilitation exercise program will lead him or her to greater self-efficacy and more expections of positive outcomes.

This prehabilitation will lead to a greater SEE and prevent the development of a detrimental health habit.

The individuals in this prehabilitation study were introduced to an exercise program that considered the concepts (see table 1.1) of the SCT. Under the guidance of the professional trainers, the concepts of the SCT were passed on to the study participants. Those SCT concepts included the appropriate skills, knowledge and adequate incentives to perform a given behavior, and confidence in one's ability to take action to overcome barriers needed for successful outcomes. These successful outcomes will lead to a greater self-efficacy within each of the prehabilitation participants. During the eight weeks of prehabilitation, the patients should have Self-Efficacy and Outcome expectations enhanced by exercise interventions. 


\section{Table 1.1}

Social Cognitive Theory

\begin{tabular}{|c|c|c|}
\hline Concept & Diffinitions & Potential Change Stratigies \\
\hline $\begin{array}{c}\text { Reciprocal } \\
\text { determination }\end{array}$ & $\begin{array}{l}\text { The dynamic interaction of } \\
\text { the person, behavior, and } \\
\text { the environment in which } \\
\text { the behavior is performed }\end{array}$ & $\begin{array}{l}\text { Consider multiple ways to } \\
\text { promote behavior change, } \\
\text { including making adjustments } \\
\text { to the environment or } \\
\text { influencing personal attitudes }\end{array}$ \\
\hline Behavior capacity & $\begin{array}{l}\text { Knowledge and skill to } \\
\text { perform a given behavior }\end{array}$ & $\begin{array}{l}\text { Promote mastery learning } \\
\text { through skills training }\end{array}$ \\
\hline Expectations & $\begin{array}{l}\text { Anticipated outcomes of } \\
\text { behavior }\end{array}$ & $\begin{array}{l}\text { Model positive outcomes of } \\
\text { healthful behavior }\end{array}$ \\
\hline Self-efficacy & $\begin{array}{l}\text { Confidence in one's ability } \\
\text { to take action and overcome } \\
\text { barriers }\end{array}$ & $\begin{array}{l}\text { Approach behavior change in } \\
\text { small steps to ensure success; } \\
\text { be specific about the desired } \\
\text { change }\end{array}$ \\
\hline $\begin{array}{l}\text { Observational } \\
\text { learning } \\
\text { (modeling) }\end{array}$ & $\begin{array}{l}\text { Behavior acquisition that } \\
\text { occurs by watching the } \\
\text { actions and outcomes of } \\
\text { others' behavior }\end{array}$ & $\begin{array}{l}\text { Offer credible role models } \\
\text { who perform the targeted } \\
\text { behavior }\end{array}$ \\
\hline Reinforcements & $\begin{array}{l}\text { Responses to a person's } \\
\text { behavior that increase or } \\
\text { decrease the likelihood of } \\
\text { reocurence }\end{array}$ & $\begin{array}{l}\text { Promote self-initiated rewards } \\
\text { and incentives }\end{array}$ \\
\hline
\end{tabular}

Adapted from (Glanz \& Rimer, 2005)

Since $\mathrm{OA}$ is so common, it is important for patients to receive the most effective and cost- efficient treatment. Most of the literature deals with rehabilitation post TKA and does not address the need for exercise interventions prior to TKA. This study compared pre and post-surgical exercise self-efficacy, outcome expectations and post surgical functional ability between TKA patients who did and did not receive a prehabilitation exercise program. 


\section{Summary}

The number of individuals undergoing TKA is expected to increase dramatically as the population ages. The patient's ability to return to activities of daily living (ADL) has personal, social and financial implications. The patient's self-efficacy and expected exercise outcomes may improve his or her rate and level of recovery. Exercise interventions introduced preoperatively to change exercise behavior prior to TKA may increase the patient's self-efficacy towards exercise participation and help accelerate the rate of the patient's postoperative recovery. Post surgical rehabilitation has been the focus of most of the literature to date; however, literature dealing directly with exercise prehabilitation prior to TKA surgery is scarce or missing from the literature. Future investigations may want to focus on the relationships between OA and the public's general health status, which includes participation in regular exercise, furthering the understanding of the impact of OA (Buckwalter, et al., 2004).

The purpose of this research was to examine the effects of prehabilitation exercise on pre and post-surgical exercise self-efficacy, outcome expectations and post surgical functional ability in TKA patients who did and those who did not receive a prehabilitation exercise. 


\section{CHAPTER II \\ REVIEW OF LITERATURE \\ Introduction}

This review of literature examined the conceptual framework provided by the Social Cognitive Theory (SCT) to determine if the introduction of prehabilitation exercise interventions prior to Total Knee Arthroplasty (TKA) is enough to change the self-efficacy of the patient post TKA, therefore affecting his or her exercise behavior levels. During an eight week prehabilitation exercise intervention, the patients would have Self-Efficacy and Outcome expectations enhanced by exercise interventions. The information presented in this chapter will show the need for introducing exercise interventions to TKA patients prior to their knee surgery in order to improve their exercise behavior following TKA surgery. It is hypothesized that this behavior change will improve functional activities of daily living and improves quality of life for $\mathrm{OA}$ patients. This review will first examine the factors (barriers and enablers) affecting exercise behaviors that are expressed by participants with arthritis conditions, such as OA. In the second section of this review, prehabilitation (exercise interventions prior to TKA) and the levels and amounts of exercise behavior (Pre \& Post TKA) will be addressed. The third section will examine the theories considered for use in this intervention. Finally, the fourth section will focus on the selection and use of the social cognitive theory (SCT) and its conceptual role in this study. 


\section{Purpose of the review}

The primary focus of this literature review was to identify, review, and analyze any new challenge or intervention in the reduction of total knee arthroplasty (TKA) surgery among the older adult community at large. This research review discusses and synthesizes key findings. This comprehensive review is a synthesis of primary sources (mainly research articles published in academic journals) gathered through multiple search strategies. Online databases available through the University of Louisville's library system (http://louisville.libguides.com/databases) (OVID, MEDLINE, PUBMED, EBSCO, PsycINFO) were used. The search of these databases was done by using a number of key words used separately and in a number of combinations to identify previous studies that included "knee," "knee joint," "outcomes," "prehabilitation," "outcome expectation," "preoperative exercise," "total knee arthroplasty," "osteoarthritis," "social cognitive theory", and "self-efficacy." The scope of this literature review included changing exercise behavior to lowering the financial costs associated with TKA. The review focused primarily on studies from the early 1990's to 2009 containing quantitative and/or qualitative analyses answering questions about persons undergoing TKA. 


\section{Factors influencing exercise}

TKA helps to lower knee joint pain and improves function however; patients still exhibit impairments in quadriceps strength and functional performance (Petterson, et al., 2009). Functional performance is reported to worsen by $20-25 \%$ one month after TKA (Mizner, et al., 2005). These strength and function deficits return slowly, and most patients recover to preoperative status; however, these strength and function impairments remain below the healthy age matched age groups for years following TKA (Minns Lowe, et al., 2007).

Healthy People 2010 explains the importance of exercise among individuals with arthritis (U.S. Government, 2000). According to many studies, exercise (resistance training) has been shown to reduce pain, delay disability, improve physical function, increase muscle strength, and reduce the risk from other chronic conditions (Creamer, 2004a; Ettinger, et al., 1997; Messier, et al., 2004). Despite the number of documented benefits of exercise for arthritis management most research has focused on adults in general and few studies have focused on the factors for individuals with arthritis (Wilcox, Der Ananian, Abbott, Vrazel, et al., 2006). Even with recent public health objectives (Government, 2000) emphasizing the role of exercise in reducing arthritis associated disability, people with arthritis are less active than those without arthritis (Hootman, Macera, Ham, Helmick, \& Sniezek, 2003; Shih, et al., 2006).

There are several unique factors or barriers that influence exercise levels among older adults with arthritis. Four broad categories of barriers to exercise have emerged in recent studies: physical, psychological, social, and environmental (Der Ananian, Wilcox, Saunders, Watkins, Evans, et al., 2006; Wilcox, Der Ananian, Abbott, Vrazel, et al., 
2006). When physical barriers were listed as hindrances to exercise, those barriers included pain, mobility limitations, comorbidities, and fatigue (Der Ananian, et al, 2006; Somers, Keefe, Godiwala, \& Hoyer, 2009).

Pain was the most frequent barrier cited as a limiting factor to exercise (Der Ananian, et al., 2006; Wilcox, Der Ananian, Abbott, Vrazel, et al., 2006). Mobility limitations that lowered the ability to perform activities of daily living (ADL) and morbidities from other illnesses, such as cardiovascular disease, were also considered barriers to exercise. Another physical factor was the role of fatigue. Many participants in recent studies cited fatigue due to the medications used to control or manage his or her arthritis prevented him or her from exercising (Der Ananian, et al, 2006; Somers, et al., 2009; Wilcox, Der Ananian, Abbott, Ramsey, \& Sharp, 2006).

Psychological barriers included the individual's attitudes and beliefs about exercise. Participants with arthritis believed that exercise was not reducing their pain, and they expressed a lack of understanding about which exercises were safe and how much exercise would be appropriate for them to perform (Der Ananian, et al., 2006; Wilcox, Der Ananian, Abbott, Vrazel, et al., 2006). Participants also had feared that they would experience pain if they were to participate in a form of exercise with which they were unfamiliar (Der Ananian, et al., 2006; Wilcox, Der Ananian, Abbott, Vrazel, et al., 2006).

Social and environmental factors included insufficient advice from their health care providers and the lack of available arthritis- specific exercise facilities or programs tailored to the arthritic patient (Der Ananian, Wilcox, Saunders, Watkins, Evans, et al., 2006). Participants stated they often did not receive good advice from their physicians. The advice they most often received lacked the details and specifics on the type, 
frequency, intensity, and duration of exercise which would be appropriate for individuals with arthritis (Der Ananian, et al., 2006). According to Der Ananian (2006), many participants stated they only were given a pamphlet or handout with exercise instructions without being given directions or referrals to facilities and/or professionals in the field that could direct and guide their exercise program.

These same studies (Der Ananian, et al., 2006; Wilcox, Der Ananian, Abbott, Vrazel, et al., 2006) go on to list the benefits and advantages that the participants believed they received from participating in exercise activities. The physical benefits included reducing pain to the point where it was more manageable. The participants reported having more energy, less stiffness, more weight loss, and a decrease in the frequency of use of medications as benefits of exercise participation (Der Ananian, et al., 2006). Many participants reported improved strength and flexibility which led to better mobility and an improvement in their activities of daily living.

Social support was also considered to be valuable among the study participants. The participants stated that having someone to exercise with provided an opportunity for social interaction and was more enjoyable than exercising alone (Der Ananian, et al., 2006). The study by Der Ananian (2006) stated the presence of knowledgeable instructors, with clinical expertise in arthritis treatment, and the availability of individualized, tailored programs led to greater motivation to exercise among participants. 


\section{Prehabilitation (introducing exercise interventions prior to TKA)}

Exercise has been a rehabilitation tool and not a preoperative intervention (prehabilitation) patients used prior to TKA surgery. A recent meta-analysis has found benefits to short term structured rehabilitation but no long term advantages (Minns Lowe, et al., 2007). Most of the literature shows rehabilitation as the most prescribed treatment for TKA patients even though rehabilitation displays poor results over time due to poor muscular strength and muscular endurance, limiting the benefits of participation in postoperative activity and thus limiting the benefits of rehabilitative therapy (Ditmyer, et al., 2002). Therefore it is important to look at other forms of interventions like prehabilitation.

Preoperative inactivity is associated with the OA orthopedic condition (Ditmyer, et al., 2002).This decline in physical activity influences muscle atrophy, such as in the quadriceps muscles, which are involved in walking and are needed for functional independence. These are the first muscles recruited during postoperative rehabilitation therapy (Ditmyer, et al., 2002).

At the current time results of preoperative interventions are inconclusive due to a lack of research evidence (Barbay \& Barbay, 2009). Preoperative exercise intervention is now being tested to determine if it improves patient outcomes post TKA surgery. Preoperative exercise has been shown to be successful prior to cardiac or abdominal surgery (Barbay, 2009). However the data on the direct effects of prehabilitation TKA exercise interventions are scarce (Rooks, et al., 2006b), although recent studies by this researcher and others now show the benefits of appropriate prehabilitation exercise interventions in treating patients with osteoarthritis (OA) prior to TKA (Brown, et al., 
2009; Kachelman, et al., in review; Topp \& Page, 2009).

This study demonstrated how to increase the older adult populations' self-efficacy towards exercise, by having them participate in an eight week prehabilitation intervention, in order to mititigate the arthritic effects and/or improve the patient's TKA surgical outcomes. In order to promote better exercise behavior, exercise self-efficacy will need to be enhanced. The information presented in this research will show the need for introducing exercise to TKA patients prior to their knee surgery in order to improve their exercise behavior post surgery.

This study may result in more physicians embracing prehabilitation exercise interventions and relaying that to their patients. The advice the physicians give to their patients must include the details and specifics on the type, frequency, intensity, and duration of exercise which would be appropriate for individuals with arthritis (Der Ananian, et al., 2006). When patients are given pamphlets or handouts with exercise instructions from their physician, there needs to be clear directions or referrals to facilities with professionals in the field that could direct and guide their exercise program.

\section{Relevant behavior theories}

When looking to put in place a new intervention, all applicable theories must be examined to determine which theory can be used to guide and direct research most effectively. When developing an intervention plan, the researcher should seek out theoryinformed methods and practical strategies to aid in directing how to go about changing a health behavior in the individual at risk. There are numerous behavioral theories which researchers could choose to use in helping to design exercise interventions ( Jones, et al., 2004). Possible theories include the theory of planned behavior (TPB) (Ajzen \& Driver, 
1991, p. 187), which proposes that "behavior intention is the proximal determinant of future behavior." The health belief model (HBM) (Rosenstock, 1974) is a psychological model that attempts to explain and predict health behaviors. The Transtheoretical model (TTM), describes the individual's motivation and readiness to change a behavior (Prochaska \& Velicer, 1997), and the Social Cognitive theory (SCT) (Bandura, 1977a), indicates that self-efficacy determines whether an individual attempts to perform a given task and how persistent he or she is when difficulties are encountered. Table 2.1 displays the factors from the theories discussed in this chapter. Most of these factors found within the different behavior models are mainly different types of outcome expectations.

Table 2.1 Psychosocial Determinants of Health Behavior

$\begin{array}{ccc}\text { Self- } & \text { Outcome Expectations } \\ \text { Efficacy }\end{array}$

Theories

Physical Social Self-

Proximal Distal Perso
$\&$

Situational System

Social

Cognitive

Theory

Health Belief

Model

Theory of

Planned

Behavior

Transtheoretical

Model

Sociocognitive determinants overlap within different theories and models of health behavior Addapted from (Bandura, 2004). 
The first theory this researcher considered using is the theory of planned behavior (TPB) which has been used in predicting exercise participation (Ajzen \& Driver, 1992). The TPB which is the successor of the Theory of Reasoned action explores the relationship between behavior and beliefs, attitudes, and intentions. The TPB shows that behavioral intention is the most important determinant of behavior (Glanz \& Rimer, 2005). According to the TPB model, behavioral intention is influenced by a person's attitude toward performing a behavior and by beliefs about whether individuals who are important to the person approve or disapprove of the behavior (subjective norm).

The TPB also includes one additional construct, perceived behavioral control, which has to do with people's beliefs that they can control a particular behavior (Glanz \& Rimer, 2005). The theory of planned behavior (Ajzen \& Driver, 1991; Ajzen \& Driver, 1992) aids in understanding how the behavior of individuals can be altered. There are three basic components of the TPB (Ajzen \& Driver, 1991). These are: 1) Behavioral beliefs about the likely consequences of the behavior; 2) Normative beliefs about the expectations of others; 3) Control beliefs about the presence of factors that may facilitate or impede the performance of the behavior (Ajzen \& Driver, 1991).

Another example of a possible theory to be considered is the Health Belief Model (HBM), developed by social psychology researchers Hochbaum, Rosenstock and Kegels, at the U.S Public Health Service in the 1950's (Model, 2002). The HBM is a theory relating to how individuals perceive the threat of a health problem and appraises recommended behaviors for preventing or managing the problem. The HBM, according to Glanz \& Rimer (2005), addresses the individual's perceptions of the threat posed by a 
health problem (susceptibility, severity). HBM also looks at the benefits of avoiding the threat and factors influencing the decision to act (barriers, cues to action, and selfefficacy). HBM has many key components: perceived susceptibility, perceived severity, perceived benefits, perceived barriers, cues to action, and self-efficacy (Glanz \& Rimer, 2005).

The HBM also postulates the following four conditions;

1) a person believes that his or her health is in jeopardy

2) a person perceives the potential seriousness of the condition in terms of pain or discomfort, time lost from work, or other outcomes

3) a person believes the benefits from the recommended behavior outweigh the costs and inconvenience.

(4) a person believes that these benefits are within their reach.

The major assumption of this model is that in order to engage in healthy behaviors, the intended audiences need to be aware of their risk for severe or lifethreatening diseases and perceive that the benefits of behavior change outweigh potential barriers or other negative aspects of recommended actions (Schiavo, 2007).

The Health Belief Model relates largely to the cognitive factors predisposing a person to a health behavior, concluding with a belief in one's self-efficacy for the behavior. The HBM leaves much still to be explained by factors enabling and reinforcing one's behavior, and these factors become increasingly important when the model is used to explain and predict more complex lifestyle behaviors that needs to be maintained over a lifetime (Model, 2002). The Health Belief Model has been applied to a broad range of health behaviors and subject populations. However, the HBM has mostly been applied to 
preventive health behaviors, which include health-promoting (e.g. diet, exercise) and health-risk behaviors (e.g. smoking).

The third theory, Transtheoretical model TTM (Prochaska \& Velicer, 1997), came about from a comparative analysis of change systems used in psychotherapy to treat addictive behaviors and has since been used as a framework to help understand an individual's readiness to change behavior (Sonstroem, 1988). The TTM has been applied to many health behaviors since the early 1980 's, ranging from over -eating and becoming overweight or obese (Johnson, et al., 2008) to the cessation of smoking (DiClemente, et al., 1991), to better safe sex practices leading to the lowering of sexually transmitted disease (Spencer, et al., 2006) and improved exercise behavior (Prochasta \& DiClemente, 1983).

According to Spencer, et al., 2006, exercise has been found to be one of the largest topic groups of published studies on TTM, except for the prevention of tobacco usage. The components of TTM (Marcus, Selby, Niaura, \& Rossi, 1992) that have been applied to exercise are stages of change (refers to a person's readiness to engage in regular exercise); processes of change (e.g., use of a support partner or reward); decisional balance (refers to the process of weighing the pros against the cons, or costs, of adopting exercise); self-efficacy (the degree of confidence a person has that he or she can exercise regularly) (Marcus, Eaton, Rossi, \& Harlow, 1994); and temptation (referring to the barriers preventing one from exercising) (Hausenblas, et al., 2001).

Prochaska's TTM of intentional behavior change describes change as a process that unfolds over time and progresses through six stages: precontemplation (not ready to take action); contemplation (getting ready); preparation (ready); action (overt change); 
maintenance (sustained change); and termination (no risk of relapse) (Prochaska \& Velicer, 1997). Progress requires the application of specific change processes such as consciousness raising (education and feedback) at the precontemplation stage and reinforcement and helping relationships during action. Public health programs tailored to each stage of change can dramatically increase recruitment, retention, and progress and "impacts on entire populations at risk for chronic disease and premature death", like those patients with OA (Model., 2002, p. 1; Prochaska \& Velicer, 1997).

Although interventions based on the TTM have been effective in increasing exercise under certain conditions, they have not been applied to a large-scale community based interventions in older adults (Greaney, et al., 2008) especially those adults facing TKA due to OA. The TTM is not the best choice for this study because the intention is not to influence the individual's inclination to change by progressing through the stages of change: precontemplation; contemplation; preparation; action, maintenance and termination. This study introduced the patient directly into a program that engaged him or her in regular exercise activities without going through any of the stages of change.

The importance of self-efficacy for initiating a pattern of regular physical activity has been shown to derive from social-cognitive theories of behavior (Bandura, 1977a). Therefore, Bandura's Social Cognitive theory (SCT) was the fourth theory to be reviewed. "SCT integrates concepts and processes from cognitive, behaviorist, and emotional models of behavior change, so it includes many constructs" (Glanz \& Rimer, 2005, p. 20). Table 2.2 defines and shows the application of the key concepts of the SCT. These concepts can be grouped into five categories (Glanz, Rimer, \& Viswanth, 2008, p. 
170): 1) psychological determinants of behavior, 2) observational learning, 3)

environmental determinants of behavior, 4) self-regulation, and 5) moral disengagement. 
Table 2.2

Social Cognitive Theory Concepts

Concept

Reciprocal

determinism

Outcome

expectations

Self-efficacy

Collective

efficacy

Observational

learning

Incentive

motivation

Facilitation

Self-regulation

Moral

disengagement
Definition

Environmental factors influence individuals, but individuals can also influence their environments and regulate his or her own behavior

Beliefs about the likelihood and value of the consequences of behavior choices

Beliefs about personal ability to perform behaviors that bring desired outcomes

Beliefs about the ability of a group to perform concerted actions that bring about desired outcomes

Learning to perform new behaviors by exposure to interpersonal displays of them

The use of rewards to modify behavior

Providing tools, resources, or environmental changes that make new behaviors easier to perform

Controlling oneself through selfmonitoring, goal-setting, feedback, and self-instruction

Ways of thinking about harmful behaviors (e.g.,. Poor exercise habits)

\section{Application in study}

Study participants are introduced to the physical therapy center and are influenced by its environment. Prehab also influences their home environment.

Changing expectations of physical outcomes due to sedentary subjects being introduced to exercise intervention

Subjects begin to believe in benefits of exercise as they see progress due to performing new behaviors

By belonging to the prehabilitation group the subjects believe that these concerted actions (Hawthorne effect) will bring about desired outcomes

The subjects learn how to perform the new exercise behaviors from watching the trained professionals perform the movements

The subject receives praise (positive reinforcement) from the trainers for performing the exercises correctly. Subjects receive motivation to increase good behavior

Subjects are given a Prehabilitation Intervention Booklet with directions to perform each individual exercise. Therabands are Provided.Trainers are provided. They are brought into the facility which changes their environment from normal settings

Subjects keep a log-book, set goals to increase strength, and follow Prehabilitation Intervention the booklet

The subjects will be influenced by the progress they make from the exercise intervention and will have a change in the way they view harmful behaviors by increasing good exercise habits

Adapted from (Glanz, et al., 2008) 


\section{SCT Conceptual Framework}

According to Bandura's SCT, self-efficacy determines whether an individual attempts to perform a given task and how persistent he or she is when difficulties are encountered (Bandura, 1997). Bandura states that "appropriate skills and adequate incentives" are needed for successful outcomes (Bandura, 1977b, p. 194). According to Bandura (1977), it is often easier to prevent detrimental health habits than to try to change them after they have become entrenched as part of an individual's lifestyle. Therefore it is important to change behavior towards exercise before it becomes a permanent way of life for the OA patient.

SCT provides a conceptual framework for understanding the factors that influence human behavior. SCT also provides the processes through which learning occurs. "But its greater significance has come from the application of SCT to the design of interventions to meet important practical challenges in medicine and public health" (Glanz, et al., 2008, p. 175).

Health knowledge can be conveyed readily, but changes in values, attitudes, and habits require greater effort. Health promotion programs that encompass the essential elements of the self-regulatory model achieve greater success (Bandura, 1986; Model., 2002). This study used the SCT because it fits with the design of this study better than any of the previous mentioned theories. Most, if not all, of the constructs of the SCT were used within this study. Behavioral capability which states that in order to perform a behavior, a person must know what to do and how to do it. The participants in this study received the needed information from trained professionals with clinical knowledge of 
OA about which exercises are safe and how much exercise would be appropriate for them to perform. Expectations would be enhanced due to the expected results an individual hopes to receive from taking action.

The construct of Self- Efficacy will be enhanced by using strategies for increasing self-efficacy that include 1) setting incremental goals, 2) behavioral contracting (committing to a formal contract), 3) monitoring and 4) reinforcement (feedback from self-monitoring or record keeping). Observational learning will occur as the participants learn through the experiences of credible others (professional trainers), rather than through their own experience. Finally the use of Reinforcements (using motivation) to change behavior will be done by having the participants meet with the trainers once a week to reinforce his or her good progress and help maintain his or her good exercise behavior.

There are two types of efficacy expectations described within the Social Cognitive Theory: self-efficacy expectations and outcome expectations. Self-efficacy expectations are the individuals' beliefs in their capabilities to perform a specific behavior. Outcome expectations are the beliefs that carrying out a specific behavior will lead to a desired outcome. An outcome expectation might be what the individual perceives to be the benefits of exercise (e.g., improving muscle strength, living longer, losing weight, or feeling good in general) (Resnick, Zimmerman, Orwig, Furstenberg, \& Magaziner, 2001). Given that self-efficacy influences outcome expectations, it is anticipated that these factors will also strengthen outcome expectations, (Jette et al., 1998; Resnick, 2000). 
Researchers have shown exercise self-efficacy is an important predictor of the adoption and maintenance of exercise behaviors (Fletcher \& Banasik, 2001). Other researchers say in order to improve exercise activity in older adults; it is useful to consider self-efficacy expectations related to exercise because these beliefs influence motivation to exercise and actual exercise activity (Resnick \& Jenkins, 2000). During this study the participants were introduced to various exercises and during the eight weeks of prehabilitation learned how to perform each exercise. Through the exercise intervention, the participants came to realize they can perform the exercises and therefore have an increase in their exercise self-efficacy.

Self-efficacy beliefs are important because if an individual believes he or she can exercise, even given constraints and impediments such as fatigue, limited time, or a chronic health condition such as arthritis, then there is a greater likelihood of him or her exercising or changing behavior towards exercising (Bandura, 1997). According to Bandura $(1977,1997)$ and the SCT, self-efficacy is the primary determinant of consistent, health-promoting levels of physical activity. Behavior change is also determined by outcome expectation that is when an individual expects his or her actions to lead to a desirable outcome. An individual might have high self-efficacy for exercise, but if he or she believes that exercise does not do anything to prevent or remediate aging or chronic health related losses, there will be little or no motivation to continue exercising (Neupert, et al., 2009). 
Individuals could have high self-efficacy expectations for exercise; however, if he or she does not believe the exercise will improve strength or function, adherence to a regular exercise program is unlikely (Neupert, et al., 2009). Past research shows there are declines in the sense of efficacy (belief an individual has in personal capabilities) and control over physical functioning among older adults (Lachman, 1986; Neupert, et al., 2009).

Self- efficacy perceptions and outcome expectations are derived from four primary information sources:1) past performance accomplishments (mastery experience), 2) vicarious experience (social modeling), 3) verbal persuasion, and 4) physiological states (physical and emotional states) (Bandura, 1977b, 1997). Vicarious experience is based on modeling the behavior of others. Individuals learn how to act and what to expect by observing other people's behavior. Then they test what they have seen or learned through modeling in their own lives. Verbal persuasion is based on the power of suggestion. Bandura wrote that verbal persuasion is used frequently because it is easy to accomplish and is likely to lead to weaker efficacy expectations than performance accomplishments because it does not provide an "authentic experiential base" (Bandura, 1977b, p. 188). Table 2.3 shows methods used for increasing self-efficacy. 


\section{Table 2.3}

\section{Methods for increasing Self-Efficacy}

Mastery experience Enabling the person to succeed in attainable but increasingly challenging performance of desired behaviors. The experience of performance mastery is the strongest influence on self-efficacy

Social modeling

Showing the person that others like themselves can do it. This should include detailed demonstrations of how the small steps taken in the attainment of a complex objective

Improving physical and emotional states

Verbal persuasion
Making sure people are well-rested before attempting a new behavior. This can include efforts to reduce stress and depression while building positive emotions. They become "excited"

Telling the person that he or she can do it. Strong encouragement can boost confidence enough to induce the first efforts toward behavior change

Source from: (Glanz, et al., 2008, p. 177)

The individual's mental state often includes anxiety due to the lack of skills or knowledge to perform the tasks. This anxiety may diminish when the person gains the skills needed to perform the tasks (Bandura, 1977b). This intervention supplied the skills needed to perform the exercise tasks. Past exercise experience is believed to exert the most powerful influence on exercise self-efficacy (Bandura, 1997). Participants within the prehabilitation group will gain exercise experience during their eight weeks of prehabilitation. This previous exercise experience prior to TKA will be of value after they undergo TKA. 
Persons in the control group with poor past exercise habits are the least likely to believe they can be successful in the future. Low exercise self-efficacy leads to exercise avoidance because, according to SCT, individuals presented with tasks they do not believe they are able to do become anxious at the prospect and avoid the situation (A Bandura, 1997; Fletcher \& Banasik, 2001).

According to SCT (Bandura, 1997), human motivation and action are essentially regulated by forethought. "This cognitive control of behavior is based on beliefs including self-efficacy expectations, which are an individuals' beliefs in their capabilities to perform a course of action to attain a desired outcome, and specific outcome expectations, which are beliefs that a certain consequence will be produced by personal action" (Resnick, Palmer, Jenkins, \& Spellbring, 2000, p. 1309). "The older adult may believe he or she is capable of performing a specific behavior, but may not believe the outcome of performing that behavior is worthwhile" (Resnick, Palmer, et al., 2000, p. S352).

There is also evidence that outcome expectations have an important influence on older adult's exercise behavior (Resnick, Palmer, et al., 2000). Resnick reported that outcome expectations were better predictors of exercise behavior than self-efficacy expectations (Resnick, Zimmerman, Orwig, Furstenberg, \& Magaziner, 2000). The belief in the health benefits of exercise is the most often reported expected outcome for engaging in physical activity (Steinhardt \& Dishman, 1989). 


\section{Summary}

The conceptual framework for this study was provided by Bandura's social cognitive theory. This theory is based on two sets of expectations: self-efficacy expectations (Bandura, 1977a) which are individuals' beliefs in their capabilities to perform a course of action to attain a desired outcome, and outcome expectations (Bandura, 1977a), which are beliefs that a certain consequence will be produced by personal action. Most of the models and theories concerning health behavior discussed in this chapter only deal with predicting health behavior habits. Most do not describe how one can change health behavior. The SCT provides predictors and principles on how to "inform, enable, guide, and motivate people to adapt habits that promote health" (Bandura, 2004, p. 146). The use of the SCT while introducing the patient to exercise prior to TKA is predicted to have long term benefits following their TKA. SCT supports the positive effects of prehabilitation exercises in terms of SEE and OEE in increasing the patient's post exercise behavior.

Researchers have shown that exercise self-efficacy is an important predictor of the adoption and maintenance of exercise behaviors. In order to improve exercise activity in older adults, it is useful to consider self-efficacy expectations related to exercise because these beliefs influence motivation to exercise and actual exercise activity. Preoperative exercise interventions introduced to change exercise behavior prior to TKA may increase the patient's self-efficacy towards exercise participation and compliance and help accelerate the rate of the patient's postoperative recovery. In this study the presence of instructors with knowledge of OA and the availability of individualized, tailored exercise prescription programs prior to TKA are predicted to lead 
to the participant's behavior change in the form of greater motivation to exercise pre and post TKA. 


\section{CHAPTER III}

\section{METHODOLOGY}

$\underline{\text { Introduction }}$

This study compared pre and post-surgical functional ability, exercise selfefficacy and outcome expectations among TKA patients who did and did not receive a prehabilitation exercise program. This chapter includes information about the significance of the study, research design, participants and the setting, protection of human subjects, instrumentation, and the plan for data collection and analysis.

\section{Significance of the Study}

This study is an intervention that could influence a patient's: 1) length of rehabilitation, 2) costs of healthcare services, 3) activities of daily living (ADLs) 4) return to work time, 5) overall quality of life. This study demonstrated the effects of an eight-week program of prehabilitation on the ability to complete functional tasks, selfefficacy for exercise and outcome expectations for exercise among TKA patients. If the intervention is found to be effective, exercise interventions may be introduced preoperatively with patients scheduled for a TKA as an intervention designed to facilitate early recovery from their surgery. The outcomes of this study have the potential to reveal that preoperative exercise can enhance self - efficacy to exercise behavior, outcome expectations and functional ability pre - surgery and post - surgical recovery. 


\section{Research design}

This study was a randomized clinical trial. Eligible volunteers, after providing an informed consent (APPENDIX A), were assessed at baseline (T1) approximately eight weeks prior to their scheduled TKA surgery. This assessment included measures of the individual's functional ability, self-efficacy to exercise, and outcome expectations for exercise. Participants were then assigned to an intervention or a control condition. Participants in the control condition received the usual care prior to and following their TKA surgery. Participants assigned to the intervention group were instructed to complete three bouts of prehabilitation each week prior to their TKA surgery. A bout of prehabilitation included a warm-up, ten resistance exercises, six stretching exercises, three step exercises and a cool-down. Following their TKA surgery prehabilitation participants received the same standard post-operative care as the control participants. All participants completed measures of their functional ability, self-efficacy to exercise and outcome expectations for exercise one week (T2) prior to their TKA surgery and again at one (T3) and two (T4) weeks following their TKA surgery. Participants also were asked to complete the SF-36 Health Survey three months post their TKA to assess quality of life. These procedures resulted in two study groups (control and intervention) being measured four times (baseline T1, T2, T3 and T4) over the duration of the study and a survey of health status three months post surgery.

Individuals in this study that were eligible and agreed to participate underwent baseline testing and then was randomly assigned to a study group by selecting from a group of shuffled unmarked envelopes containing a card assigning them to either a prehabilitation group (treatment) or a usual treatment group (control). Participants in the 
treatment group then participated in three sessions of prehabilitation per week, one supervised session and two unsupervised, for eight weeks prior to their TKA. Following the TKA, all subjects in the treatment and control groups participated in the standard post-TKA rehabilitation program.

\section{$\underline{\text { Intervention }}$}

The prehabilitation treatment group was given a prehabilitation training booklet which explains all five components of the prehabilitation training program including warm up, resistance exercises, flexibility exercises, step training and a cool down (See Appendix B). Components of this training program have been demonstrated to improve either performance of functional tasks, knee pain or the markers of rehabilitation among older adults (Topp, et al, 2009b). The prehabilitation training booklet was based upon previous guidelines for older adult exercise programs (Topp, Mikesky, Dayhoff, \& Holt, 1996).

One of the critical components of any exercise training program is the principle of specificity. This principle of training stipulates that the more closely the training mimics the evaluation method, the greater the improvement in the evaluation method as a result of the training (Fleck \& Kraemer, 1997). A number of the components of the prehabilitation program are similar to the functional tasks that were evaluated. Examples of this include squatting with Thera band resistance to increase the subject's ability to rise up from a chair and step exercises to improve the subject's ability to ascend and descend a flight of stairs. Thus, the prehabilitation training program involved exercises designed to improve strength, flexibility, and coordination which are critical components of the 
functional tasks which were being evaluated as outcome variables.

Participants were requested to complete the prehabilitation training protocol three times per week, once per week under the supervision of the project staff at the Physical Therapy Clinic located at Bellarmine University and two times per week without supervision at home. All three prescribed sessions included the same warm up, resistance exercises, flexibility exercises, step training and a cool down. Thus, participants could schedule their supervised session for any of the three prescribed sessions per week and be consistent with their exercise prescription. This method of partially supervising the exercise intervention has previously resulted in acceptable adherence by older participants without making unreasonable demands upon their time commitment to the supervised exercise sessions (Topp, et al., 1996; Topp, Mikesky, \& Thompson, 1998; Topp, et al., 2001). Participants in this group were taught how to record each session of prehabilitation training in an exercise $\log$ (See Appendix C).

Initially a session of prehabilitation training included approximately five minutes of warming up, 15 minutes of resistance training exercises, 15 minutes of flexibility exercises, ten minutes of step training and five minutes of cool down exercises (See Appendix B). The warm-up consisted of unweighted leg joint movements to increase blood flow to the muscles of the legs, trunk, and arms. Following the warm-up, subjects completed eight dynamic muscle strengthening exercises including squats, ankle dorsi/plantar, hamstring flexion, bicep curls, triceps extensions, chest press and seated row. During the first training week, each participant performed one set of ten repetitions of each strengthening exercise using a Theraband with sufficient resistance to produce 
"moderate" fatigue following the final repetition. Individual training progressed under the supervision of the researcher until weeks seven and eight, during which each participant performed one or two sets of ten repetitions of each exercise using a Theraband with sufficient resistance to produce "moderate" fatigue following the final repetition with a two-minute rest between sets (approximately 20 minutes).

Following completion of the resistance training exercises, within each session of prehabilitation, participants completed six flexibility exercises. Over the entire duration of the eight-week prehabilitation training program, the flexibility exercises included two repetitions of static stretching for 20 seconds for each flexibility exercise. The flexibility exercises emphasized knee extension/flexion, hip flexion/extension, trunk extension/flexion and shoulder flexion/extension/rotation. Following completion of the flexibility exercises, subjects completed three step-training exercises. These step-training exercises included going up and down a single step forwards and then sideways to the left and right. During the first week of the prehabilitation program, participants completed eight repetitions of each of the step exercise using a two or three - inch step. The number of repetitions and the height of the step of each of these step exercises were increased over the eight-week prehabilitation intervention. During the $8^{\text {th }}$ week of the prehabilitation program, participants completed 20 repetitions of each of the step exercises using a four or seven-inch step. The cool-down consisted of five minutes of unweighted leg joint movements of the muscles of the legs, trunk, and arms. If the participant is unable to complete the initial level of training or was unable to progress at any week in the eight-week training schedule, an individualized training program was developed for him or her consistent with that participant's level of training ability. This 
individualized prehabilitation training program strived to have the individual achieve the same level of training for all five components as prescribed in the prehabilitation exercise booklet. The number of repetitions and sets for all components of the prehabilitation program was recorded in the exercise log.

\section{Adherence with Prehabilitation}

The inability to maintain a commitment to an exercise program has been a problem for many disciplines including fitness and rehabilitation (Annesi \& Annesi, 2004). Research shows a $40 \%$ to $65 \%$ dropout rate of those who initiate a physical activity regiment often within the first three months (Annesi \& Annesi, 2004). This study employed the intent to treat (ITT) (Chow \& Lui, 1998) principle of retaining all subjects randomized into the prehabilitation group regardless of their adherence with the prehabilitation intervention. The ITT principle is based on the initial treatment intent, not on the actual treatment given (Lachin, 2000). No intervention was provided during the postoperative period other than the standard post-TKA rehabilitation program, to all participants as part of their usual post TKA care. Individuals supervising the participant's postoperative rehabilitation had no knowledge of the participant's group assignment. This protocol resulted in a two-group repeated measures design with functional tasks, selfefficacy for exercise and outcome expectations for exercise as the outcome variables of interest.

Although the ITT principle did not consider the subject's treatment adherence, this variable was monitored. Adherence to the prehabilitation treatment was monitored, to aid in the progression of the subject's strength, through exercise logs (see appendix C). The logs were monitored weekly by the staff member conducting the supervised exercise 
session but completed by each participant following each session of prehabilitation exercise. These exercise logs requested each participant in the intervention group to document the date, specific components, duration and intensity of the exercise they performed. The resistance training component was recorded as the intensity or level of resistance employed during the exercise, the number of repetitions, and the number of sets of repetitions of strength exercises completed during each treatment session. The flexibility component was recorded as the number of each flexibility exercises completed. Finally, the number and type of step exercises was also reported in the exercise logs.

\section{Participants and setting}

Over the ten-month duration of the study, it was estimated that 40 patients scheduled for a TKA would need to be screened. The anticipated drop-out rate based on a current ongoing TKA study at Bellarmine University was $25 \%$. Thus in order to obtain the sample of 30 subjects who would undergo baseline testing and complete all four data collection points an initial sample of 40 would be recruited into the study. During the study period (June 09-March 2010) 67 participants were eligible to participate in the study. Twenty-five participants indicated that they were not interested in participating in the study. Forty-two OA participants ( 31 female, 11 male, mean age $=61$ years, no significant difference in age, $p=.385$ ) who met the inclusion criteria and were scheduled for a total knee arthroplasty (TKA) were contacted to see if they were interested in participating in the study. Of the 42,37 were interested and recruited into the study ( $\mathrm{n}=$ 19 PRE, $n=18 \mathrm{CON})$. The final sample $(\mathrm{n}=16 \mathrm{PRE}, \mathrm{n}=15 \mathrm{CON})$ included 31 subjects (22 female, 9 male) that consented to participate, came in for baseline (T1) testing and completed some data collection. 
Eligible community-residing individuals age 40 years or older were initially identified by the participating orthopedic surgeon(s) clinics. All patients who initially met the inclusion criteria (see Appendix D) and were scheduled to have an elective TKA, at least eight weeks out from surgery were invited to participate in the study. If an eligible patient expressed an interest in participating in the study, contact information was collected by the individual scheduling surgery in the orthopedic surgeon(s) clinic and passed on to the research study director. In order to facilitate recruitment of participants, the individual scheduling surgery was paid $\$ 50$ for each individual he or she referred to the study. All potential participants who expressed an interest in being involved in the research were contacted. During this phone contact, the patient was given details of the project and informed that he or she had the right to decline participation or withdraw from the study at anytime without affecting their pre or postoperative TKA treatment. Potential participants were excluded during this telephone interview if they reported a history of uncontrolled angina, cardiomyopathy severe enough to compromise cardiac functioning, any other health problem that prohibited moderate exercise, or if they were currently taking nitrates, digitalis, or phenothiazines. These exclusion criteria (See Appendix D) are based upon the American College of Sports Medicine's guidelines (ACSM, 2009). Potential participants were also excluded if they reported involvement in an exercise program more than one time per week during the previous month. This method strived to ensure a sample that was as representative as possible of communityresiding adults who were scheduled for unilateral TKA for treatment for knee OA (Der Ananian, et al, 2006; Hootman, Macera, Ham, Helmick, Sniezek, et al., 2003). 
During the preliminary phone call, if the individual agreed to participate in the study, he or she was scheduled for an appointment at the Bellarmine University Physical Therapy Clinic. Each individual who agreed to participate was asked to sign an informed consent form explaining the risks and benefits of participating in the study prior to any data being collected. Only individuals who reported no contraindications to moderate intensity exercise, who were scheduled for a unilateral TKA, who were 40 years or older, and who stated they could make a commitment to the research protocol was included as participants for this study. Potential participants who are unable to read and write English or engage in a formal exercise program greater than once per week were excluded from the study.

A number of incentives were provided to the participants for participating in the research protocol. All participants had access to free parking adjacent to the building which houses the Bellarmine University Physical Therapy Clinic. Participants received $\$ 10$ for each of the first three data collection sessions (baseline, T2, T3) they complete and $\$ 20$ upon completion of the final data collection session (T4) for a total of $\$ 50$ for completing all data collection sessions (see table 3.0). Table 3 displays the data collection timeline. 


\section{Table 3.0}

Data collection timeline

\begin{tabular}{|c|c|c|c|c|c|}
\hline T1 & $\mathrm{T} 2$ & TKA & T3 & T4 & 3 month \\
\hline $\begin{array}{l}\text { Baseline or eight } \\
\text { weeks prior to } \\
\text { initial TKA }\end{array}$ & $\begin{array}{l}\text { Just one week } \\
\text { prior to initial } \\
\text { TKA }\end{array}$ & Surgery & $\begin{array}{l}\text { One week } \\
\text { following } \\
\text { initial } \\
\text { TKA }\end{array}$ & $\begin{array}{l}\text { Two weeks } \\
\text { following } \\
\text { initial TKA }\end{array}$ & $\begin{array}{c}\text { follow-up } \\
\text { SF-36 }\end{array}$ \\
\hline
\end{tabular}

Prehabilitation intervention prior to TKA

\section{$\underline{\text { Data Collection }}$}

The prehabilitation group had variables collected that included: background data, ability to complete functional tasks, self-efficacy to exercise and outcome expectations for exercise and, adherence with prehabilitation (See Figure 3.1). Background information (age, gender, BMI, co-morbidities etc. See Appendix E) was collected at the baseline testing point only since it was assumed these variables would not change over the duration of the ten week study protocol. Information related to adherence with prehabilitation was collected from the treatment subjects, while the control subjects were left to do normal activities, for eight weeks prior to their TKA. Ability to complete functional tasks, self-reported questionnaires was collected from all subjects at eight and one week(s) prior to the subject's TKA, and at seven and 14 days postoperatively.

Adherence with prehabilitation was collected weekly from each subject in the prehabilitation intervention group. The Medical Outcomes Study 36-Item Short-Form 
(SF-36) (see APPENDIX F) was administered at three months post TKA. The same investigator was responsible for collecting the data at each data collection point.

Figure 3.1 displays the instruments which were used at each data collection point. 


\section{Figure 3.1}

Instruments to Operationalize Variables

$\underline{\text { Variable }}$

Background Data

Self-reported questionnaires
Instruments

- Demographic Questionnaire (at baseline T1)

- The self-efficacy exercise (SEE) scale collected at each data point $\mathrm{T} 1, \mathrm{~T} 2, \mathrm{~T} 3, \mathrm{~T} 4$.

- Outcome Expectations for Exercise (OEE) scale collected at each data point $\mathrm{T} 1, \mathrm{~T} 2, \mathrm{~T} 3, \mathrm{~T} 4$.

Ability to complete functional tasks at each data point $\mathrm{T} 1$, $\mathrm{T} 2, \mathrm{~T} 3, \& \mathrm{~T} 4$.

- 6 minute walk distance (6MW)

- Timed up and go test (TUG)

- Ascend/descend 19 stairs (ST)

- Sit-to-stand in 30 seconds

Adherence with prehabilitation

- Exercise logs completed by the subject and reviewed by the exercise leader

Health related quality of life (HRQL)

- Medical Outcomes Study 36-Item Short-Form (SF-36) 


\section{Sample size consideration}

The sample size estimate was based on the three hypotheses of this study. Statistical analysis of these hypotheses consisted of using a between group repeated measures analysis of variance (RM-ANOVA) to determine differences in the change between groups over the data collection times. Background characteristics which were different between the groups at baseline were also included in the RM-ANOVA as potential covariates. The effect sizes for these dependent measures (SEE, OEE) were calculated based on a previous study by Harnirattisai (2005) which found that similar exercise interventions with knee OA patients after TKA surgery resulted in improvements in these measures of SEE and OEE. The sample size required for this study was found to be three per group for the SEE and 15 per group for the OEE variable. The measure of functional ability (sit to stand) used to determine sample size was estimated from a study by Topp et al, 2009. The sample size required for the functional ability portion of this study was based upon this previous trial and was found to be three participants per group.

The anticipated effect sizes for this study were conservatively estimated. The study employed the intent to treat (ITT) (Chow \& Lui, 1998) principle of retaining all participants randomized into the prehabilitation group regardless of their adherence with the prehabilitation intervention. Participants lost to follow up would be replaced through oversampling in order to maintain a sufficient sample size to ensure adequate statistical power. The standard method of determining sample size between treatments with covariance correction for baseline scores within a repeated measures model employed the following formula (Overall \& Doyle, 1994): 


$$
\mathrm{n}=2\left(\mathrm{Z}_{\beta}+\mathrm{Z}_{\alpha}\right)^{2}\left(1-\mathbf{r}^{2}\right) /\left(\operatorname{Mean}_{1}-\operatorname{Mean}_{2} / \mathrm{SD}\right)^{2}
$$

A conservative $\mathrm{r}^{2}$ between pre and post test means was estimated to be .5 (level of correlation) for each variable being studied to estimate sample size. These sample size estimates are based upon obtaining statistical power $(1-\beta)$ of 0.80 for the analysis of each dependent variable with an overall $\alpha=0.05$. Under these assumptions, the sample needed in each group to complete the posttest to yield approximately $80 \%$ power is presented in Table 3.1. Therefore, it was estimated that by enrolling 40 subjects and employing the ITT principle, anticipating a $25 \%$ dropout the proposed final sample of 30 subjects ( $\mathrm{n}=15$ per study group) will have at least $80 \%$ power to detect a clinically significant effect of the treatments on the principle dependent variables.

\section{Table 3.1}

Sample size estimates for outcome variables were based on previous studies (T. Harnirattisai \& R. A. Johnson, 2005; Topp, et al., 2009b).

\begin{tabular}{|l|c|c|c|c|}
\hline \multicolumn{1}{|c|}{ Variable* $^{*}$} & $\begin{array}{c}\text { Baseline } \\
\text { Mean } \pm \mathrm{SD}\end{array}$ & $\begin{array}{c}\text { Expected } \\
\text { Change (f) }\end{array}$ & $\begin{array}{c}\text { Effect } \\
\text { Size } \\
(\mathrm{d})\end{array}$ & $\begin{array}{c}\text { Sample size } \\
\text { needed per group } \\
(\mathrm{n})\end{array}$ \\
\hline SEE & $4.98 \pm 1.18$ & $2.4(48 \%)$ & 4.14 & 3 \\
\hline OEE & $4.29 \pm .39$ & $.35(8 \%)$ & .80 & 15 \\
\hline Sit to Stand & $10.39 \pm .78$ & $1.6(16 \%)$ & 4.2 & 3 \\
\hline
\end{tabular}

SEE = Self-Efficacy for Exercise; OEE = Outcome Expectations for Exercise; Sit to Stand = capacity to rise repeatedly from a chair 
Assessment Tools

\section{Performance of Four Functional Tasks}

Procedures to assess the participant's performance of functional tasks was conducted in the Bellarmine University Physical Therapy Clinic. The clinic is located at 2001 Newburg road in the 2120 building. The clinic is located on the second floor with two walls of open windows. The added light from the windows allows for safe maneuvering about the 1000 square foot room. The floor space allows for a 30 meter track to be utilized. The clinic is fully functional with multiple machines and equipment to assess functional ability of the study participants. All of these assessments (See Appendix G) used standardized protocols developed for, and/or protocols previously implemented with adults with knee OA prior to and following a TKA procedure. These assessments were conducted in the following order: written assessments of background and self-efficacy to exercise and outcome expectations for exercise, six minute walk distance, get up and go, sit-to-stand, ascend and descend stairs. This ordering was done to minimize the effect of fatigue on assessing the performance of the four functional tasks. Any affect this assessment ordering had on the outcome variables was considered constant since the test ordering remained the same at each data collection point for all participants.

Participants were asked to perform each of the four functional tasks as "quickly and safely as you can" and were allowed a five-minute rest period between each assessment trial. Participants at each data collection point were allowed to use any assistive device 
they choose to complete the task (cane, walker, railing etc.). Use of assistive devices employed during performance of each functional task was documented on the data collection form in advance of the data collection at the eight week (T1) and one week (T2) prior to TKA and the one week (T3) and two weeks (T4) following TKA, each participant was asked to consume their prescribed or usual over-the-counter pain medication at least one hour but no more than three hours prior to their scheduled testing time. Also, during these assessments participants were asked to disclose, on a collection form, (See Appendix $\mathrm{H}$ ) to the research staff member collecting the data the type and dose of the pain medication they consumed to control their pain over the previous 24 hours. This procedure attempted to standardize all subjects receiving pain medication immediately prior to data collection and to minimize the pain during the data collection procedures.

Functional ability was assessed by the participant's ability to complete four functional tasks: the distance covered during a six-minute walk distance test, timed get up and go test (TUG), sit to stands completed in 30 seconds and the time to ascend and descend 19 stairs.

The six-minute walk distance test was conducted following a three to five minute warm-up that included static stretching of the lower body. Participants were instructed that they may stop during the test if they experienced fatigue or pain and may resume walking once they felt they were able. No verbal encouragement was offered to the participants during the evaluation. 
All walks were conducted on a flat, indoor 30 meter track marked off in one meter segments. Participants were tested individually in order to promote individual pacing and were discouraged from walking in groups or pairs. Participants were instructed to cover as much distance as possible without pushing themselves beyond what they consider being safe. Elapsed time was announced at the $3^{\text {rd }}, 4^{\text {th }}$ and $5^{\text {th }}$ minutes. At the end of the six minutes, the test administrator recorded the distance covered by the participant to the nearest one meter mark. The score for the six minute walk was determined by the total distance walked in meters. The six-minute walk test has a test-retest reliability of $r=0.91$ - 0.94 (Stillwell, Forman, McElwain, Simpson, \& Garber, 1996) and has been demonstrated to be a valid indicator of submaximal $(r=0.82$ and 0.71 for males and females, respectively) and maximal aerobic capacity among older adults $(r=0.76)$ (Stillwell, et al., 1996).

The timed get up and go test (TUG) measured the time it took a participant to rise from a chair with no armrest and walk three meters, turn and return to a sitting position in the same chair. The procedure was explained and then demonstrated for the participant by the research personnel prior to the trial taking place. The score for this functional task was determined by the duration of time taken to complete the task within $100^{\text {th }}$ of a second.

The timing of the trial began with the participant's first movement after being told 'go' and concluded when the participant returned to a sitting position in the chair. The TUG test is widely used as an assessment of ability to complete functional tasks among older adults or adults with functional limitations (Hershkovitz \& Brill, 2006; Hershkovitz, Gottlieb, Beloosesky, \& Brill, 2006). Psychometric assessments of the TUG 
indicate that the time score (1) is reliable (inter-rater and intra-rater); (2) correlates well with log-transformed scores on the Berg Balance Scale $(r=-0.81)$, gait speed $(r=-0.61)$ and Barthel Index of ADL $(r=-0.78)$; and (3) predicts the patient's ability to go outside alone safely (Podsiadlo \& Richardson, 2000). These data suggest that the TUG test is a reliable and valid test for quantifying functional mobility that may also be useful in following clinical change over time.

Sit-to-stand in 30 seconds assessment was employed to determine the subject's capacity to rise repeatedly from a chair over a 30 -second period of time. Each subject began the assessment by being seated in a firm chair which had no armrest. Subjects were informed to assume an upright standing position followed by a seated position as many times as possible within a 30 -second time interval. The test began on the subject's first movement. The test then ended following a 30-second interval announced by the technician conducting the assessments. The number of complete stands (up from and then down to the chair) was considered the subjects score for this assessment. This assessment has demonstrated high validity in correlation with a one repetition max (1RM) leg press and a good test-retest reliability $(r=.89)$ (C. J. Jones, Rikli, \& Beam, 1999; Rikli \& Jones, 1999).

Ascend/descend stairs (ST) assessments were used to determine the subject's ability to ascend and descend a flight of nineteen standard seven inch stairs located in the Bellarmine University Physical Therapy Clinic. The starting position was with the subject standing facing the stairs, no further than 12 " from the first step, with hands at sides.

Subjects were asked to climb the 19 stairs. Following a 30 second rest, subjects were asked to descend the stairs to the starting position. The end of the test was when 
both of the subject's feet reached the top or bottom of the staircase respectively. The trial was measured to the nearest 100th of a second using a stopwatch. Previous studies of patients prior to and following TKA have found these measures sensitive to prehabilitation interventions (Brown, et al., 2009; Jaggers, et al., 2007; Topp, et al, 2008; Topp, et al, 2009a).

\section{Self-efficacy to exercise and outcome expectations for exercise measures}

Self-efficacy to exercise and outcome expectations for exercise were measured by using the self-efficacy for exercise (SEE) scale (See Appendix I) (McAuley, 1993); and the outcome expectations for exercise (OEE) scale (See Appendix J) (Steinhardt \& Dishman, 1989). This was done by having the subjects complete a brief paper and pencil self-questionnaire.

The social cognitive theory (SCT) states that specific efficacy expectations affect behavior, motivational level, thought patterns, and emotional reactions in response to any situation (Bandura, 1977; 1986; 1995; 1997). There are two types of efficacy expectations described within the SCT: self-efficacy expectations and outcome expectations. Self-efficacy expectations are the individuals' beliefs in their capabilities to perform a specific behavior. Outcome expectations are the beliefs that carrying out a specific behavior will lead to a desired outcome. An example of an outcome expectation might be what the individual perceives to be the benefits of exercise (i.e., improving muscle strength, living longer, losing weight, or feeling good in general) (Resnick, et al., 2001). This study used two different patient instrumentation measurement tools of Selfefficacy and outcome expectation. These tools consist of survey questions which examined many variables such as attitude, motivation, and personality. 


\section{Patient measurement of Self-efficacy}

Resnick and Jenkins (2000) tested the reliability and validity of the Self-Efficacy for Exercise (SEE) scale (See Appendix I). The SEE scale is a revision of McAuley's (1990; unpublished) self-efficacy barriers to exercise measure. Originally this was a 13item scale that focused on self-efficacy expectations related to one's ability to continue exercising in the face of barriers to exercise (Resnick \& Jenkins, 2000). Since then, it has been revised for older adults on the basis of quantitative and qualitative research so it would be appropriate for the older age population (Resnick \& Spellbring, 2000). Construct validity of the SEE scale was tested using two empirically supported hypothesis: (a) Individuals with good health status are more likely to have stronger selfefficacy expectations (Grembowski, et al., 1993), and (b) individuals with good mental health are more likely to have stronger self-efficacy expectations (Bandura, 1997).

Reliability and validity testing was performed using a sample of 187 older adults. Of the 187 participants, 71 participated in regular exercise activity. Face to face interviews were completed which included the SEE. Exercise activity was based on verbal report of participation in aerobic exercise. Internal consistency $(\alpha=0.92)$, and a squared multiple regression coefficient using structural equation modeling provided further evidence of reliability ( $\mathrm{R}^{2}$ ranged from 0.38 to .76 ). The scale is scored by adding the responses to obtain the total score and dividing by the number of items. The internal consistency of the SEE scale was evidenced by an alpha of .70 or more (Nunnally \& Bernstein, 1994). Results from the Resnick \& Jenkins, (2000) study showed there was sufficent evidence supporting the validity of the SEE scale using construct and criterion related validity. 


\section{Patient measurement of Outcome Expectations}

A second study by Resnick and Jenkins (2000) used the Outcome Expectations for Exercise (OEE) scale (see appendix J), a nine - item measure based on descriptive epidemiologic studies (Steinhardt $\&$ Dishman, 1989) that asks individuals to identify expected positive outcomes of physical activity. Item responses are based on a five-point Likert scale ranging from one (strongly disagree) to five (strongly agree). The scale is scored by adding the responses to obtain the total score and dividing by the number of items. The reliability of this measure was demonstrated by a coefficient alpha of 0.78 and a test retest correlation of $r=0.89(p<0.05)($ Steinhardt \& Dishman, 1989).

\section{Patient measurement of perceived health status}

This study used the SF-36 (Medical Outcomes Study 36-Item Short-Form Health Survey) to evaluate the intervention treatment on the participants of this study (McDowell \& Newell, 1996). The SF-36 is an evaluative scale designed as an indicator of health related quality of life (HRQL) and perceived health status (McDowell \& Newell, 1996; Ware \& Kosinski, 2001). This survey can be used in general (elderly individuals) or specific populations (TKA patients with OA) (Finch, Brooks, Stratford, \& Mayo, 2002). The survey can be used for comparing the health status of patients with different conditions, and for comparing patients to the general population (Finch, et al., 2002). The survey was developed by John E. Ware and the Rand Corporation in 1990 (Finch, et al., 2002). The original survey included 245 items found in the Rand's Medical Outcomes Study (MOS) which focused on chronic medical conditions (McDowell \& 
Newell, 1996). The SF-36 (Finch, et al., 2002; McDowell \& Newell, 1996) includes eight multi-item scales used to measure:

- Physical functioning (PF) (10 items)

- Role limitations due to physical health (RP) (4 items)

- Bodily pain (BP) (2 items)

- General health perceptions (GH) (5 items)

- Vitality (VT) (4 items)

- Social functioning (SF) (2 items)

- Role limitations owing to emotional problems (RE) (3 items)

- Mental health (MH) (5 items)

The scores on all sub - scales range from $0-100$, with higher scores indicating better health. Reliability of the survey has been tested in many different patient groups. Combining the results from the previous studies, the median alpha reliability for all eight scales exceeds 0.80, except for the two- item social functioning scale (0.76) (McDowell $\&$ Newell, 1996). The administration of the survey normally takes 5 to 10 minutes to complete; elderly people may need more time (Finch, et al., 2002). Scores for items on each scale are added to give sub-scale scores. The raw scores are transformed to a 0-100 scale using the following formula: transformed scale $=[($ actual raw score- lowest possible raw score)/possible raw score range] x 100 (Finch, et al., 2002). 


\section{Statistical analysis plan}

This study used descriptive statistics to aid in summarizing data about the population and variables that have been chosen to be examined. The study used inferential statistics to assess the plausibility of the study hypotheses. Tests of significance helped determine if the observed differences were real differences or simply the result of sampling.

This research study is a true experimental research design, which includes randomization, control groups, and experimental groups (Cottrell \& McKenzie, 2005). This type of experimental research design is considered to be one of the strongest types of designs controlling for most threats to internal validity (Cottrell \& McKenzie, 2005).

This study used a longitudinal study design which involved repeated observations by the researcher of the same groups of people over multiple periods of time (Cottrell \& McKenzie, 2005). The statistical methods used to address the research hypotheses in this study were used to compare repeated measures of the subject's ability to complete functional tasks, and measures of SEE and OEE. This study used a simple three step approach to analyzing the data collected over time.

Step one began with the data being entered cleaned and checked for accuracy against the original data collection forms. In step two, repeated measures analysis of variance (RM-ANOVA) calculations, were used to determine the main effects of group (control vs. treatment), items (T1 vs T2 vs T3 vs T4) and the interaction of group and time on the outcome variables.

Analysis of covariance (ANCOVA) was used to equalize differences at baseline (T1) between groups. Step three, if significant main or interaction effects were detected 
with the RM-ANOVA, planned comparisons using post hoc tests. The Bonferroni correction method (Abdi, 2007), independent and paired samples $\mathrm{T}$ tests were performed. The planned comparisons were done to look for specific changes. For instance, PRE and CON groups were compared at each time point, and time points were compared within groups to determine the significant differences between individual group means. These post hoc comparisons compensate to maintain the overall for Type 1 error at .05 (Newsom, 2006).

Results were tabulated and presented graphically in chapter four. 


\section{CHAPTER IV}

\section{$\underline{\text { Results }}$}

This chapter presents the results from the associated analyses of the thesis. Analyses included calculating descriptive statistics of the sample and inferential statistics to address the study hypotheses. One-way repeated measures ANOVAs (RM-ANOVA) was used to investigate hypotheses one, two and three by examining the effects of group (PRE vs. CON) and time on the dependent variables over the four data collection time points (Baseline T1, T2, T3 and T4). Significant main or interaction effects were then explored in more detail by using traditional Post Hoc tests and planned comparisons that included the Bonferroni correction method (Abdi, 2007), independent and paired samples $\mathrm{T}$ tests. The post hoc tests were used to evaluate changes over time and planned comparisons to identify how the groups differed.

During data collection, it became clear there were a substantial number of subjects who did not have data collected at T3. This attrition caused a decline in statistical power in the preliminary analysis; therefore a secondary analysis was performed using the same statistical model to evaluate study hypotheses one, two and three exclusive of T3 data. This secondary analysis consisted of RM- ANOVAs being developed for each outcome variable while examining the effect of group (PRE vs. CON) and time over the remaining three data collection points (T1, T2 and T4). 
Again for this secondary analysis significant main or interaction effects were explored in more detail using Post Hoc tests that included the Bonferroni correction method, independent and paired samples $\mathrm{T}$ tests. The post hoc tests were again used to evaluate change over time and to identify how groups differed.

Finally, hypothesis four was evaluated by univariate comparisons between the PRE and CON groups at three months follow-up after their TKA. This analysis examined changes in health-related quality of life which were measured with the SF-36 questionnaire (Medical Outcomes Study 36-Item Short-Form Health Survey).

\section{Participants}

During the study period (June 09 - March 2010) 67 participants were eligible to participate in the study. Twenty-five participants indicated that they were not interested in participating in the study. As a result forty-two OA participants (31 female, 11 male, mean age $=61$ years, no significant difference in age, $p=.385$ ) who met the inclusion criteria and were scheduled for a total knee arthroplasty (TKA) were contacted to see if they were interested in participating in the study. Of the 42,37 were interested and recruited into the study $(n=19$ PRE, $n=18 \mathrm{CON})$. The analytic sample $(n=16$ PRE, $n=$ $15 \mathrm{CON}$ ) only included 31 subjects ( 22 female, 9 male) that were consented to participate, came in for baseline (T1) testing and completed some data collection (See fig. 4.1). 
Figure 4.1 Flow diagrams of participants through Randomized intervention

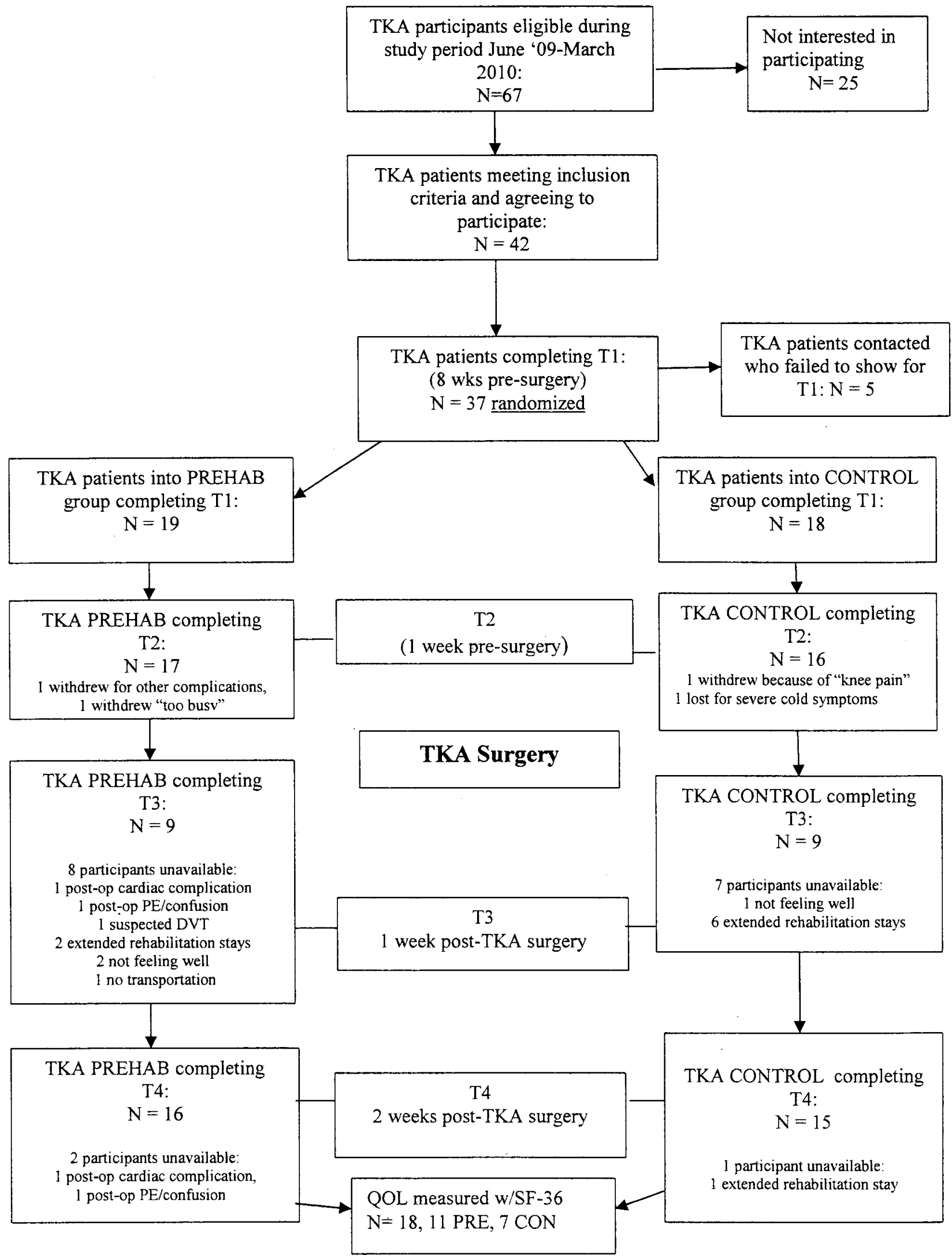


Both groups had similar Body Mass Indexes (BMIs) $(\mathrm{PRE}=38.8(8.8)$ and $\mathrm{CON}$ $=34.6(7.6),(p=126)$. Five subjects never showed up for data collection and did not consent to participate and another eight (four - PRE, four - CON) were loss to follow-up due to differing reasons. These reasons included (1) four participants that required extended inpatient rehabilitation and could not make the final two data collections, (2) one with an infection, (3) one who had a cold and flu symptoms causing them not to be able to leave their home and (4) two that did not wish to continue in the study. This resulted in a twenty-two percent dropout rate during the duration of the study. The dropout rate for this study was lower than the predicted rate of $25 \%$; therefore the results of this study are not threatened due to a high response rate. Although the attrition at $\mathrm{T} 3$ was higher than expected $(50 \%)$ the attrition rate for $\mathrm{T} 3$ did not limit the results of the study.

The purpose of the current study was to assess whether outcomes can be achieved in knee osteoarthritis $(\mathrm{OA})$ patients who engaged in guided exercise prior to TKA, when compared to knee OA patients who do not engage in guided exercise prior to TKA. Outcomes studied included higher self-efficacy to exercise (SEE), higher outcome expectations for exercise (OEE) and higher post surgical functional ability. A secondary purpose was to determine if knee OA patients who engage in guided exercise prior to TKA report higher levels of general health-related quality of life three - months following their surgery compared to knee OA patients who don't engage in pre-operative guided exercise. 
Table 4.0

Demographic Characteristics of the Subjects $(N=31)$

\begin{tabular}{|c|c|c|c|c|c|}
\hline Characteristic & $N$ & $\%$ & PRE & $\mathrm{CON}$ & $\begin{array}{c}P \\
\text { value }\end{array}$ \\
\hline & & & 16 & 15 & \\
\hline Age & 31 & & $60(8.3)$ & $67(9.5)$ & .46 \\
\hline BMI & 31 & & $38.8(8.8)$ & $34.6(7.6)$ & .38 \\
\hline Male & 9 & 30 & $6(38 \%)$ & $3(20 \%)$ & .17 \\
\hline \multicolumn{6}{|l|}{ Ethnicity } \\
\hline $\begin{array}{l}\text { African American } \\
\text { Hispanic }\end{array}$ & $\begin{array}{l}3 \\
1\end{array}$ & $\begin{array}{l}1 \\
3\end{array}$ & $\begin{array}{c}2(12.5 \%) \\
0\end{array}$ & $\begin{array}{l}1(7 \%) \\
1(7 \%)\end{array}$ & .52 \\
\hline White & 27 & 87 & $14(87.5 \%)$ & $13(87 \%)$ & \\
\hline \multicolumn{6}{|l|}{ Current Marital Status } \\
\hline Single & 2 & 7 & 2 & 0 & .37 \\
\hline Married/committed relationship & 25 & 8 & 12 & 13 & \\
\hline Divorced/widowed & 4 & 13 & 2 & 2 & \\
\hline Knee affected & & & $(\mathrm{R}-9, \mathrm{~L}-7)$ & (R-10,L-5) & \\
\hline
\end{tabular}

\section{Exercise adherence}

During the study the PRE group participated in an average of $6(5.6+1.5)$ supervised sessions, and according to their self-reported exercise log sheets, a total of 16 $(16.3+6.0)$ exercise sessions during their pre-habilitation exercise program. The average length of the pre-habilitation episode was 6 weeks $(6.3+1.5)$. This resulted in an exercise compliance rate of $89 \%$. 


\section{Initial Analysis}

Hypothesis one was evaluated using a RM-ANOVA which included the within factor time points (T1, T2, T3 and T4) and the between group factor (PRE vs CON). The interaction of group and time was also evaluated. The dependent variable in this model was self-efficacy for exercise (SEE). The sample size for this analysis was $20(n=P R E$ 10, CON 10) participants. The of time effect was non-significant, Wilks' Lamda $=0.89$, $F(3,16)=.606, p=.62$. The between groups comparison was also non - significant, $F(1$, 18) $=.034, p=.86$. There was no significant interaction effect on SEE, Wilks' Lamda $=$ $0.87, F(3,16)=.784, p=.52$. However, the observed power for the main effect of time test was only .62 for time and .52 for the interaction between time and group. Neither the PRE group nor the CON group had a significant change in their SEE over the four data collection points of the study as seen in figure 4.2.

Figure 4.2 SEE Means for Group x Time four data points - initial data

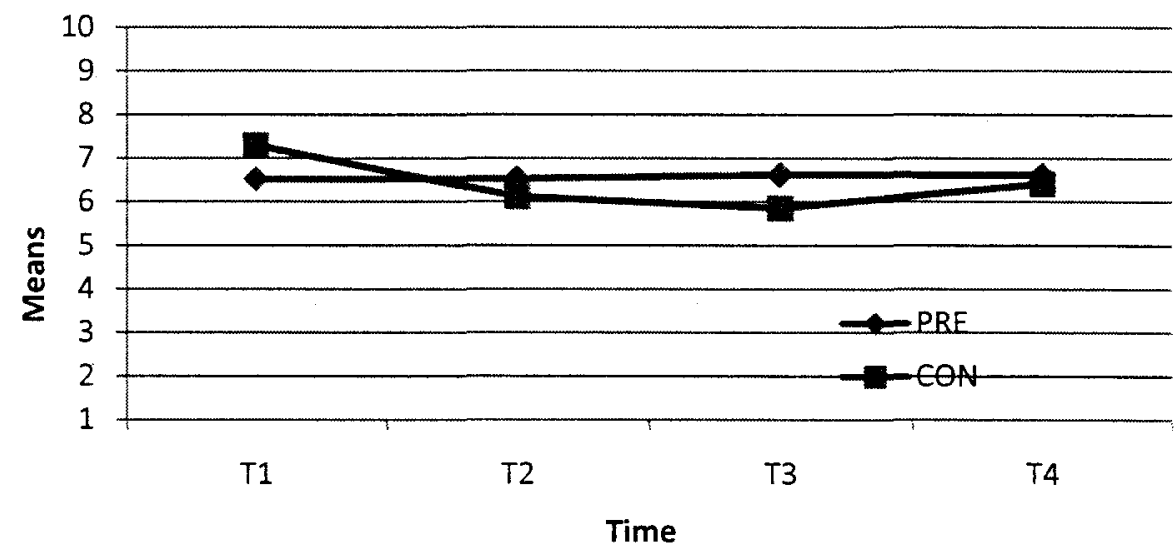

Note: Higher scores indicate higher SEE 


\section{$\underline{\text { SEE excluding T3 }}$}

A secondary analysis of SEE was performed because there were a high number of study participants (PRE 5, CON 6) who did not complete data collection at T3. In order to maximize statistical power a secondary analysis of the SEE data was completed excluding T3 data. There were several reasons for this loss of T3 data. Those reasons included (1) extended inpatient rehabilitation by three PRE and four CON subjects along with (2) medical complications like infections (1 PRE and $2 \mathrm{CON}$ ) and (3) cold symptoms causing one PRE to miss due to inability to leave their home. This resulted in a sample of $31(n=15 \mathrm{CON}$ and $n=16$ PRE) participants being evaluated.

This analysis examined the main effects of time (T1, $\mathrm{T} 2$, and $\mathrm{T} 4)$, and group (PRE vs $\mathrm{CON}$ ) as well as the group $\mathrm{x}$ time interaction. The effect of time remained nonsignificant for SEE, Wilks' Lamda $=0.97, F(2,28)=.430, p=.655$. There was no significant interaction effect on SEE, Wilks' Lamda $=0.96, F(2,28)=.537, p=.590$. The observed power for this test was .113 for time and .130 for time $\mathrm{x}$ group. The between groups comparison was also non - significant, $F(1,29)=.549, p=.465$.

\section{Hypothesis Two; outcome expectations for exercise (OEE)}

The evaluation of hypothesis two employed a similar statistical model as above to determine significant differences in OEE within the sample over the duration of the study. There was a non-significant effect of time on OEE, Wilks' Lamda $=0.72, F(3,16)$ $=2.06, p=.146$. 
There was no significant interaction effect on OEE, Wilks' Lamda $=0.97, F(3,16)=$ $.142, p=.933$. The observed power for this test was .430 for time and .071 for time $\mathrm{x}$ group interaction. The between groups comparison was non - significant, $F(1,18)=.187$, $p=.069$, although there was a trend towards significance. Whether significance will be reached when the sample size is increased is unclear but likely.

\section{Outcome expectations for exercise (OEE) excluding T3}

The secondary analysis of OEE excluding T3 indicted a similar pattern as the initial analysis only this time there was a significant effect of time on OEE, Wilks' Lamda = $0.709, F(2,28)=5.75, p=.008$. There was no significant interaction effect on OEE, Wilks' Lamda $=0.986, F(2,28)=.199, p=.821$. The observed power for this test was .828 for time and .078 for time $\mathrm{x}$ group interaction. While time was significant, between group comparison was not $F(1,29)=.604, p=.443$. Post Hoc analysis, using the Bonferroni correction method, of time (See table 4.1) indicated that the groups significantly declined between $\mathrm{T} 2$ and $\mathrm{T} 4$. Additional planned comparisons using $\mathrm{T}$ tests (Independent and Paired Samples) looked at between groups and within group changes over time. These tests indicated no significant differences. The PRE and CON groups did not significantly change their OEE over the three data collection points of the study as seen in figure 4.3 . 
Table 4.1

Pairwise comparison of time, secondary data (T1, T2 and T4) on OEE

\begin{tabular}{|c|c|c|c|c|c|c|}
\hline \multirow[b]{2}{*}{ Time } & \multirow[b]{2}{*}{ Time } & \multirow[b]{2}{*}{$\begin{array}{c}\text { Mean } \\
\text { difference }\end{array}$} & \multirow[b]{2}{*}{$\begin{array}{c}\text { Standard } \\
\text { Error }\end{array}$} & \multirow[b]{2}{*}{$\mathrm{p}$-value } & \multicolumn{2}{|c|}{$\begin{array}{c}95 \% \text { Confidence } \\
\text { Interval for Difference }\end{array}$} \\
\hline & & & & & $\begin{array}{l}\text { Lower } \\
\text { Bound }\end{array}$ & $\begin{array}{l}\text { Upper } \\
\text { Bound }\end{array}$ \\
\hline \multirow[t]{2}{*}{1} & 2 & .00 & .10 & .961 & -.20 & .21 \\
\hline & 4 & .21 & .8 & .020 & .03 & .38 \\
\hline \multirow[t]{2}{*}{2} & 1 & -.00 & .10 & .961 & -.21 & .20 \\
\hline & 4 & .20 & .07 & .009 & .05 & .35 \\
\hline
\end{tabular}

Note: Adjustment for multiple comparisons: Bonferroni.

Figure 4.3 OEE for Group x Time three data points Means

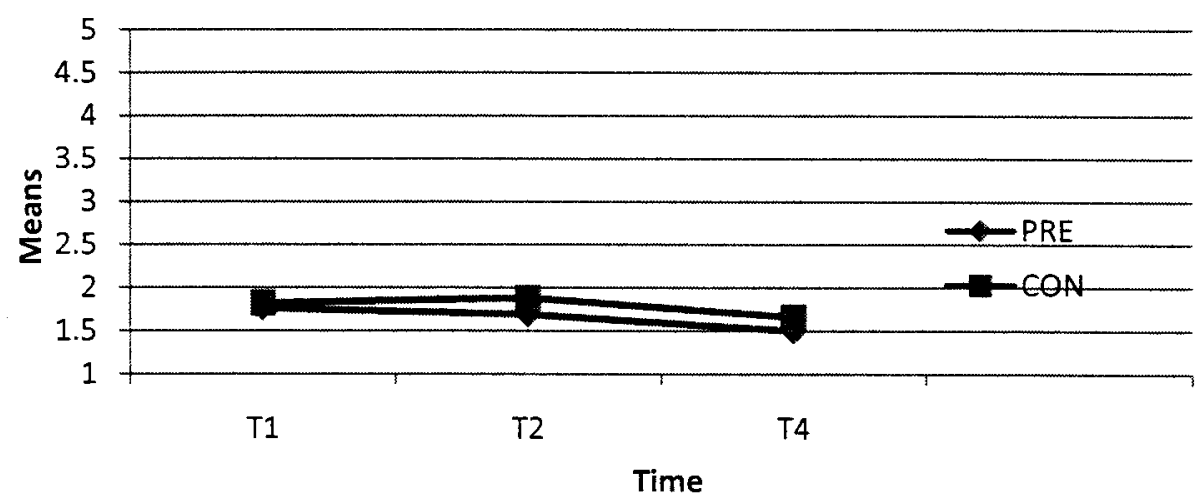

Note: Lower scores indicate higher OEE 


\section{Hypothesis three: functional abilities}

Hypothesis three was evaluated through conducting a RM-ANOVA with the main effects time (T1, T2, T3 and T4) and group (PRE vs CON) and interaction of group and time as the sources of variability on measures of functional ability. Measures of functional ability included six-minute walk distance, timed get up and go test (TUG), sitto-stand repetitions (chair raises) in 30 seconds and the time required to ascend and descend a flight of stairs.

There was a significant effect of time on the six minute walk distance, Wilks' Lamda $=0.082, F(3,14)=52.2, p<.001$. There was a significant interaction effect on six minute walk distance, Wilks' Lamda $=0.546, F(3,14)=3.8, p=.033$. The observed power for this test was 1.00 for time and .70 for time $\mathrm{x}$ group. The between groups comparison was non - significant, $F(1,16)=2.93, p=.106$.

Post Hoc analysis, using the Bonferroni correction method, of time (See table 4.2) indicated that the groups significantly declined between $\mathrm{T} 1$ and $\mathrm{T} 3, \mathrm{~T} 2$ and $\mathrm{T} 3$, and $\mathrm{T} 3$ and $\mathrm{T} 4$. Independent samples $\mathrm{T}$ tests looking at between groups showed no significant difference (See table 4.3). Additional planned comparisons using Paired Samples T tests looked at within group changes over time. Specifically, looking at group (PRE) there was a significant decline from $\mathrm{T} 1$ to $\mathrm{T} 3, t(8)=6.87, \mathrm{p}<.001$, a significant decline from $\mathrm{T} 1$ to $\mathrm{T} 4, t(14)=6.48, p=<.001$ a significant decline from $\mathrm{T} 2$ to $\mathrm{T} 3, t(8)=7.58, \mathrm{p}<.001$, and a significant decline between $\mathrm{T} 2$ and $\mathrm{T} 4, t(14)=8.00, \mathrm{p}<.001$, however a significant increase between $\mathrm{T} 3$ and $\mathrm{T} 4 t(8)=-6.10, \mathrm{p}<.001$ was seen. There was an increase between $\mathrm{T} 1$ and $\mathrm{T} 2, t(16)=-2.25, \mathrm{p}=.039$ but it was not significant (see table 4.4). 
In tables 4.4 and 4.5 , planned comparisons within each group are presented. Table 4.5 specifically presents data for the $\mathrm{CON}$ group in which there was a significant decline from $\mathrm{T} 1$ to $\mathrm{T} 3, t(8)=10.53, p<.001$, from $\mathrm{T} 1$ to $\mathrm{T} 4, t(14)=9.77, p=<.001$, from $\mathrm{T} 2$ to $\mathrm{T} 3, t(8)=11.2, \mathrm{p}<.001$, a significant decline between $\mathrm{T} 2$ and $\mathrm{T} 4, t(13)=10.6, p<.001$, and between T3 and T4, $t(8)=-6.29, p<.001$, however a non significant increase between $\mathrm{T} 1$ and $\mathrm{T} 2, t(14)=1.02, p=.032$ was seen (see table 4.5).

The PRE group increased between T1 and T2 (See Fig. 4.4) but it was not a significant change with the alpha values ( $p=.0125$ ) adjusted using the Bonferroni correction to control for $\alpha$ inflation. The $\mathrm{CON}$ group decreased between $\mathrm{T} 1$ and $\mathrm{T} 2$, as seen in figure 4.4 , but it was not a significant change.

Figure 4.4 6 minute walk - initial data, 4 data points means

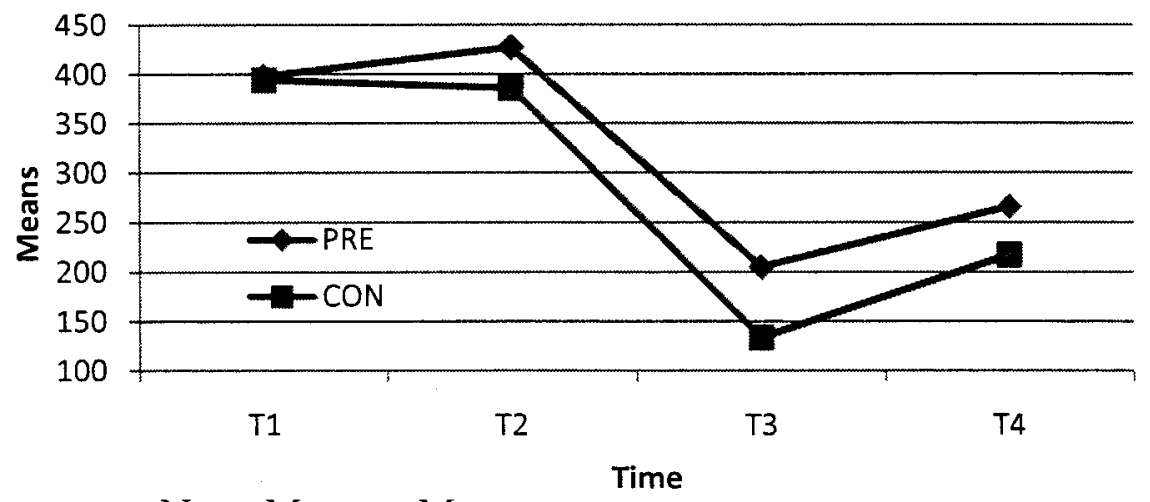

Note: Means $=$ Meters 


\section{Table 4.2}

Pairwise Comparisons of six minute walk time, initial data

\begin{tabular}{|c|c|c|c|c|c|c|}
\hline \multirow[t]{2}{*}{ Time } & \multirow[t]{2}{*}{ Time } & \multirow{2}{*}{$\begin{array}{c}\text { Mean } \\
\text { difference }\end{array}$} & \multirow{2}{*}{$\begin{array}{l}\text { Standard } \\
\text { Error }\end{array}$} & \multirow[t]{2}{*}{$\mathrm{p}$-value } & \multicolumn{2}{|c|}{$\begin{array}{l}95 \% \text { Confidence } \\
\text { Interval for } \\
\text { Difference }\end{array}$} \\
\hline & & & & & $\begin{array}{l}\text { Lower } \\
\text { Bound }\end{array}$ & $\begin{array}{l}\text { Upper } \\
\text { Bound }\end{array}$ \\
\hline \multirow[t]{3}{*}{1} & 2 & -10.16 & 6.21 & .729 & -28.87 & 8.53 \\
\hline & 3 & 227.05 & 18.74 & $<.001$ & 170.67 & 283.43 \\
\hline & 4 & 155.05 & 17.68 & $<.001$ & 101.86 & 208.24 \\
\hline \multirow[t]{3}{*}{2} & 1 & 10.16 & 6.21 & .729 & -8.53 & 28.87 \\
\hline & 3 & 237.22 & 18.42 & $<.001$ & 181.78 & 292.65 \\
\hline & 4 & 165.22 & 16.70 & $<.001$ & 114.96 & 215.48 \\
\hline \multirow[t]{3}{*}{3} & 1 & -227.05 & 18.74 & $<.001$ & -283.43 & -170.67 \\
\hline & 2 & -237.22 & 18.42 & $<.001$ & -292.65 & -181.78 \\
\hline & 4 & -72.00 & 8.27 & $<.001$ & -96.88 & -47.11 \\
\hline
\end{tabular}

Note: Adjustment for multiple comparisons: Bonferroni. 


\section{Table 4.3}

Six minute walk distance (6MWD) group statistics Independent Samples T Test

\begin{tabular}{|c|c|c|c|c|c|c|}
\hline Variable & Group & $\mathrm{N}$ & Mean (SD) & $\mathrm{df}$ & $\mathrm{t}$ & $\mathrm{p}$ value \\
\hline \multirow[t]{2}{*}{ 6MWD T1 } & $\mathrm{CON}$ & 18 & $\begin{array}{l}354.4 \\
(72.6)\end{array}$ & 35 & -.955 & .346 \\
\hline & PRE & 19 & $\begin{array}{l}375.8 \\
(63.5)\end{array}$ & & & \\
\hline \multirow[t]{2}{*}{ 6MWD T2 } & CON & 15 & $\begin{array}{l}352.5 \\
(68.4)\end{array}$ & 30 & -1.793 & .083 \\
\hline & PRE & 17 & $\begin{array}{l}393.3 \\
(57.2)\end{array}$ & & & \\
\hline \multirow[t]{2}{*}{ 6MWD T3 } & $\mathrm{CON}$ & 9 & $\begin{array}{l}133.5 \\
(59.6)\end{array}$ & 16 & -2.07 & .055 \\
\hline & PRE & 9 & $\begin{array}{c}204.8 \\
(84.4)\end{array}$ & & & \\
\hline \multirow[t]{2}{*}{ 6MWD T4 } & $\mathrm{CON}$ & 15 & $\begin{array}{l}209.2 \\
(40.1)\end{array}$ & 28 & -1.90 & .067 \\
\hline & PRE & 15 & $\begin{array}{l}249.8 \\
(71.9)\end{array}$ & & & \\
\hline
\end{tabular}

Note: all alpha values $(\alpha)$ were adjusted using Bonferroni correction to control for $\alpha$ Inflation. New $\alpha$ inflation Bonferroni correction .05/4 $=0.0125$

*Indicates significant difference at $p<.0125$ 
Table 4. 4

PRE Group Six minute walk distance (6MWD) Paired Samples T Test

\begin{tabular}{cccccc}
\hline Times Compared & $\mathrm{N}$ & Mean (SD) & $\mathrm{df}$ & $\mathrm{t}$ & $\mathrm{p}$ value \\
\hline 6MWD T1 vs 6MWD T2 & 17 & $374.8(64.8)$ & 16 & -2.25 & .039 \\
& 17 & $392.3(57.2)$ & & & \\
6MWD T1 vs 6MWD T3 & 9 & $398.3(73.5)$ & 8 & 6.87 & $<.001^{*}$ \\
& 9 & $204.9(84.4)$ & & & \\
6MWD T1 vs 6MWD T4 & 15 & $378.2(63.5)$ & 14 & 6.48 & $<.001^{*}$ \\
& 15 & $249.8(71.9)$ & & & \\
6MWD T2 vs 6MWD T3 & 9 & $427.1(51.7)$ & 8 & 7.58 & $<.001^{*}$ \\
& 9 & $204.8(84.4)$ & & & \\
6MWD T2 vs 6MWD T4 & 15 & $3974(71.9)$ & 14 & 8.00 & $<.001^{*}$ \\
& 15 & $249.8(71.9)$ & & & \\
6MWD T3 vs 6MWD T4 & 9 & $204.8(84.4)$ & 8 & -6.10 & $<.001^{*}$ \\
& 9 & $265.5(84.6)$ & & & \\
\hline
\end{tabular}

Note: *Indicates significant difference at $p<.0125$

Table 4. 5

CON Group Six minute walk distance (6MWD) Paired Samples T Test

\begin{tabular}{cccccc}
\hline Times Compared & N & Mean (SD) & df & t & p value \\
\hline 6MWD T1 vs 6MWD T2 & 15 & $358.0(76.9)$ & 14 & 1.023 & .324 \\
& 15 & $352.5(68.4)$ & & & \\
6MWD T1 vs 6MWD T3 & 9 & $394.2(59.3)$ & 8 & 10.53 & $<.001^{*}$ \\
& 9 & $133.6(59.6)$ & & & \\
6MWD T1 vs 6MWD T4 & 15 & $360.8(75.7)$ & 14 & 9.77 & $<.001^{*}$ \\
& 15 & $209.2(40.1)$ & & & \\
6MWD T2 vs 6MWD T3 & 9 & $385.7(46.6)$ & 8 & 11.2 & $<.001^{*}$ \\
& 9 & $133.5(59.6)$ & & & \\
6MWD T2 vs 6MWD T4 & 14 & $357.7(67.8)$ & 13 & 10.6 & $<.001^{*}$ \\
& 14 & $206.8(40.5)$ & & & \\
6MWD T3 vs 6MWD T4 & 9 & $133.5(59.6)$ & 8 & -6.29 & $<.001^{*}$ \\
& 9 & $216.8(43.2)$ & & & \\
\hline
\end{tabular}

Note: ${ }^{*}$ Indicates significant difference at $p<.0125$ 


\section{$\underline{\text { Six minute walk excluding T3 }}$}

The secondary analysis of the six minute walk excluding $\mathrm{T} 3$ indicted a similar pattern in the results as seen in (See table 4.6) the initial analysis of the four data collecting points again there was a significant effect of time on six minute walk, Wilks' Lamda $=0.141, F(2,26)=79.07, p<.001$, interaction of group and time, $p=.095$. The observed power for this test was .99 for time and .469 for time $\mathrm{x}$ group. While the time effect was significant, between group comparison was not significant, $F(1,27)=.2 .55, p$ $=.122$. The PRE group increased between $\mathrm{T} 1$ and $\mathrm{T} 2$ (See Fig. 4.5) it was not a significant change with the alpha values adjusted using the Bonferroni correction to control for $\alpha$ inflation. The CON group decreased between $\mathrm{T} 1$ and $\mathrm{T} 2$, as seen in figure 4.5 , it was not a significant change.

\section{Table 4.6}

Pairwise comparison of six minute walks time, secondary data

\begin{tabular}{|c|c|c|c|c|c|c|}
\hline \multirow[b]{2}{*}{ Time } & \multirow[b]{2}{*}{ Time } & \multirow[b]{2}{*}{$\begin{array}{c}\text { Mean } \\
\text { difference }\end{array}$} & \multirow[b]{2}{*}{$\begin{array}{l}\text { Standard } \\
\text { Error }\end{array}$} & \multirow[b]{2}{*}{$\mathrm{p}$-value } & \multicolumn{2}{|c|}{$\begin{array}{l}95 \% \text { Confidence Interval } \\
\text { for Difference }\end{array}$} \\
\hline & & & & & $\begin{array}{l}\text { Lower } \\
\text { Bound }\end{array}$ & $\begin{array}{l}\text { Upper } \\
\text { Bound }\end{array}$ \\
\hline \multirow[t]{2}{*}{1} & 2 & -7.52 & 5.04 & .441 & -20.40 & 5.34 \\
\hline & 4 & 141.70 & 12.91 & $<.001$ & 108.72 & 174.67 \\
\hline \multirow[t]{2}{*}{2} & 1 & 7.52 & 5.04 & .441 & -5.34 & 20.40 \\
\hline & 4 & 149.22 & 11.76 & $<.001$ & 119.20 & 179.25 \\
\hline
\end{tabular}

Note: Adjustment for multiple comparisons: Bonferroni. 
Figure 4.5 six minute walk - secondary data, 3 data point means

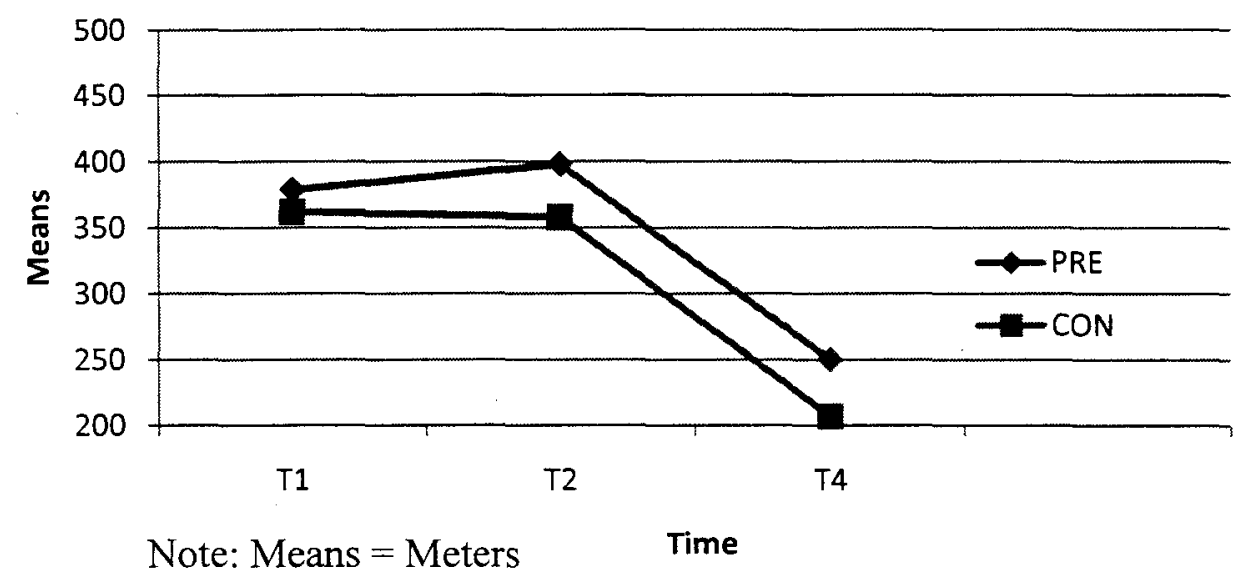

The Timed get up and go test (TUG) measured the time a participant required to rise from an unarmed chair, unassisted and walk three meters, turn and return to a sitting position in the same chair. The score for this functional task was determined by the duration of time taken to complete the task within $100^{\text {th }}$ of a second.

Hypothesis three was evaluated initially by using the TUG data by conducting a RM-ANOVA with time (T1, T2, T3 and T4) and group (PRE vs CON) and interaction of group and time as the sources of variability. There was a significant effect of time on the TUG test, Wilks' Lamda $=0.212, F(3,14)=17.32, p<.001$. There was no significant interaction effect on TUG, Wilks' Lamda $=0.709, F(3,14)=1.92, \mathrm{p}=.173$. The observed power for this test was 1.00 for time and .391 for time $\mathrm{x}$ group. The between groups comparison was significant, $F(1,16)=225.81, p=.043$. 
Post Hoc analysis of the TUG, using the Bonferroni correction method, of time (See table 4.7) indicated that the groups significantly declined between $\mathrm{T} 1$ and $\mathrm{T} 3, \mathrm{~T} 1$ and $\mathrm{T} 4$, $\mathrm{T} 2$ and $\mathrm{T} 3, \mathrm{~T} 2$ and $\mathrm{T} 4$, and $\mathrm{T} 3$ and $\mathrm{T} 4$. Independent samples $\mathrm{T}$ Tests looking at between groups differences showed no significant difference (See table 4.8). Additional planned comparisons using Paired Samples T Tests looked at within group changes over time. Specifically, looking at group (PRE) a significant decline from $\mathrm{T} 1$ to $\mathrm{T} 3, t(8)=-3.57, \mathrm{p}$ $=.007$ was observed, significant decline from $\mathrm{T} 1$ to $\mathrm{T} 4, t(14)=-3.70, \mathrm{p}=.002$, significant decline from $\mathrm{T} 2$ to $\mathrm{T} 3, t(8)=-3.82, \mathrm{p}=.005$, significant decline between $\mathrm{T} 2$ and $\mathrm{T} 4, t(14)=-5.07, p<.001$, a non -significant increase between $\mathrm{T} 3$ and $\mathrm{T} 4, t(8)=2.65$, $p=.029$ was seen, and between $\mathrm{T} 1$ and $\mathrm{T} 2, t(16)=2.07, p=.054$ (see table 4.9 ).

Table 4.10 specifically presented data of group (CON) where we saw a significant decline from $\mathrm{T} 1$ to $\mathrm{T} 3, t(8)=-5.16, p<.001$, significant decline from $\mathrm{T} 1$ to $\mathrm{T} 4, t(14)=-$ 9.62, $p=<.001$, significant decline from $\mathrm{T} 2$ to $\mathrm{T} 3, t(8)=-5.26, p=.001$, significant decline between $\mathrm{T} 2$ and $\mathrm{T} 4, t(14)=-7.50, p<.001$. However a significant increase was seen between T3 and T4, $t(8)=4.05, \mathrm{p}=.004$, and a non significant increase between $\mathrm{T} 1$ and $\mathrm{T} 2, t(15)=-1.18, p=.256$. The PRE group increased between $\mathrm{T} 1$ and $\mathrm{T} 2$ (See Fig. 4.7) but it was not a significant change with the alpha values $(p=.0125)$ adjusted using the Bonferroni correction to control for $\alpha$ inflation. Although the CON group appears to decrease between $\mathrm{T} 1$ and $\mathrm{T} 2$, as seen in figure 4.7 , it was not a significant difference. 
Figure 4.6 TUG - initial data means

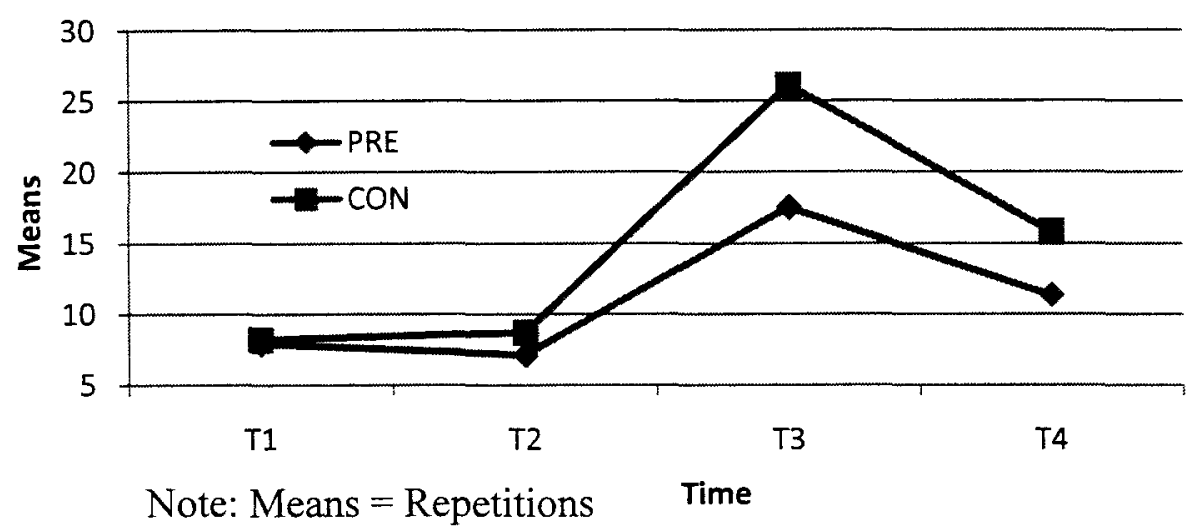

\section{Table 4.7}

Pairwise comparison of TUG time, initial data

\begin{tabular}{|c|c|c|c|c|c|c|}
\hline \multirow[t]{2}{*}{ Time } & \multirow[t]{2}{*}{ Time } & \multirow{2}{*}{$\begin{array}{c}\text { Mean } \\
\text { difference }\end{array}$} & \multirow{2}{*}{$\begin{array}{c}\text { Standard } \\
\text { Error }\end{array}$} & \multirow[t]{2}{*}{ p-value } & \multicolumn{2}{|c|}{$\begin{array}{c}95 \% \text { Confidence } \\
\text { Interval for } \\
\text { Difference }\end{array}$} \\
\hline & & & & & $\begin{array}{l}\text { Lower } \\
\text { Bound }\end{array}$ & $\begin{array}{l}\text { Upper } \\
\text { Bound }\end{array}$ \\
\hline \multirow[t]{3}{*}{1} & 2 & .16 & .35 & .999 & -.91 & 1.22 \\
\hline & 3 & -13.78 & 2.19 & $<.001$ & -20.38 & -7.16 \\
\hline & 4 & -5.53 & .86 & $<.001$ & -8.11 & -2.94 \\
\hline \multirow[t]{3}{*}{2} & 1 & -.16 & .35 & .999 & -1.22 & .91 \\
\hline & 3 & -13.93 & 2.15 & $<.001$ & -20.39 & -7.48 \\
\hline & 4 & -5.68 & .77 & $<.001$ & -8.00 & -3.37 \\
\hline \multirow[t]{3}{*}{3} & 1 & 13.78 & 2.19 & $<.001$ & 7.17 & 20.38 \\
\hline & 2 & 13.93 & 2.15 & $<.001$ & 7.47 & 20.39 \\
\hline & 4 & 8.25 & 1.73 & $<.001$ & 3.05 & 13.44 \\
\hline
\end{tabular}

Note: Adjustment for multiple comparisons: Bonferroni. 


\section{Table 4.8}

TUG group statistics Independent Samples T Test

\begin{tabular}{ccccccc}
\hline Variable & Group & $\mathrm{N}$ & Mean (SD) & $\mathrm{df}$ & $\mathrm{t}$ & $\mathrm{p}$ value \\
\hline TUG T1 & CON & 18 & $9.64(2.55)$ & 35 & .485 & .6 .31 \\
& PRE & 19 & $9.19(3.07)$ & & & \\
TUG T2 & CON & 16 & $10.02(2.60)$ & 31 & 2.55 & .016 \\
& PRE & 17 & $8.11(1.60)$ & & & \\
TUG T3 & CON & 9 & $26.11(10.59)$ & 16 & 1.87 & .080 \\
& PRE & 9 & $17.55(8.70)$ & & & \\
TUG T4 & CON & 15 & $17.21(4.61)$ & 28 & 1,84 & .076 \\
& PRE & 15 & $13.81(5.45)$ & & & \\
\hline
\end{tabular}

Note: all alpha values $(\alpha)$ were adjusted using Bonferroni correction to control for $\alpha$ Inflation. New $\alpha$ inflation Bonferroni correction .05/4 $=0.0125$

${ }^{*}$ Indicates significant difference at $p<.0125$

Table 4. 9

PRE Group TUG Paired Samples T Test

\begin{tabular}{cccccc}
\hline Times Compared & $\mathrm{N}$ & Mean (SD) & $\mathrm{df}$ & $\mathrm{t}$ & $\mathrm{p}$ value \\
\hline TUG T1 vs TUG T2 & 17 & $9.26(3.21)$ & 16 & 2.07 & .054 \\
& 17 & $8.11(1.60)$ & & & \\
TUG T1 vs TUG T3 & 9 & $7.87(2.21)$ & 8 & -3.57 & $.007^{*}$ \\
& 9 & $17.55(8.70)$ & & & \\
TUG T1 vs TUG T4 & 15 & $8.78(2.16)$ & 14 & -3.70 & $.002^{*}$ \\
& 15 & $13.81(5.45)$ & & & \\
TUG T2 vs TUG T3 & 9 & $7.09(1.01)$ & 8 & -3.82 & $.005^{*}$ \\
& 9 & $17.55(8.70)$ & & & \\
TUG T3 vs TUG T4 & 9 & $17.55(8.70)$ & 8 & 2.65 & .029 \\
& 9 & $11.32(2.35)$ & & & \\
TUG T2 vs TUG T4 & 15 & $7.97(1.47)$ & 14 & -5.07 & $<.001^{*}$ \\
& 15 & $13.81(5.45)$ & & & \\
\hline
\end{tabular}

Note: *Indicates significant difference at $p<.0125$ 
Table 4. 10

CON Group TUG Paired Samples T Test

\begin{tabular}{cccccc}
\hline Times Compared & $\mathrm{N}$ & Mean (SD) & $\mathrm{df}$ & $\mathrm{t}$ & $\mathrm{p}$ value \\
\hline TUG T1 vs TUG T2 & 16 & $9.57(2.66)$ & 15 & $-1 .{ }^{\prime} 18$ & .256 \\
& 16 & $10.02(2.60)$ & & & \\
TUG T1 vs TUG T3 & 9 & $8.23(2.05)$ & 8 & -5.16 & $.001^{*}$ \\
& 9 & $26.11(10.59)$ & & & \\
TUG T1 vs TUG T4 & 15 & $9.55(2.75)$ & 14 & -9.62 & $<.001^{*}$ \\
& 15 & $17.21(4.61)$ & & & \\
TUG T2 vs TUG T3 & 9 & $8.70(1.47)$ & 8 & -5.26 & $.001^{*}$ \\
& 9 & $26.11(10.59)$ & & & \\
TUG T3 vs TUG T4 & 9 & $26.11(10.59)$ & 8 & 4.05 & $.004^{*}$ \\
& 9 & $15.84(4.90)$ & & & \\
TUG T2 vs TUG T4 & 15 & $9.98(2.68)$ & 14 & -7.50 & $<.001^{*}$ \\
& 15 & $17.21(4.61)$ & & & \\
\hline
\end{tabular}

Note: ${ }^{*}$ Indicates significant difference at $p<.0125$

\section{TUG excluding T3}

The secondary analysis of TUG test excluding T3 indicted a similar pattern (See table 4.11 ) as the initial analysis of the four data collecting points. Similar to above there was a significant effect of time on TUG, Wilks' Lamda $=.270, F(2,27)=36.52, p<$ .001 . There was a significant interaction effect on TUG, Wilks' Lamda $=.834, F(2,27)=$ $2.68, p<.001$.The observed power for this test was 1.00 for time and .493 for time $\mathrm{x}$ group. While time was significant, between group comparison was not significant, $F(1$, $28)=.4 .04, p=.054$. The PRE group increased between T1 and T2 (See Fig. 4.7) it was not a significant change with the alpha values $(p=.0125)$ adjusted using the Bonferroni correction to control for $\alpha$ inflation. Although the CON group appears to decrease between $\mathrm{T} 1$ and $\mathrm{T} 2$, as seen in figure 4.7 , it was not a significant difference. Both groups significantly changed between $\mathrm{T} 2$ and $\mathrm{T} 4$. 
Figure 4.7 TUG - secondary data means

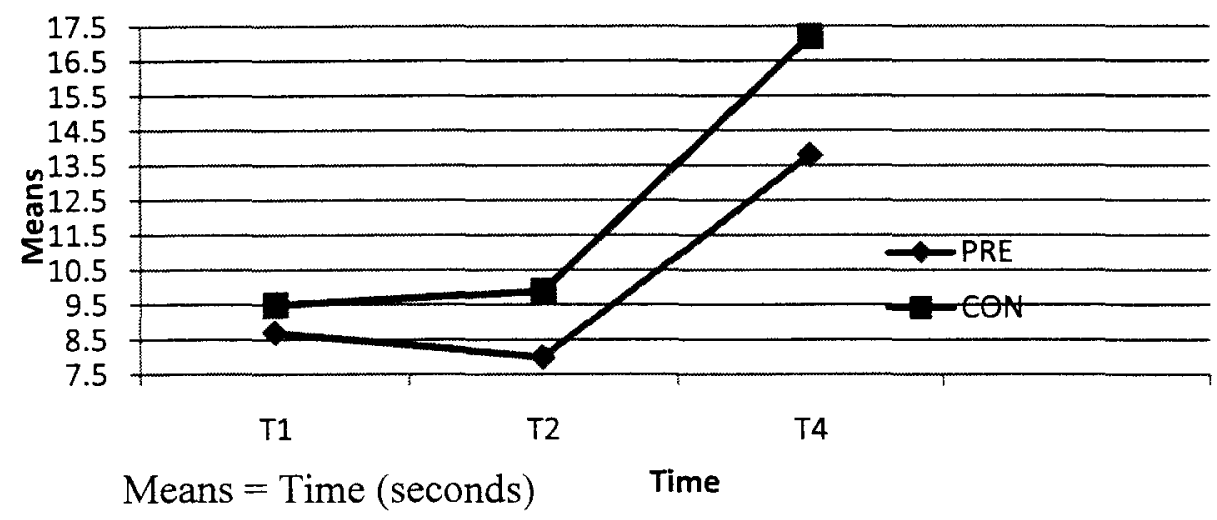

\section{Table 4.11}

Pairwise comparison of TUG time, secondary data

\begin{tabular}{ccccccc}
\hline Time & Time & $\begin{array}{c}\text { Mean } \\
\text { difference }\end{array}$ & $\begin{array}{c}\text { Standard } \\
\text { Error }\end{array}$ & p-value & \multicolumn{2}{c}{$\begin{array}{c}\text { Interval for } \\
\text { Difference } \\
\text { Lower }\end{array}$} \\
\hline 1 & 2 & .18 & .29 & .999 & -.56 & .93 \\
Bound & Bound \\
\hline & 4 & -6.34 & .78 & $<.001$ & -8.35 & -4.34 \\
2 & 1 & .18 & .29 & .999 & -.93 & .56 \\
& 4 & -6.53 & .75 & $<.001$ & -8.44 & -4.62 \\
\hline
\end{tabular}

Note: Adjustment for multiple comparisons: Bonferroni. 
Sit-to-stand in 30 seconds assessment was employed to determine the subject's capacity to rise repeatedly from a chair over a 30 -second period of time.

Hypothesis three was evaluated by using the sit - to - stand data through conducting a RM-ANOVA with time (T1, T2, T3 and T4) and group (PRE vs CON) and interaction of group and time as the sources of variability. There was a significant effect of time on the sit-to-stand test, Wilks' Lamda $=0.251, F(3,13)=.12 .92, p<.001$. There was no significant interaction effect on sit - to - stand, Wilks' Lamda $=.868, F(3,13)=.660, p=$ .591. The observed power for this test was .97 for time and .152 for time $\mathrm{x}$ group. The between groups comparison was significant, $F(1,15)=9.86, p=.007$.

Post Hoc analysis of the sit - to - stand (chair raises), using the Bonferroni correction method, of time (See table 4.12) indicated that the groups significantly declined between $\mathrm{T} 1$ and $\mathrm{T} 2, \mathrm{~T} 1$ and $\mathrm{T} 3, \mathrm{~T} 2$ and $\mathrm{T} 3, \mathrm{~T} 2$ and $\mathrm{T} 4$, and $\mathrm{T} 3$ and $\mathrm{T} 4$. Independent samples $\mathrm{T}$ tests looking at between groups showed no significant difference (See table 4.13). Additional planned comparisons using Paired Samples T tests (See table 4.14), examined within group changes over time. Specifically, looking at group (PRE) significant increases between $\mathrm{T} 1$ and $\mathrm{T} 2, t(16)=-3.86, p=.001$ was seen, non significant decline from $\mathrm{T} 1$ to $\mathrm{T} 3, t(8)=2.06, p=.073)$, non significant decline from $\mathrm{T} 1$ to $\mathrm{T} 4$, $t(14)=1.25, p=.230$, significant decline from $\mathrm{T} 2$ to $\mathrm{T} 3, t(8)=3.83, p=.005$, significant decline between $\mathrm{T} 2$ and $\mathrm{T} 4, t(14)=3.55, p=.003$, non - significant increases between $\mathrm{T} 3$ and $\mathrm{T} 4, t(8)=-2.41, p=.042$. 
Table 4.15 specifically presented data of group (CON) and a non significant increase between $\mathrm{T} 1$ and $\mathrm{T} 2, t(15)=-2.33, p=.034$ was seen, a significant decline from $\mathrm{T} 1$ to $\mathrm{T} 3, t(7)=5.50, p=.001$, significant decline from $\mathrm{T} 1$ to $\mathrm{T} 4, t(13)=3.05, p=.009$, significant decline from $\mathrm{T} 2$ to $\mathrm{T} 3, t(7)=7.20, p<.001$, significant decline between $\mathrm{T} 2$ and $\mathrm{T} 4, t(13)=3.64, p=.003$, significant decline between $\mathrm{T} 3$ and $\mathrm{T} 4, t(7)=-2.51, p=$ .04. The PRE group significantly increased between T1 and T2 (See Fig. 4.8) with the alpha values ( $p=.0125$ ) adjusted using the Bonferroni correction to control for $\alpha$ inflation. The CON group means increased between $\mathrm{T} 1$ and $\mathrm{T} 2$, as seen in figure 4.8 , but it was not a significant change.

Figure 4.8 Sit to stand - initial data, 4 data points

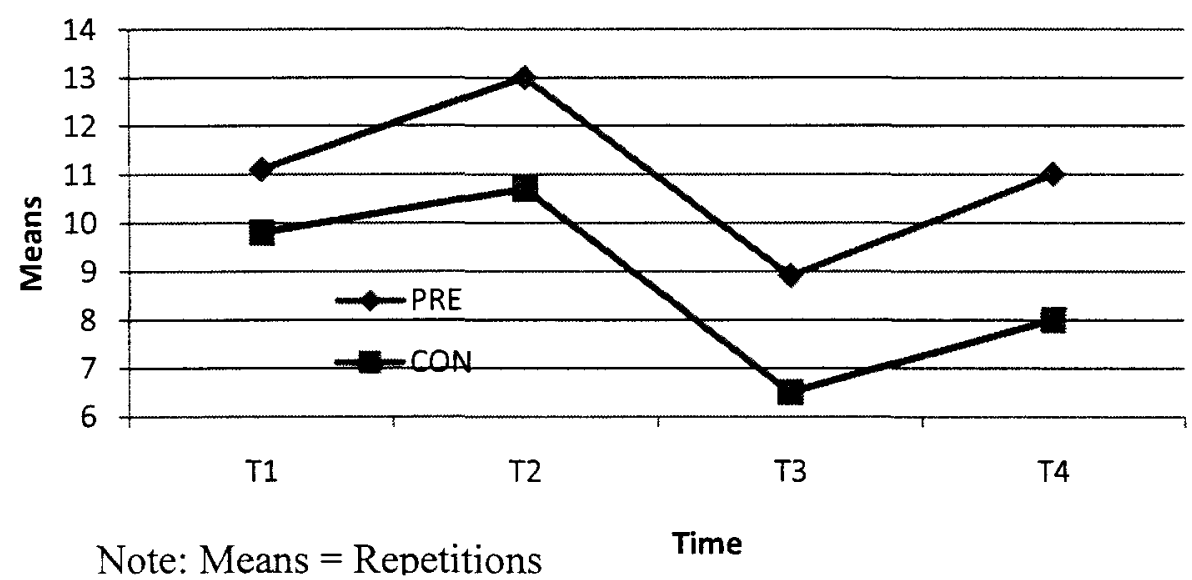




\section{Table 4.12}

Pairwise comparison of Sit -to-stand time, initial data

\begin{tabular}{|c|c|c|c|c|c|c|}
\hline \multirow[t]{2}{*}{ Time } & \multirow[t]{2}{*}{ Time } & \multirow{2}{*}{$\begin{array}{c}\text { Mean } \\
\text { difference }\end{array}$} & \multirow{2}{*}{$\begin{array}{c}\text { Standard } \\
\text { Error }\end{array}$} & \multirow[t]{2}{*}{$\mathrm{p}$-value } & \multicolumn{2}{|c|}{$\begin{array}{l}95 \% \text { Confidence } \\
\text { Interval for } \\
\text { Difference }\end{array}$} \\
\hline & & & & & $\begin{array}{l}\text { Lower } \\
\text { Bound }\end{array}$ & $\begin{array}{l}\text { Upper } \\
\text { Bound } \\
\end{array}$ \\
\hline \multirow[t]{3}{*}{1} & 2 & -1.44 & .45 & .038 & -2.83 & -.05 \\
\hline & 3 & 2.73 & .63 & .004 & .80 & 4.67 \\
\hline & 4 & .931 & .55 & .687 & -.75 & 2.61 \\
\hline \multirow[t]{3}{*}{2} & 1 & -1.44 & .45 & .038 & .05 & 2.83 \\
\hline & 3 & 4.18 & .63 & $<.001$ & 2.25 & 6.10 \\
\hline & 4 & 2.37 & .52 & .002 & .78 & 3.96 \\
\hline \multirow[t]{3}{*}{3} & 1 & -2.73 & .63 & .004 & -4.67 & -.80 \\
\hline & 2 & 4.18 & .63 & .000 & -6.10 & -2.25 \\
\hline & 4 & -1.80 & .54 & .028 & -3.45 & -.15 \\
\hline
\end{tabular}

Note: Adjustment for multiple comparisons: Bonferroni. 
Table 4.13

Sit-to-stand group statistics Independent Samples T Test

\begin{tabular}{ccccccc}
\hline Variable & Group & $\mathrm{N}$ & Mean (SD) & $\mathrm{df}$ & $\mathrm{t}$ & $\mathrm{p}$ value \\
\hline CHAIR T1 & CON & 18 & $9.1192 .47)$ & 35 & -.643 & .525 \\
& PRE & 19 & $9.63(2.45)$ & & & \\
CHAIR T2 & CON & 16 & $9.68(2.54)$ & 31 & -2.519 & .017 \\
& PRE & 17 & $12.05(2.84)$ & & & \\
CHAIR T3 & CON & 8 & $6.50(1.60)$ & 15 & -2.23 & .041 \\
& PRE & 9 & $8.89(2.62)$ & & & \\
CHAIR T4 & CON & 14 & $6.78(2.51)$ & 27 & -1.61 & .119 \\
& PRE & 15 & $8.86(4.17)$ & & & \\
\hline
\end{tabular}

Note: all alpha values $(\alpha)$ were adjusted using Bonferroni correction to control for $\alpha$ Inflation. New $\alpha$ inflation Bonferroni correction .05/4 $=0.0125$

*Indicates significant difference at $p<.0125$

Table 4. 14

PRE Group Sit-to-stand Paired Samples T Test

\begin{tabular}{cccccc}
\hline Times Compared & $\mathrm{N}$ & Mean (SD) & $\mathrm{df}$ & $\mathrm{t}$ & $\mathrm{p} \mathrm{value}$ \\
\hline CHAIR T1 vs CHAIR T2 & 17 & $9.94(2.41)$ & 16 & -3.86 & .001 \\
& 17 & $12.06(2.84)$ & & & \\
CHAIR T1 vs CHAIR T3 & 9 & $11.11(2.14)$ & 8 & 2.06 & .073 \\
& 9 & $8.88(2.62)$ & & & \\
CHAIR T1 vs CHAIR T4 & 15 & $10.20(2.17)$ & 14 & 1.25 & .230 \\
& 15 & $8.86(4.17)$ & & & \\
CHAIR T2 vs CHAIR T3 & 9 & $13.0(2.00)$ & 8 & 3.83 & .005 \\
& 9 & $8.89(2.61)$ & & & \\
CHAIR T3 vs CHAIR T4 & 9 & $8.89(2.61)$ & 8 & -2.41 & .042 \\
& 9 & $11.0(2.17)$ & & & \\
CHAIR T2 vs CHAIR T4 & 15 & $12.0(2.50)$ & 14 & 3.55 & .003 \\
& 15 & $8.86(4.17)$ & & & \\
\hline
\end{tabular}

Note: ${ }^{*}$ Indicates significant difference at $p<.0125$ 
Table 4.15 CON Group Sit-to-stand Paired Samples T Test

\begin{tabular}{cccccc}
\hline Times Compared & $\mathrm{N}$ & Mean (SD) & $\mathrm{df}$ & $\mathrm{t}$ & $\mathrm{p}$ value \\
\hline CHAIR T1 vs CHAIR T2 & 16 & $8.81(2.10)$ & 15 & -2.33 & .034 \\
& 16 & $9.68(2.54)$ & & & \\
CHAIR T1 vs CHAIR T3 & 8 & $9.75(1.38)$ & 7 & 5.50 & .001 \\
& 8 & $6.50(1.60)$ & & & \\
CHAIR T1 vs CHAIR T4 & 14 & $8.57(2.13)$ & 13 & 3.05 & .009 \\
& 14 & $6.78(2.51)$ & & & \\
CHAIR T2 vs CHAIR T3 & 8 & $10.75(2.25)$ & 7 & 7.20 & $<.001$ \\
& 8 & $6.50(1.60)$ & & & \\
CHAIR T3 vs CHAIR T4 & 8 & $6.50(1.60)$ & 7 & -2.51 & .040 \\
& 8 & $8.0(1.77)$ & & & \\
CHAIR T2 vs CHAIR T4 & 14 & $9.57(2.71)$ & 13 & 3.64 & .003 \\
& 14 & $6.78(2.52)$ & & & \\
\hline
\end{tabular}

Note: ${ }^{*}$ Indicates significant difference at $p<.0125$

\section{$\underline{\text { Sit }- \text { to }- \text { stand excluding T3 }}$}

The secondary analysis of sit-to-stand test excluding T3 indicted a similar pattern (See table 4.16) as the initial analysis of the four data collecting points again there was a significant effect of time on sit-to-stand, Wilks' Lamda $=0.437, F(2,26)=16.75, p<$ .001 . There was no significant interaction of group and time, $p=.535$. The observed power for this test was .999 for time and .145 for time $\mathrm{x}$ group. Time was significant and between group comparison was significant, $F(1,27)=5.93, p=.022$. The PRE group increased between T1 and T2 (See Fig. 4.9) it was a significant change with the alpha values $(p=.0125)$ adjusted using the Bonferroni correction to control for $\alpha$ inflation. The CON group increased between $\mathrm{T} 1$ and $\mathrm{T} 2$, as seen in figure 4.9 , it was not a significant difference. Both groups significantly changed between T2 and T4. 
Figure 4.9 Sit to stand - secondary data, 3 data points

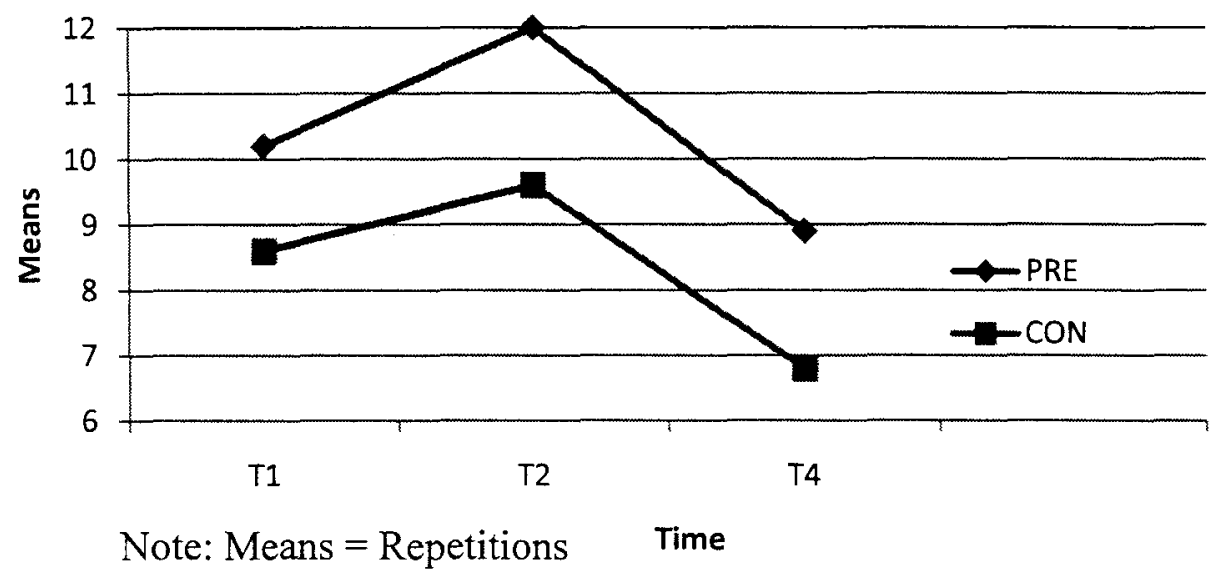

Table 4.16

Pairwise comparison of Sit -to-stand time, secondary data

\begin{tabular}{|c|c|c|c|c|c|c|}
\hline & \multirow[t]{2}{*}{ Time } & \multirow{2}{*}{$\begin{array}{c}\text { Mean } \\
\text { difference }\end{array}$} & \multirow{2}{*}{$\begin{array}{l}\text { Standard } \\
\text { Error }\end{array}$} & \multirow[t]{2}{*}{$\mathrm{p}$-value } & \multicolumn{2}{|c|}{$\begin{array}{l}95 \% \text { Confidence } \\
\text { Interval for } \\
\text { Difference }\end{array}$} \\
\hline & & & & & $\begin{array}{l}\text { Lower } \\
\text { Bound }\end{array}$ & $\begin{array}{l}\text { Upper } \\
\text { Bound }\end{array}$ \\
\hline \multirow[t]{2}{*}{1} & 2 & -1.40 & .34 & $<.001$ & -2.28 & -.51 \\
\hline & 4 & 1.56 & .61 & .054 & -.02 & 3.14 \\
\hline \multirow[t]{2}{*}{2} & 1 & -1.40 & .34 & $<.001$ & .51 & 2.28 \\
\hline & 4 & 2.96 & .58 & $<.001$ & 1.46 & 4.46 \\
\hline
\end{tabular}

Note: Adjustment for multiple comparisons: Bonferroni. 
Ascend/descend stairs assessments were used to determine the subject's ability to ascend and descend a flight of nineteen standard seven inch stairs. Subjects were asked to climb19 stairs. Following a 30 second rest, subjects were asked to descend the stairs to the starting position. There was a drop in the number of PRE and CON subjects who were physically able or mentally willing to ascend and descend the stairs.

Hypothesis three was evaluated by using the ascending stair data through conducting a RM-ANOVA with time $(\mathrm{T} 1, \mathrm{~T} 2, \mathrm{~T} 3$ and $\mathrm{T} 4)$ and group $(\mathrm{PRE}=6 \mathrm{vs} \mathrm{CON}=$ 5) and interaction of group and time as the sources of variability. There was a significant effect of time on the ascending stair test, Wilks' Lamda $=0.062, F(3,7)=35.30, p<$ .001. There was no significant interaction effect on ascending stairs, Wilks' Lamda $=$ .482, $F(3,7)=2.51, p=.143$.The observed power for this test was 1.00 for time and .393 for time $\mathrm{x}$ group. The between groups comparison was significant, $F(1,9)=5.29, p=$ .047 .

Post Hoc analysis of the ascending stairs using the Bonferroni correction method, of time (See table 4.17) indicated that the groups significantly declined between $\mathrm{T} 1$ and $\mathrm{T} 3$, $\mathrm{T} 1$ and $\mathrm{T} 4, \mathrm{~T} 2$ and $\mathrm{T} 3, \mathrm{~T} 2$ and $\mathrm{T} 4$, and $\mathrm{T} 3$ and $\mathrm{T} 4$. Independent samples $\mathrm{T}$ tests looking at between groups showed no significant differences between the groups across time (See table 4.18). Additional planned comparisons using Paired Samples T Tests (See table 4.19), examined within group changes over time. Specifically, looking at group (PRE) a non - significant increase between $\mathrm{T} 1$ and $\mathrm{T} 2, t(16)=2.66, p=.017$ was seen, significant decline from $\mathrm{T} 1$ to $\mathrm{T} 3, t(5)=-5.36, p=.003$, significant decline from $\mathrm{T} 1$ to $\mathrm{T} 4, t(13)=-$ $5.90, p<.001)$, significant decline from $\mathrm{T} 2$ to $\mathrm{T} 3, t(5)=-6.60, p=.001$, significant decline between $\mathrm{T} 2$ and $\mathrm{T} 4, t(13)=-7.37, p<.001$, significant increase between $\mathrm{T} 3$ and 
$\mathrm{T} 4, t(5)=5.09, p=.004$.

Table 4.20 specifically presented data of group (CON) and a non significant increase between $\mathrm{T} 1$ and $\mathrm{T}, t(14)=.427, p=.676$ was seen, a significant decline from $\mathrm{T} 1$ to $\mathrm{T} 3, t(4)=-6.87, \mathrm{p}=.002$, significant decline from $\mathrm{T} 1$ to $\mathrm{T} 4, t(9)=-6.92, p<.001$, significant decline from $\mathrm{T} 2$ to $\mathrm{T} 3, t(4)=-7.63, p=.002$, significant decline between $\mathrm{T} 2$ and $\mathrm{T} 4, t(8)=-8.38, p<.001$, significant increase between $\mathrm{T} 3$ and $\mathrm{T} 4, t(4)=5.79, p=$ .004 . The PRE group increased between $\mathrm{T} 1$ and $\mathrm{T} 2$ but it was not significant (See Fig. 4.10) with the alpha values $(p=.0125)$ adjusted using the Bonferroni correction to control for $\alpha$ inflation. The CON group appeared to increase between $\mathrm{T} 1$ and $\mathrm{T} 2$, as seen in figure 4.10 , but it was not a significant change. 
Figure 4.10 Ascend stairs - initial data, 4 data points means

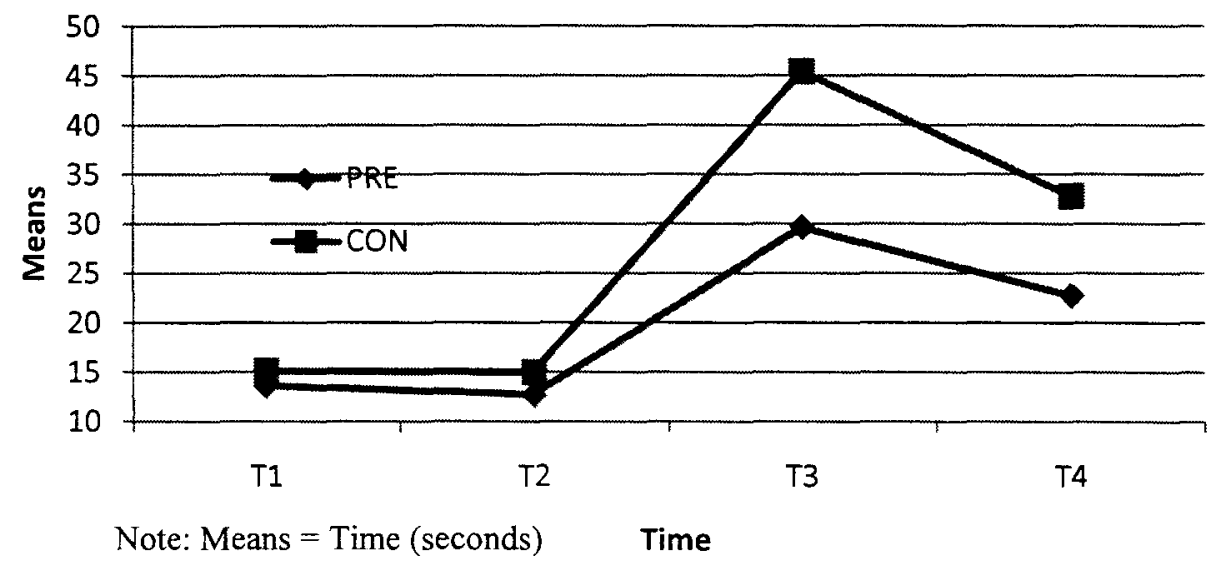

Table 4.17

Pairwise comparison of Ascending stair time, initial data

\begin{tabular}{|c|c|c|c|c|c|c|}
\hline \multirow[t]{2}{*}{ Time } & \multirow[t]{2}{*}{ Time } & \multirow{2}{*}{$\begin{array}{c}\text { Mean } \\
\text { difference }\end{array}$} & \multirow{2}{*}{$\begin{array}{c}\text { Standard } \\
\text { Error }\end{array}$} & \multirow[t]{2}{*}{ p-value } & \multicolumn{2}{|c|}{$\begin{array}{l}95 \% \text { Confidence } \\
\text { Interval for } \\
\text { Difference }\end{array}$} \\
\hline & & & & & $\begin{array}{l}\text { Lower } \\
\text { Bound }\end{array}$ & $\begin{array}{l}\text { Upper } \\
\text { Bound }\end{array}$ \\
\hline \multirow[t]{3}{*}{1} & 2 & .51 & .60 & .999 & -1.53 & 2.56 \\
\hline & 3 & -23.12 & 2.58 & $<.001$ & -31.80 & -14.43 \\
\hline & 4 & -13.37 & 2.42 & .002 & -21.52 & -5.23 \\
\hline \multirow[t]{3}{*}{2} & 1 & -.51 & .60 & .999 & -2.56 & 1.53 \\
\hline & 3 & -23.63 & 2.28 & $<.001$ & -31.33 & -15.93 \\
\hline & 4 & -13.89 & 2.05 & $<.001$ & -20.79 & -6.99 \\
\hline \multirow[t]{3}{*}{3} & 1 & 23.12 & 2.58 & $<.001$ & 14.43 & 31.80 \\
\hline & 2 & 23.63 & 2.28 & $<.001$ & 15.93 & 31.33 \\
\hline & 4 & 9.74 & 1.23 & $<.001$ & 5.59 & 13.89 \\
\hline
\end{tabular}

Note: Adjustment for multiple comparisons: Bonferroni. 
Table 4.18

Ascend stairs group statistics Independent Samples T Test

\begin{tabular}{ccccccc}
\hline Variable & Group & $\mathrm{N}$ & Mean (SD) & $\mathrm{df}$ & $\mathrm{t}$ & $\mathrm{p}$ value \\
\hline Ascend stairs T1 & CON & 18 & $21.83(9.93)$ & 35 & 1.85 & .072 \\
& PRE & 19 & $16.74(6.51)$ & & & \\
Ascend stairs T2 & CON & 15 & $21.08(10.69)$ & 30 & 2.22 & .034 \\
& PRE & 17 & $14.45(5.69)$ & & & \\
Ascend stairs T3 & CON & 5 & $45.38(11.63)$ & 9 & 2.91 & .017 \\
& PRE & 6 & $29.63(5.88)$ & & & \\
Ascend stairs T4 & CON & 10 & $32.76(7.64)$ & 22 & 1.08 & .289 \\
& PRE & 14 & $28.81(9.49)$ & & &. \\
\hline
\end{tabular}

Note: all alpha values $(\alpha)$ were adjusted using Bonferroni correction to control for $\alpha$ Inflation. New $\alpha$ inflation Bonferroni correction $.05 / 4=0.0125$

*Indicates significant difference at $p<.0125$

\section{Table 4. 19}

PRE Group ascend stairs Paired Samples T Test

\begin{tabular}{cccccc}
\hline Times Compared & $\mathrm{N}$ & Mean (SD) & df & $\mathrm{t}$ & $\mathrm{p}$ value \\
\hline Ascend T1 vs Ascend T2 & 17 & $16.67(6.86)$ & 16 & 2.66 & .017 \\
& 17 & $14.45(5.69)$ & & & \\
Ascend T1 vs Ascend T3 & 6 & $13.60(3.67)$ & 5 & -5.36 & .003 \\
& 6 & $29.63(5.88)$ & & & \\
Ascend T1 vs Ascend T4 & 14 & $15.88(6.30)$ & 13 & -5.90 & $<.001$ \\
& 14 & $28.81(9.49)$ & & & \\
Ascend T2 vs Ascend T3 & 6 & $12.68(3.55)$ & 5 & -6.60 & .001 \\
& 6 & $29.63(5.88)$ & & & \\
Ascend T3 vs Ascend T4 & 6 & $29.63(5.88)$ & 5 & 5.09 & .004 \\
& 6 & $22.70(6.11)$ & & & \\
Ascend T2 vs Ascend T4 & 14 & $13.96(4.58)$ & 13 & -7.37 & $<.001$ \\
& 14 & $28.81(9.49)$ & & & \\
\hline
\end{tabular}

Note: ${ }^{*}$ Indicates significant difference at $\mathrm{p}<.0125$ 


\section{Table 4.20}

CON Group ascend stairs Paired Samples T Test

\begin{tabular}{lccccc}
\hline Times Compared & $\mathrm{N}$ & Mean (SD) & $\mathrm{df}$ & $\mathrm{t}$ & $\mathrm{p}$ value \\
\hline Ascend T1 vs Ascend T2 & 15 & $21.42(10.47)$ & 14 & .427 & .676 \\
& 15 & $21.08(10.69)$ & & & \\
Ascend T1 vs Ascend T3 & 5 & $15.17(3.63)$ & 4 & -6.87 & .002 \\
& 5 & $45.38(11.63)$ & & & \\
Ascend T1 vs Ascend T4 & 10 & $16.62(6.37)$ & 9 & -6.92 & $<.001$ \\
& 10 & $32.76(7.64)$ & & & \\
Ascend T2 vs Ascend T3 & 5 & $15.06(3.46)$ & 4 & -7.63 & .002 \\
& 5 & $45.38(11.64)$ & & & \\
Ascend T3 vs Ascend T4 & 5 & $45.38(11.64)$ & 4 & 5.79 & .004 \\
Ascend T2 vs Ascend T4 & 5 & $32.83(10.99)$ & & & \\
$\mathrm{N}$ & 9 & $14.98(3.81)$ & 8 & -8.38 & $<.001$ \\
\hline
\end{tabular}

Note: ${ }^{*}$ Indicates significant difference at $\mathrm{p}<.0125$

\section{Ascending stair excluding T3}

The secondary analysis of ascending stair test excluding T3 indicated a similar pattern (See table 4.21) as the initial analysis of the four data collecting points again there was a significant effect of time on ascending stairs, Wilks' Lamda $=0.143, F(2,20)=$ $59.95, p<.001$. There was a significant interaction effect on ascending stairs, Wilks' Lamda $=.863, F(2,20)=1.59, p<.001$. The observed power for this test was 1.00 for time and .297 for time $x$ group. While time was significant, between group comparison was not significant, $F(1,21)=.275, p=.605$. The PRE group increased between $\mathrm{T} 1$ and T2 (See Fig. 4.11) it was a non - significant change with the alpha values $(p=.0125)$ adjusted using the Bonferroni correction to control for $\alpha$ inflation. The CON group appeared to increase between $\mathrm{T} 1$ and $\mathrm{T} 2$, as seen in figure 4.9; it was not a significant 
change. Both groups significantly declined changed between $\mathrm{T} 2$ and $\mathrm{T} 4$.

Figure 4.11 Ascend stairs - secondary data, 3 data points means

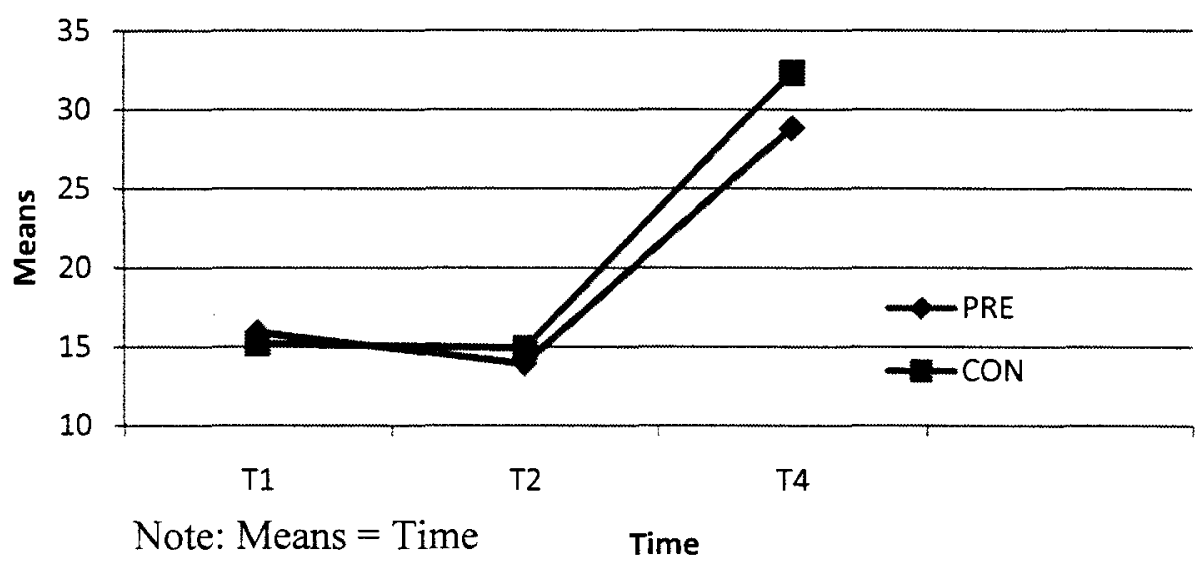

Table 4.21

Pairwise comparison of Ascending stair time, secondary data

\begin{tabular}{ccccccc}
\hline Time & Time & Mean & Standard & p-value & \multicolumn{2}{c}{$\begin{array}{c}\text { 95\% Confidence } \\
\text { Interval for } \\
\text { Difference } \\
\text { Lower }\end{array}$} \\
Bound & $\begin{array}{c}\text { Upper } \\
\text { Bound }\end{array}$ \\
\hline 1 & 2 & 1.02 & .51 & .178 & -.31 & 2.37 \\
& 4 & -15.04 & 1.66 & $<.001$ & -19.35 & -10.72 \\
2 & 1 & -1.02 & .51 & .178 & -2.37 & .31 \\
& 4 & -16.06 & 1.50 & $<.001$ & -19.99 & -12.14 \\
\hline
\end{tabular}

Note: a Adjustment for multiple comparisons: Bonferroni. 
Hypothesis three was evaluated by using the descending stair initial data through conducting a RM-ANOVA with time (T1, T2, T3, and T4) and group (PRE vs CON) and interaction of group and time as the sources of variability. There was a significant effect of time on the descending stair test, Wilks' Lamda $=.111, F(3,7)=18.68, p=.001$. There was no significant interaction effect on descending stairs, Wilks' Lamda $=.521$, $F(3,7)=2.14, p=.183$. The observed power for this test was .998 for time and .341 for time $\mathrm{x}$ group. The between groups comparison was also significant, $F(1,9)=6.45, p=$ .032 .

Post Hoc analysis of the descending stairs using the Bonferroni correction method, of time (See table 4.22) indicated that the groups significantly declined between T1 and $\mathrm{T} 3, \mathrm{~T} 1$ and $\mathrm{T} 4, \mathrm{~T} 2$ and $\mathrm{T} 3, \mathrm{~T} 2$ and $\mathrm{T} 4$, and $\mathrm{T} 3$ and $\mathrm{T} 4$. Independent samples $\mathrm{T}$ tests looking at between groups showed significant differences between the groups across time at T3 (See table 4.23). Additional planned comparisons using Paired Samples T tests looked at within group changes over time. Specifically, looking at group (PRE) (See table 4.24), non - significant increase between $\mathrm{T} 1$ and $\mathrm{T} 2, t(16)=1.94, p=.070$ was seen, non - significant decline from $\mathrm{T} 1$ to $\mathrm{T} 3, t(5)=-2.83, p=.037$, significant decline from $\mathrm{T} 1$ to $\mathrm{T} 4, t(12)=-4.56, p=.001$, significant decline from $\mathrm{T} 2$ to $\mathrm{T} 3, t(5)=-4.09, p=.009$, significant decline between $\mathrm{T} 2$ and $\mathrm{T} 4, t(12)=-6.11, p<.001$, non - significant increase between $\mathrm{T} 3$ and $\mathrm{T} 4, t(5)=3.69, p=.014$.

Table 4.25 specifically presented data of group (CON) and a non significant decline between $\mathrm{T} 1$ and $\mathrm{T} 2, t(14)=-.630, p=.539$ was seen, a significant decline from $\mathrm{T} 1$ to $\mathrm{T} 3$, $t(4)=-4.96, p=.002$, significant decline from $\mathrm{T} 1$ to $\mathrm{T} 4, t(9)=-8.54, p<.001$, significant decline from $\mathrm{T} 2$ to $\mathrm{T} 3, t(4)=-6.59, p=.003$, significant decline between $\mathrm{T} 2$ and $\mathrm{T} 4, t(8)$ 
$=-10.18, p<.001$, significant increase between $\mathrm{T} 3$ and $\mathrm{T} 4, t(4)=4.94, p=.008$. The PRE group increased between $T 1$ and $T 2$ but it was not significant change (See Fig. 4.12) with the alpha values $(p=.0125)$ adjusted using the Bonferroni correction to control for $\alpha$ inflation. The CON group appeared to decrease between $\mathrm{T} 1$ and $\mathrm{T} 2$, as seen in figure 4.12 , but it was not a significant change.

Figure 4.12 Descend stairs - initial data, 4 data points means

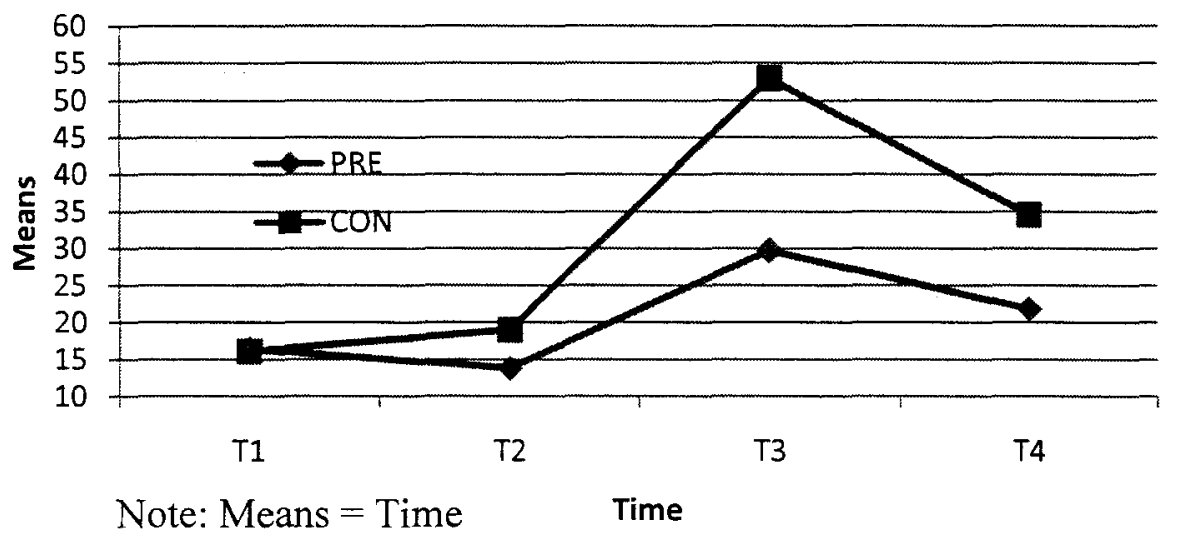


Table 4.22

Pairwise comparison of descending stair time, initial data

\begin{tabular}{ccccccc}
\hline & & & & & \multicolumn{3}{c}{$\begin{array}{c}9 \% \text { Confidence } \\
\text { Interval for }\end{array}$} \\
& & & Mean & Standard & p-value & \multicolumn{2}{c}{$\begin{array}{c}\text { Difference } \\
\text { Lower }\end{array}$} & $\begin{array}{c}\text { Upper } \\
\text { Bound }\end{array}$ \\
\hline 1 & 2 & -.18 & 1.88 & .999 & -6.53 & 6.16 \\
& 3 & -25.07 & 4.24 & $<.001$ & -39.34 & -10.80 \\
2 & 4 & -11.85 & 2.52 & .007 & -20.34 & -3.36 \\
& 1 & .18 & 1.88 & .999 & -6.16 & 6.53 \\
& 3 & -24.88 & 3.16 & $<.001$ & -35.52 & -14.24 \\
& 4 & -11.66 & 1.70 & $<.001$ & -17.38 & -5.93 \\
& 1 & 25.07 & 4.24 & $<.001$ & 10.80 & 39.34 \\
& 2 & 24.88 & 3.16 & $<.001$ & 14.24 & 35.52 \\
& 4 & 13.22 & 2.06 & $<.001$ & 6.27 & 20.17 \\
\hline
\end{tabular}

Note: Adjustment for multiple comparisons: Bonferroni. 
Table 4.23

Descend stairs group statistics Independent Samples T Test

\begin{tabular}{lcccccc}
\hline \multicolumn{1}{c}{ Variable } & Group & $\mathrm{N}$ & Mean (SD) & $\mathrm{df}$ & $\mathrm{t}$ & $\mathrm{p}$ value \\
\hline Descend stairs T1 & CON & 18 & $22.24(10.89)$ & 35 & 1.20 & .237 \\
& PRE & 19 & $18.55(7.56)$ & & & \\
Descend stairs T2 & CON & 15 & $23.89(11.76)$ & 30 & 2.37 & .024 \\
& PRE & 17 & $15.63(7.76)$ & & & \\
Descend stairs T3 & CON & 5 & $52.95(15.73)$ & 9 & 3.21 & .011 \\
& PRE & 6 & $29.77(7.61)$ & & & \\
Descend stairs T4 & CON & 10 & $34.95(6.70)$ & 21 & 1.42 & .169 \\
& PRE & 13 & $29.09(11.58)$ & & & \\
\hline
\end{tabular}

Note: all alpha values $(\alpha)$ were adjusted using Bonferroni correction to control for $\alpha$ Inflation. New $\alpha$ inflation Bonferroni correction .05/4 $=0.0125$

*Indicates significant difference at $p<.0125$

\section{Table 4. 24}

PRE Group descend stairs Paired Samples T Test

\begin{tabular}{cccccc}
\hline Times Compared & $\mathrm{N}$ & Mean (SD) & $\mathrm{df}$ & $\mathrm{t}$ & $\mathrm{p}$ value \\
\hline Descend T1 vs Descend T2 & 17 & $18.07(7.51)$ & 16 & 1.94 & .070 \\
& 17 & $15.62(7.76)$ & & & \\
Descend T1 vs Descend T3 & 6 & $16.44(6.38)$ & 5 & -2.83 & .037 \\
& 6 & $29.77(7.61)$ & & & \\
Descend T1 vs Descend T4 & 13 & $16.54(7.36)$ & 12 & -4.56 & .001 \\
& 13 & $29.09(11.58)$ & & & \\
Descend T2 vs Descend T3 & 6 & $13.86(8.07)$ & 5 & -4.09 & .009 \\
& 6 & $29.77(7.61)$ & & & \\
Descend T3 vs Descend T4 & 6 & $29.77(7.61)$ & 5 & 3.69 & .014 \\
& 6 & $21.82(5.46)$ & & & \\
Descend T2 vs Descend T4 & 13 & $14.80(7.92)$ & 12 & -6.11 & $<.001$ \\
& 13 & $29.09(11.58)$ & & & \\
\hline
\end{tabular}

Note: $*$ Indicates significant difference at $\mathrm{p}<.0125$ 
Table 4.25 CON Group descend stairs Paired Samples T Test

\begin{tabular}{cccccc}
\hline Times Compared & N & Mean (SD) & df & $\mathrm{t}$ & p value \\
\hline Descend T1 vs Descend T2 & 15 & $23.01(11.80)$ & 14 & -.630 & .539 \\
& 15 & $23.89(11.76)$ & & & \\
Descend T vs Descend T3 & 5 & $16.14(5.74)$ & 4 & -4.96 & .008 \\
& 5 & $52.95(13.73)$ & & & \\
Descend T1 vs Descend T4 & 10 & $15.98(5.10)$ & 9 & -8.54 & $<.001$ \\
Descend T2 vs Descend T3 & 10 & $34.95(6.70)$ & & & \\
& 5 & $19.09(8.49$ & 4 & -6.59 & .003 \\
Descend T3 vs Descend T4 & 5 & $52.95(15.73)$ & & & \\
& 5 & $32.95(15.73)$ & 4 & 4.94 & .008 \\
Descend T vs Descend T4 & 9 & $17.28(6.96)$ & 8 & -10.18 & $<.001$ \\
& 9 & $35.13(7.08)$ & & & \\
\hline
\end{tabular}

Note: *Indicates significant difference at $\mathrm{p}<.0125$

\section{Descending stair excluding T3}

The secondary analysis of descending stair test excluding T3 indicted a similar pattern (See table 4.26) as the initial analysis of the four data collecting points again there was a significant effect of time on descending stair, Wilks' Lamda $=0.163, F(2,19)=$ $48.74, p<.001$. There was no significant interaction effect on descending stairs, Wilks' Lamda $=.829, F(2,19)=1.96, p=.168$. The observed power for this test was 1.00 for time and .355 for time $\mathrm{x}$ group. While time was significant, between group comparison was not significant, $F(1,20)=.659, p=.426$.

The PRE group increased between T1 and T2, (See Fig. 4.13) it was a non significant change with the alpha values $(p=.0125)$ adjusted using the Bonferroni correction to control for $\alpha$ inflation. The CON group appeared to declined between T1 and $\mathrm{T} 2$, as seen in figure 4.13 , it was not a significant change. Both groups significantly declined changed between $\mathrm{T} 2$ and $\mathrm{T} 4$. 
Figure 4.13 Descend stairs - secondary data, 3 data points means

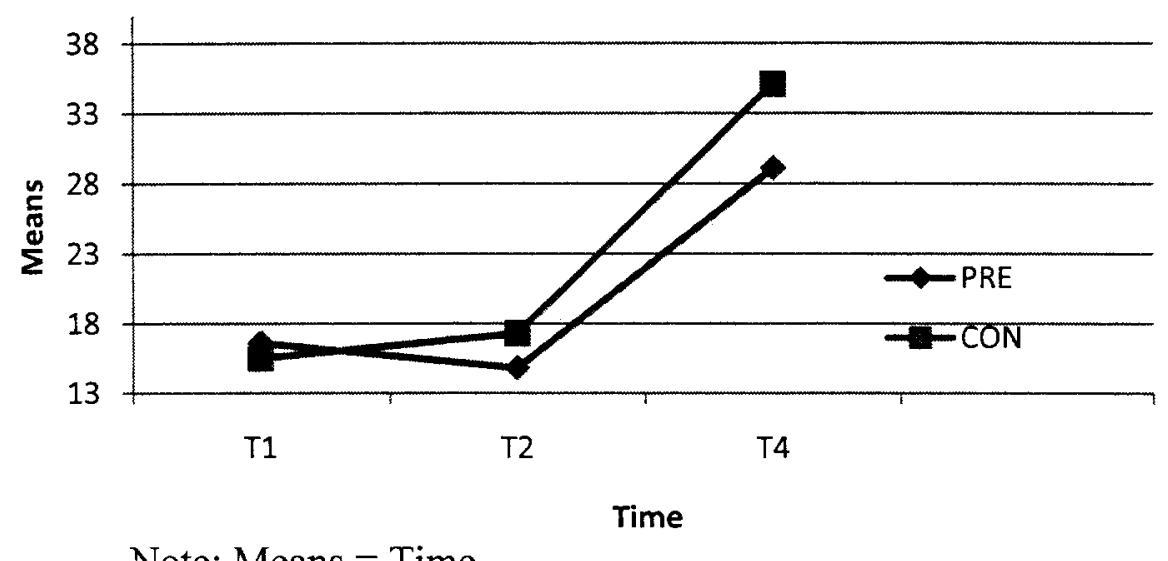

Note: Means $=$ Time

Table 4.26

Pairwise comparison of descending stair time, secondary data

\begin{tabular}{ccccccc}
\hline Time & & & & & \multicolumn{2}{c}{$\begin{array}{c}95 \% \text { Confidence } \\
\text { Interval for } \\
\text { Difference }\end{array}$} \\
& & $\begin{array}{c}\text { Mean } \\
\text { difference }\end{array}$ & $\begin{array}{c}\text { Standard } \\
\text { Error }\end{array}$ & p-value & \multicolumn{2}{c}{$\begin{array}{c}\text { Lower } \\
\text { Upper }\end{array}$} \\
\hline 1 & 2 & -.03 & 1.01 & .999 & -2.68 & 2.62 \\
& 4 & -16.09 & 1.92 & $<.001$ & -21.13 & -11.06 \\
2 & 1 & .03 & 1.01 & .999 & -2.62 & 2.68 \\
& 4 & -16.06 & 1.58 & $<.001$ & -20.21 & -11.91 \\
\hline
\end{tabular}

Note: a Adjustment for multiple comparisons: Bonferroni. 


\section{Hypothesis Four: General health-related quality of life (HRQL)}

The SF-36 was utilized to address the fourth hypotheses to test for differences in QOL between the two study groups (PRE and CON) to determine if the knee OA (KOA) patients who completed an eight-week prehabilitation program prior to TKA surgery would report higher levels of general health-related quality of life three months following their TKA surgery compared to OA patients who do not complete a prehabilitation program prior to their TKA surgery. Data was analyzed using the QualityMetric Health Outcomes ${ }^{\mathrm{TM}}$ scoring algorithms, one sample and independent samples t-tests.

General health-related quality of life (HRQL) was measured using the SF-36 questionnaire (Medical Outcomes Study 36-Item Short-Form Health Survey) to evaluate the intervention treatment on the participants of this study. Twenty participants reached the three month follow up after their TKA surgery. All twenty have returned surveys. Two of the returned surveys were not completed correctly resulting in 18 complete surveys being returned $(\mathrm{n}=18,11 \mathrm{PRE}, 7 \mathrm{CON})$. The SF-36 was self-administered and completed three months postoperatively by the patients.

The health status concepts measured by the SF-36 included physical functioning $(\mathrm{PF})$, role limitations due to physical health (RP), bodily pain (BP), general health perceptions (GH), vitality (VT), social functioning (SF), role limitations owing to emotional problems (RE), and mental health $(\mathrm{MH})$.

The eight concepts of the SF-36 are combined into two summary scales, the physical component scale (PCS) and the mental component scale (MCS).

The PCS and MCS scores (higher scores = better) were calculated and presented as 
summary measure scores, norm-based scoring (each scale is scored to have the same average and standard deviation), by the QualityMetric scoring software. The PCS and MCS group mean scores were compared to mean scores of the 1998 General U.S population norms for OA (Ware \& Kosinski, 2001). The mean score norms for the General U.S population with OA is $\mathrm{PCS}=\underline{38.97}$ (11.24) and $\mathrm{MCS}=\underline{46.35}$ (12.27) (Ware and Kosinki, 2001). The summary report scores for the TKA patients in this study three months post surgery was $40.22(9.42)$ for PCS and MCS $55.39(9.12)$ as seen in figures 4.14 and 4.15. Both of these scores were found to be higher than the scores for individuals with OA in the general U.S population.

When the two study groups (PRE and CON) were analyzed separately the scores were found to be higher for the PRE group, PCS 43.33 (6.92) (See figure 4.16) and MCS 55.99 (6.15) (See figure 4.17), when compared to the U.S general population with OA. The CON group was found to be lower in their PCS score of 38.07 (9.31) (See figure 4.16) when compared to the U.S general population with OA but they had higher MSC scores 53.87 (14.31) when compared to the general population with OA 46.35 MCS (See figure 4.17). 
Figure 4.14 PCS mean score comparisons of Population Norms vs TKA

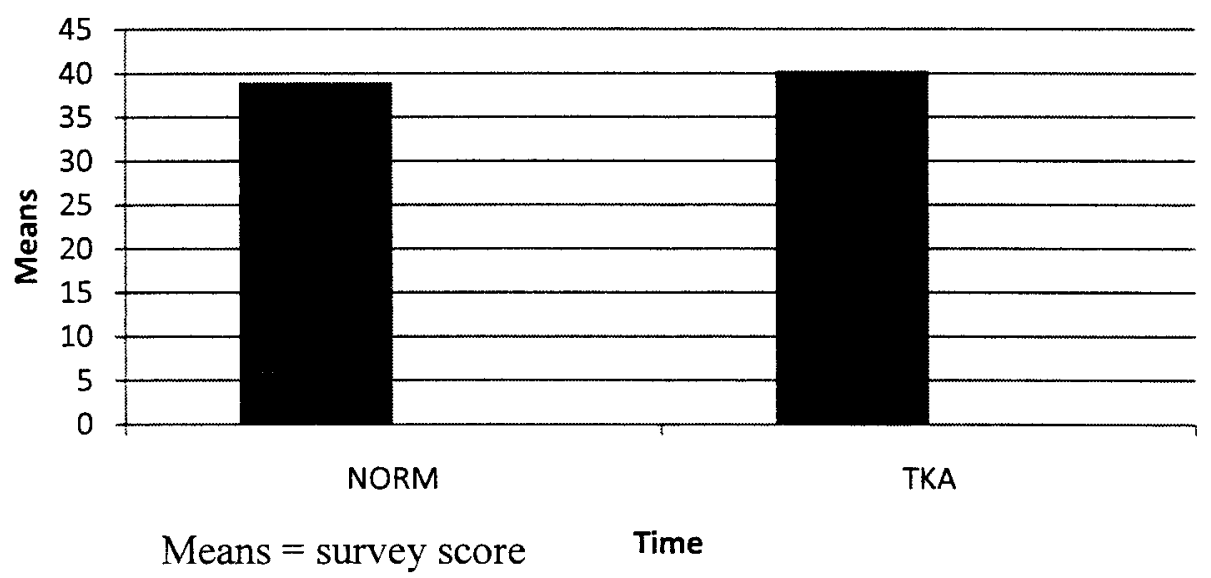

Note: Higher scores indicate better physical functioning as indicated by the PCS

Figure 4.15 MCS comparison of TKA participants vs Norm 3 months post surgery

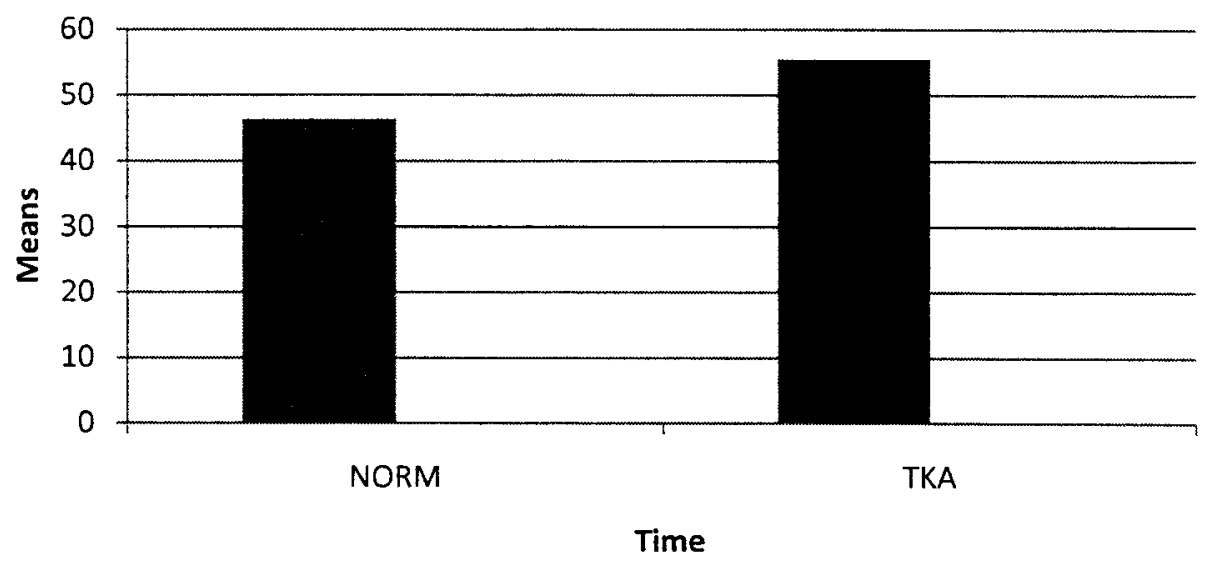

Means $=$ survey score

Note: Higher scores indicate better mental health as indicated by the MCS 
Figure 4.16 PCS mean score comparisons of Population Norms vs TKA and CON

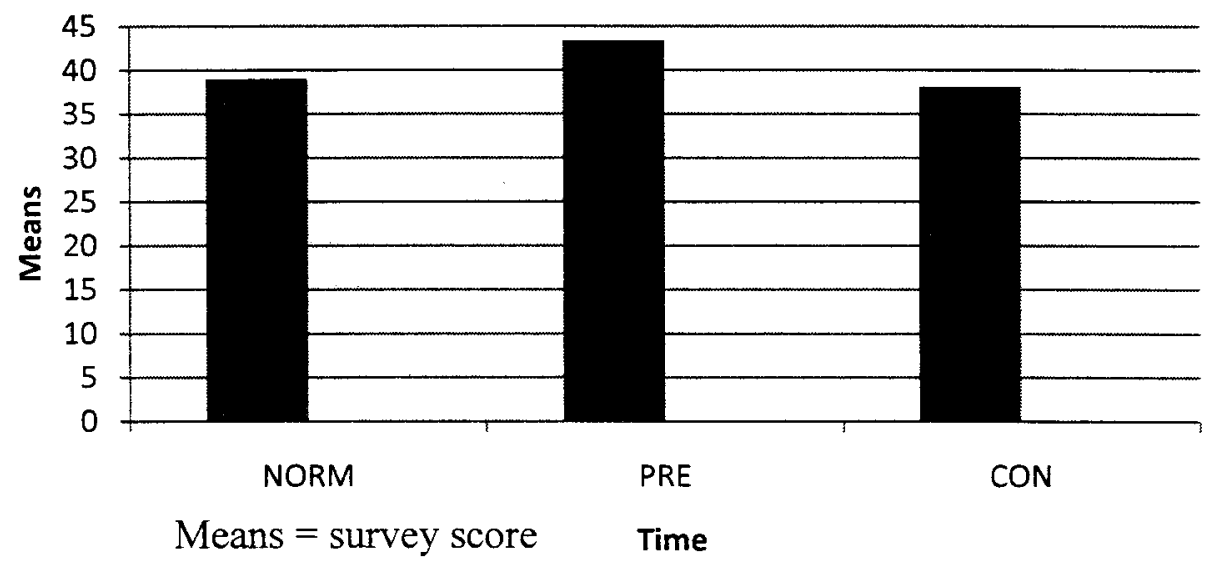

Note: Higher scores indicate better physical functioning as indicated by the PCS

Figure 4.17 MCS mean score comparisons of Norms vs TKA and CON

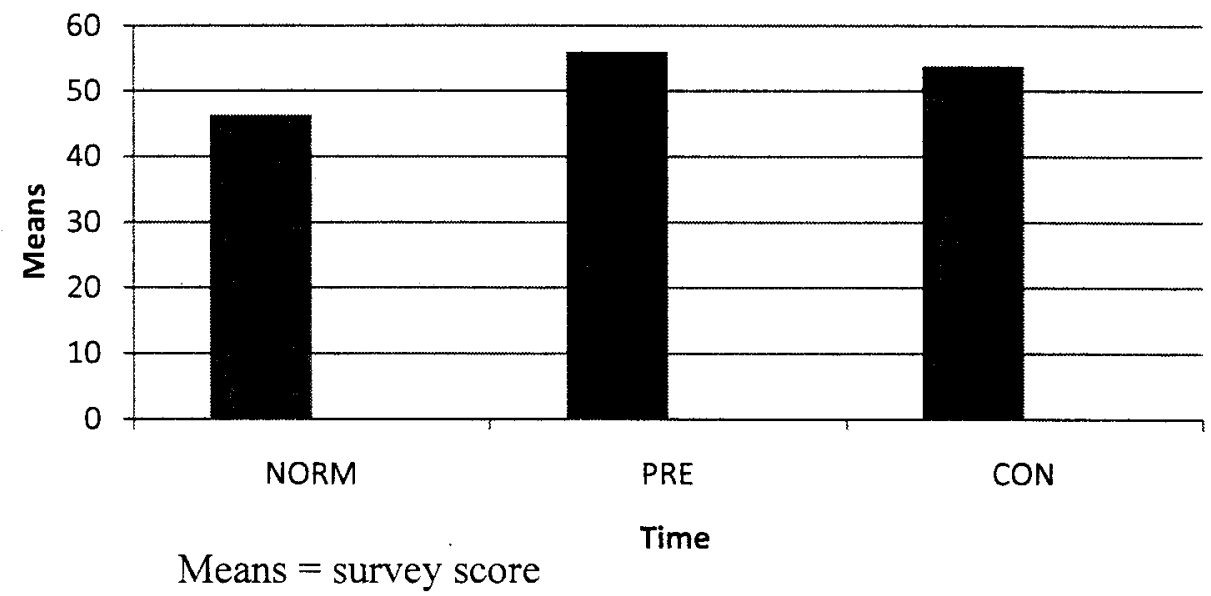

Note: Higher scores indicate better mental health as indicated by the MCS 
One sample t-tests were calculated to determine if the PRE group or CON group differed from the population norms found in the SF - 36 Physical and Mental Health Summary Manual. As seen in table 4.29 the PRE group was significantly $(p<.05)$ different from the population norms in all eight health status concepts while the CON group was only significantly different in the $\mathrm{RE}(\mathrm{p}<.020)$ and $\mathrm{MH}(\mathrm{p}<.004)$ concepts. Since we ran multiple $t$ tests we used the Bonferroni correction to set alpha at $.05 / 20$ for each $t$ test in order to correct for type I errors. The new alpha $(p=.0025)$ for each test. The Bonferroni correction values can be seen in table 4.27. The PRE group was significantly $(\mathrm{p}<.0025)$ different from the population norms in seven health status concepts, but not found to be significantly different in the bodily pain (BP) component. The CON group was only significantly different in the RE $(p<.0025)$ concept. The PRE group was significantly $(\mathrm{p}<.05)$ different from the population norms in MCS and not significant in the PCS component. The CON group was not significantly $(p<.0025)$ different from the population norms in MCS or PCS components. The CON group was also not significantly different in the PCS or MCS at $\mathrm{p}<.05$.

Next independent t-tests were calculated to determine if the PRE group differed from the CON group on any of the SF-36 measures. These data findings are displayed in table 4.9 showing the comparisons of prehabilitation and control groups three months post TKA. These data were analyzed with $\mathrm{p}<.05$, being the minimal level of statistical significance.

As table 4.28 indicates the groups significantly differed on PF only $(t=2.3, p=.04)$ with the PRE group (mean $\mathrm{X}=66.4$ ) scoring significantly higher than the CONs (mean $\mathrm{X}=$ 39.3). 


\section{Table 4.27}

Comparison of PRE and CON group means to population norm means 3 months post TKA using One Sample T-TEST (N= PRE 11, CON 7)

\begin{tabular}{|c|c|c|c|c|c|}
\hline Variable & $\begin{array}{l}\text { Population } \\
\text { Mean }\end{array}$ & Group & $\begin{array}{c}\text { Sample } \\
\text { mean }\end{array}$ & $\mathrm{t}$ & $\begin{array}{c}\mathrm{p} \text { value } \\
(\mathrm{p}<.0025)\end{array}$ \\
\hline $\mathrm{PF}$ & $39.14(11.82)$ & $\begin{array}{l}\text { CON } \\
\text { PRE }\end{array}$ & $\begin{array}{l}39.3(30.2) \\
66.4(20.7)\end{array}$ & $\begin{array}{l}.013 \\
4.35\end{array}$ & $\begin{array}{c}.990 \\
<.001^{*}\end{array}$ \\
\hline $\mathrm{RP}$ & $41.36(11.87)$ & $\begin{array}{l}\text { CON } \\
\text { PRE }\end{array}$ & $\begin{array}{l}64.3(28.3) \\
75.6(19.1)\end{array}$ & $\begin{array}{l}2.14 \\
5.95\end{array}$ & $\begin{array}{c}.076 \\
<.001^{*}\end{array}$ \\
\hline $\mathrm{BP}$ & $39.67(9.91)$ & $\begin{array}{l}\text { CON } \\
\text { PRE }\end{array}$ & $\begin{array}{l}47.5(22.8) \\
59.9(19.1)\end{array}$ & $\begin{array}{l}.918 \\
3.50\end{array}$ & $\begin{array}{l}.394 \\
.006\end{array}$ \\
\hline GH & $40.99(11.51)$ & $\begin{array}{l}\text { CON } \\
\text { PRE }\end{array}$ & $\begin{array}{l}62.4(23.5) \\
73.2(21.2)\end{array}$ & $\begin{array}{l}2.42 \\
5.03\end{array}$ & $\begin{array}{c}.052 \\
<.001 *\end{array}$ \\
\hline VT & $44.09(10.560$ & $\begin{array}{l}\text { CON } \\
\text { PRE }\end{array}$ & $\begin{array}{l}59.8(31.0) \\
60.2(12.9)\end{array}$ & $\begin{array}{l}1.34 \\
4.15\end{array}$ & $\begin{array}{c}.228 \\
<.002^{*}\end{array}$ \\
\hline SF & $42.78(12.75)$ & $\begin{array}{l}\text { CON } \\
\text { PRE }\end{array}$ & $\begin{array}{l}66.1(37.3) \\
84.1(17.7)\end{array}$ & $\begin{array}{l}1.65 \\
7.71\end{array}$ & $\begin{array}{l}.150 \\
<.001^{*}\end{array}$ \\
\hline $\mathrm{RE}$ & $43.50(12.85)$ & $\begin{array}{l}\text { CON } \\
\text { PRE }\end{array}$ & $\begin{array}{l}79.8(30.4) \\
95.4(10.7)\end{array}$ & $\begin{array}{c}3.16 \\
15.99\end{array}$ & $\begin{array}{r}.020^{*} \\
<.001^{*}\end{array}$ \\
\hline MH & $45.46(11.68)$ & $\begin{array}{l}\text { CON } \\
\text { PRE }\end{array}$ & $\begin{array}{l}81.4(20.8) \\
81.4(13.1)\end{array}$ & $\begin{array}{l}4.58 \\
9.12\end{array}$ & $\begin{array}{c}.004 \\
<.001^{*}\end{array}$ \\
\hline PCS & $38.97(11.24)$ & $\begin{array}{l}\text { CON } \\
\text { PRE }\end{array}$ & $\begin{array}{c}35.4(11.0) \\
43.3(7.2)\end{array}$ & $\begin{array}{c}-.854 \\
1.99\end{array}$ & $\begin{array}{l}.426 \\
.074\end{array}$ \\
\hline MCS & $46.35(12.27)$ & $\begin{array}{l}\text { CON } \\
\text { PRE }\end{array}$ & $\begin{array}{c}54.4(13.1) \\
56.0(6.0)\end{array}$ & $\begin{array}{l}1.63 \\
5.29\end{array}$ & $\begin{array}{c}.155 \\
<.001 *\end{array}$ \\
\hline
\end{tabular}

Note * indicates significant difference at $\mathrm{p}<.0025$ (Bonferroni correction alpha at $(.05 / 20)$, two-tailed 
Table 4.28 Comparison of PRE and CON 3 month post TKA using Independent Sample T-Test

\begin{tabular}{|c|c|c|c|c|}
\hline Variable & Group & Mean (SD) & $\mathrm{t}$ & $\mathrm{P}$ \\
\hline $\begin{array}{l}\text { Physical Functioning } \\
\qquad(\mathrm{PF})\end{array}$ & $\begin{array}{l}\text { Control } \\
\text { Prehab }\end{array}$ & $\begin{array}{l}39.3(30.2) \\
66.4(20.7)\end{array}$ & 2.3 & $.04^{*}$ \\
\hline Role-Physical (RP) & $\begin{array}{l}\text { Control } \\
\text { Prehab }\end{array}$ & $\begin{array}{l}64.3(28.3) \\
75.6(19.0)\end{array}$ & 1.0 & .33 \\
\hline Bodily Pain (BP) & $\begin{array}{l}\text { Control } \\
\text { Prehab }\end{array}$ & $\begin{array}{l}47.6(22.8) \\
59.9(19.2)\end{array}$ & 1.2 & .23 \\
\hline General Health $(\mathrm{GH})$ & $\begin{array}{l}\text { Control } \\
\text { Prehab }\end{array}$ & $\begin{array}{l}62.4(23.5) \\
73.2(21.2)\end{array}$ & 1.0 & .33 \\
\hline Vitality (VT) & $\begin{array}{l}\text { Control } \\
\text { Prehab }\end{array}$ & $\begin{array}{l}59.8(31.0) \\
60.2(12.9)\end{array}$ & .04 & .97 \\
\hline Social Functioning (SF) & $\begin{array}{l}\text { Control } \\
\text { Prehab }\end{array}$ & $\begin{array}{l}66.1(37.3) \\
84.1(17.8)\end{array}$ & 1.4 & .18 \\
\hline Role-Emotional (RE) & $\begin{array}{l}\text { Control } \\
\text { Prehab }\end{array}$ & $\begin{array}{l}79.8(30.4) \\
95.5(10.8)\end{array}$ & 1.6 & .13 \\
\hline Mental Health (MH) & $\begin{array}{l}\text { Control } \\
\text { Prehab }\end{array}$ & $\begin{array}{l}81.4(20.8) \\
81.4(13.0)\end{array}$ & .01 & .99 \\
\hline PCS & $\begin{array}{l}\text { Control } \\
\text { Prehab }\end{array}$ & $\begin{array}{l}35.4(11.0) \\
43.3(7.2)\end{array}$ & -1.8 & .08 \\
\hline MCS & $\begin{array}{l}\text { Control } \\
\text { Prehab }\end{array}$ & $\begin{array}{l}54.4(13.1) \\
56.0(6.0)\end{array}$ & -.35 & .73 \\
\hline
\end{tabular}

Note $*$ indicates significant difference at $\mathrm{P}<.05$, two-tailed 


\section{CHAPTER V}

\section{Conclusions}

This conclusion begins by presenting a review of the four previous chapters of this study. First the review will consist of introducing information about the background of the problem and current literature, theory, clinical and social information about the problem and how the research was directed. Then the chapter will examine the research hypotheses and discuss how the analysis of the data supported or did not support each hypothesis. Modifications in current practice and theory based on the findings of the study will be presented. Finally the chapter will discuss limitations of the study and explore future study designs to address these limitations.

\section{Introduction and overview}

Osteoarthritis $(\mathrm{OA})$ is the clinical condition of joint pain and dysfunction caused by joint degeneration, and loss of articular cartilage. This disease is one of most common chronic health problems affecting over 27 million Americans. The clinical classification of $\mathrm{OA}$ includes symptoms of persistent joint pain and stiffness along with joint degeneration. Once a patient develops $\mathrm{OA}$, they suffer from the disease for the remainder of their lives, and the severity of pain and disability generally increases.

Progression of these symptoms often leads to decreased mobility, deconditioning, reduced functional ability, and increased knee pain, all of which contribute to declines in the patient's quality of life.

Lower extremity OA has been shown to be a risk factor for disability. Patients 
with lower extremity OA may have limitations that impair their ability to perform activities of daily living (ADL), such as walking, bathing, dressing, use of toilet, and performing normal household chores.

Data from the Centers for Disease Control and Prevention (CDC) show that OA is expected to impact the lives of an estimated 67 million adults in the United States by the year 2030. Osteoarthritis accounts for 55\% of all arthritis-related hospitalizations; representing over 409,000 hospitalizations. Knee and hip replacement procedures represent $35 \%$ of all total arthritis-related procedures during hospitalization. OA disables about $10 \%$ of individuals who are over the age of 60 , lowering the quality of life of more than 20 million Americans, and adds a cost of over $\$ 60$ billion per year to the U. S. economy. These estimates of economic impact do not include the pain and suffering, adverse psychosocial effects, lost activities of daily living, and decreased ability to participate in regular exercise that could improve general health and lower health care costs. 


\section{Background of the problem}

\section{The general public is facing a significant public health problem as a result of}

OA. Better health promotion and management interventions from public and private health agencies, along with disease prevention measures, have the potential to reduce the prevalence of disability among OA patients.

Since the most effective treatment of knee OA is an expensive procedure, Total Knee Arthroplasty (TKA), helping patients postpone the surgery and/or maximize the outcomes of surgery are necessary. Decreasing the burden of OA will require finding methods of preventing and slowing the joint degeneration OA causes.

Exercise has been shown to be beneficial for older adults with OA because it helps to decrease pain and aid in maintaining joint function. Therapeutic resistance exercise for increasing muscle strength in patients with knee $\mathrm{OA}$ is recommended. Finding ways to increase and promote exercise participation in this population will need to include exercise intervention strategies, along with pain management, adaptive strategies and behavioral skills.

One way to promote exercise behavior is to enhance exercise self-efficacy, or perceived beliefs in control over one's ability to exercise (Bandura, 1997). To improve exercise activity in older adults, it is useful to consider self-efficacy expectations (desired results) to exercise, along with outcome expectations (expected benefits and costs of performing a behavior), because these beliefs influence motivation to exercise and actual exercise activity (Resnick \& Jenkins, 2000). 
Physical activities that include planned exercise offer great opportunities for individuals to extend their years of independence and reduce their functional limitations. Regular participation in physical activities is one of the best ways for older adults, including those with disabilities, to help prevent chronic disease, promote independence, and increase quality of life in old age. Exercise by the OA patient has been shown to improve pain, function and increase self-efficacy to exercise.

Exercise is considered by many to be a cornerstone of rehabilitation following TKA; however, there has not been much attention placed on the role of exercise prior to an individual undergoing TKA surgery. Enhancing knee strength preoperatively may result in reduction of activity limitations, less work disability, improved quality of life, and lower health care costs. Data on the direct effects of prehabilitation TKA exercise interventions are scarce, although a couple of studies by us (Brown, et al., 2010; Topp, et al, 2009), do support the claim that prehabilitation interventions improve functional abilities.

Recent evidence suggests decision-making theories (like the social cognitive theory SCT) may be applicable to physical activities. People are more likely to start and maintain physical activity if they feel confident about their ability to be successful and if they are given opportunities to actively participate in physical activity, which leads to enhancing their self-efficacy.

This researcher believes that by introducing the OA patient to a prehabilitation exercise program will lead him or her to a greater self-efficacy with expected positive outcomes. This prehabilitation will lead to a greater SEE and prevent the development of a detrimental health habit such as physical inactivity. 


\section{$\underline{\text { Study design }}$}

The individuals in the intervention group of this study were introduced to an exercise program that incorporated the concepts of the social cognitive theory (SCT), discussed in detail in chapters two and three. Under the guidence of the professional trainers, during the eight weeks of prehabilitation, the concepts of the SCT were be passed on to the study participants. Those SCT concepts (covered in chapter two) included the appropriate skills and adequate incentives, knowledge and skills to perform a given behavior, and confidence in one's ability to take action to overcome barriers needed for successful outcomes. The SCT guided the eight week process of prehabilitation exercise interventions prior to TKA to change the self-efficacy of the patient post - TKA, therefore affecting his or her exercise behavior levels.

Initial analysis of the study hypotheses one, two and three was guided by the analysis plan proposed in chapter three and included repeated measures ANOVA (RMANOVA) examining the effect of group (PRE vs. CON) and time on the dependent variables over the four data collection points (Baseline T1, T2, T3 and T4). Significant main or interaction effects were explored further by calculating post hoc comparisons.

Since a substantial number of subjects were unavailable for.T3 testing which contributed to declines in statistical power in the initial analysis a secondary analysis was completed using the same statistical model to evaluate study hypotheses one, two and three but without the T3 data collection point. Finally, hypothesis four was evaluated by univariate comparisons between the PRE and CON groups at three months following their TKA on measures of general health-related quality of life. 


\section{Discussion of the research hypotheses}

The purpose of this study was to assess whether knee OA patients who engage in guided exercise prior to TKA have higher self-efficacy to exercise (SEE), higher outcome expectations for exercise (OEE) and higher post surgical functional ability than those who do not. Persons with higher SEE and OEE were hypothesized to do better during post surgery rehab and therefore recover more fully

This study used two different patient instrumentation measurement tools of selfefficacy and outcome expectation (discussed in chapter three) to address hypotheses one and two of this study. These tools consist of survey questions which examine many variables such as attitude, motivation, and personality.

The Self-Efficacy for Exercise (SEE) scale is a revision of McAuley's (1990; unpublished) self-efficacy barriers to exercise measure. Originally this was a 13-item scale that focused on self-efficacy expectations related to one's ability to continue exercising in the face of barriers to exercise. The Outcome Expectations for Exercise (OEE) scale (Resnick \& Jenkins, 2000), a nine - item measure, that asks individuals to identify expected positive outcomes of physical activity. 


\section{Hypothesis one}

Hypothesis one stated that knee OA patients who complete an eight-week prehabilitation program prior to TKA surgery will demonstrate an increase in scores as measured by the Self-Efficacy to Exercise (SEE) scale (higher scores are better) prior to surgery and at seven and 14 days post surgery compared to OA patients who do not complete a prehabilitation program prior to their TKA surgery. The research data indicated no significant effect of the time, group or group $\mathrm{x}$ time on SEE. This finding does not support hypothesis one. However it is interesting to observe in Figure 4.1 that the SEE, of the PRE appeared to be consistently maintained over the study, and actually trended upward after their TKA at $\mathrm{T} 3$ and $\mathrm{T} 4$, but did not increase to a significant difference. I did not observe this trend in the CON group; the SEE of the CON demonstrated a downward trend before and after their TKA and only trended upward at T3 to T4 after starting into their rehabilitation. These trends observed among the PRE and CON groups are similar to previous studies that have shown an increase in self-efficacy to exercise (SEE) in patients who participated in exercise (Ettinger, et al., 1997; Rooks, et al., 2006b). Other researchers have found that exercise interventions with knee OA patients after TKA resulted in improvements in these measures of SEE (T. Harnirattisai \& A. J. Johnson, 2005). Even though SEE scores of the PRE group did not increase significantly they were maintained and trended upward and returned higher than their original baseline score while the CON groups' SEE scores decreased over the course of the study and fell below their baseline scores at the end of the study. 
I believe this finding supports the theoretical suppositions outlined in the SCT. This maintenance and rise over time of the PRE group's SEE scores and the downward trend prior to and following TKA of the CON group's SEE scores, even though they were not found to be significant, appears to be a cognitive response of the PRE group completing eight weeks of prehabilitation exercise and the $\mathrm{CON}$ group not experiencing the intervention. Through the exercise intervention, the PRE participants seemed to develop a cognitive response and began believing they could perform the exercises. This exercise experience prior to TKA came to be of cognitive value to the PRE group as they carried this previous experience with them after they underwent TKA.

The PRE group's self-efficacy to exercise may have increased by setting incremental goals and reaching them and through feedback from self- monitoring and record keeping. These findings are consistent with the framework of the social cognitive theory (SCT) in that the PRE group having "past performance accomplishments" saw the progress they had made during the eight weeks of prehabilitation and this contributed to their increases in self-efficacy. Persons in the CON group, with poor exercise habits, appeared to experience some declines in self-efficacy between T1 and T2, T2 and T3 that may have contributed to lower SEE scores. I know that self-efficacy influences outcome expectations (Resnick, et al., 2001) and this may help explain why when looking at the Outcome Expectations for Exercise (OEE) scores of the CON group the data showed they had a significant difference in their outcome expectations as seen in the next section of the discussion. 


\section{Hypothesis two}

Hypothesis two stated that knee OA (KOA) patients who complete an eight-week prehabilitation program prior to TKA surgery will demonstrate an improvement in scores as measured by the Outcome Expectation for Exercise (OEE) scale (lower numbers indicated higher outcome expectations) prior to surgery and at seven and 14 days post surgery compared to OA patients who do not complete a prehabilitation program prior to their TKA surgery. Data analysis indicated a significant time effect on OEE. The PRE and $\mathrm{CON}$ groups changed in their outcome expectations for exercise between T2 and T4 (See fig.4.3). The CON group declined between $\mathrm{T} 1$ and $\mathrm{T} 2$ but improved at $\mathrm{T} 4$ as the PRE group maintained OEE scores at T2. The PRE group did not significantly change but steadily maintained their scores at $\mathrm{T} 2$ and improved their OEE scores from $\mathrm{T} 1$ to $\mathrm{T} 4$ over the course of the study. The PRE group had higher OEE scores than the CON group at T4, but the scores were not significantly different. Data presented in figure 4.3 showed that the OEE, of the PRE was maintained or trended upward while the OEE of the CON demonstrated lower scores than the PRE at T2 and T4. These findings appear to support hypothesis two.

Even though OEE scores of the PRE group did not increase significantly they trended in the hypothesized direction of higher outcome expectations at $\mathrm{T} 2$, before their TKA, and remained higher than their baseline values after their TKA at T4. The CON groups' OEE scores decreased prior to their TKA and improved only slightly after their TKA. This increase of OEE at T4 for the CON group may be attributable to their participation in rehabilitation following their TKA which positively affected their expectations of the outcomes of their participation in exercise. 
Outcome expectations, as described by the SCT, are beliefs that carrying out a specific behavior will lead to a desired outcome. This outcome expectation might be what the PRE group perceives to be the benefits of exercise (e.g., improving muscle strength, improved function, or feeling good in general). Through the exercise intervention the PRE participants came to realize the value of the consequences of performing exercise and changing their behavior choices. As they realized and saw results (e.g., better functioning and improved strength) due to their exercise performance they began to change expectations of physical outcomes due to changing from a sedentary lifestyle to becoming an exerciser by being introduced to an exercise intervention.

This interpretation of the findings supports the social cognitive theory (SCT) with the PRE group having "past performance accomplishments, and a mastery of skills". By seeing the progress they had made during the eight weeks of prehabilitation, by previously performing the exercises and experiencing improved function and gains in strength, the PRE group steadily improved their OEE scores over the course of the study. Persons in the CON group with poor exercise habits, with no past exercise experience, remained sedentary and may have believed they could not expect a better outcome post TKA. Because the CON group had no previous exercise experience to show them how exercise could improve their function and strength I speculate that they developed lower OEE scores. 


\section{Hypothesis three}

Hypothesis three stated that knee $\mathrm{OA}(\mathrm{KOA})$ patients who complete an eight-week

prehabilitation program prior to TKA surgery would demonstrate an improved functional ability (sit to stand, walking time, stair time) at seven and 14 days post surgery compared to OA patients who do not complete a prehabilitation program prior to their TKA surgery. Measures of functional ability included six - minute walk distance, timed get up and go test (TUG), sit-to-stand repetitions (chair raises) in 30 seconds and the time required to ascend and descend a flight of stairs.

The analysis indicated a significant time effect on the six minute walk distance. The CON group significantly declined from their baseline level when compared to T3 and T4. Analysis indicated that both groups significantly declined between $\mathrm{T} 1$ and $\mathrm{T} 3, \mathrm{~T} 2$ and $\mathrm{T} 3$, and T3 and T4. Independent samples T tests looking at between groups showed no significant difference. The PRE group did not significantly change their walking distance over the six minute walk during the course of the study. Even though the PRE six minute walking distance did not significantly increase over time the PRE group did remain consistently higher, although nonsignificantly higher, than the $\mathrm{CON}$ walking distance at (T2, T3, and T4). These findings appear to support hypothesis three. I speculate that the PRE group benefited from the exercise intervention, through (better functioning and improved strength), and saw an increase in the six minute walking distance at $\mathrm{T} 2$. This small increase at T2 may not big large enough to show a significant effect but I speculate it was enough to keep the PRE group from significantly changing their distance over the six minute walk at $\mathrm{T} 3$ and $\mathrm{T} 4$ post TKA. By previously performing the exercises in the intervention the PRE group experienced improved function at $\mathrm{T} 2, \mathrm{~T} 3$, and $\mathrm{T} 4$, they 
steadily and consistently maintained better walking times over the CON group over the course of the study. Persons in the CON group with poor exercise habits, with no past exercise, significantly declined.

The analysis indicated a significant time and between group effects on the TUG (up and go) times. TUG times significantly changed over time. Differences were found between the PRE group and CON group at T3 andT4. The PRE group got faster at these two points. Analysis indicated that the groups significantly declined between $\mathrm{T} 1$ and $\mathrm{T} 3$, $\mathrm{T} 1$ and T4, T2 and T3, T2 and T4, and T3 and T4. Analysis indicated that the CON group significantly slowed between T1 and T4. The Pre groups also significantly changed their TUG time over the 4 data collection points of the study but were always higher than the CON group's times.

Even though the PRE group's TUG times did not increase over time the PRE group did remain functionally better than the CON group's TUG times at (T2, T3, and T4). I believe these findings also support hypothesis three. I believe the PRE group benefited from the exercise intervention and saw an increase in the TUG time at T2 as a direct result of their specific resistance training. Again this small increase at T2 may not have been big large enough to demonstrate a statistical significant change but it was enough to keep the PRE group from significantly worsening their TUG times at T3 and T4 post TKA. By previously performing the exercises in the intervention the PRE group experienced improved function at $\mathrm{T} 2, \mathrm{~T} 3$, and $\mathrm{T} 4$, they steadily and consistently maintained better TUG times over the CON group over the course of the study starting at T2. Persons in the CON group who did not participate in the prehabilitation intervention significantly declined in their functional ability as measured by the TUG. This is a result 
of the specificity of training principle the PRE group benefited from. This principle of specificity will be discussed in detail in the next section.

Hypotheses three was again evaluated by examining the number of sit-to-stand repetitions. The analysis indicated a significant effect of the time and group on this outcome variable. Analysis indicated that the CON group and PRE groups were significantly different at $\mathrm{T} 2, \mathrm{~T} 3$, and $\mathrm{T} 4$ times and the PRE group was significantly higher at T2 compared to T1. I believe these findings also supports hypothesis three. This shows that the PRE group benefited from the exercise intervention, (better functioning), and demonstrated an increased ability to perform chair raises. This significant difference between $\mathrm{T} 1$ and $\mathrm{T} 2$ is directly related to the training effects of the exercise intervention on the PRE groups sit to stand results.

This is a result of the specificity of training principle the PRE group benefited from. The specificity of training principle states that "the body's physiological responses and adaptations to exercise training are specific to the type of exercise and muscle groups involved" (Heyward, 2010, p. 47). For example resistance exercises, such as the Theraband squatting exercises performed by the PRE group during their intervention, have been found to be effective for improving quadriceps muscular strength. Furthermore, the gains in muscular fitness are specific to the exercised muscle groups, type and speed of contraction, and training intensity (Heyward, 2010, p. 48).

The PRE group's training directly involved the use of resistance bands being used during a free standing squat exercise to improve functional ability. This increase in chair raises prior to TKA resulted in better functional ability of the PRE group at T3 and T4. The PRE group was also significantly higher than the CON at T4. At T4 the PRE group 
returned to approximately their baseline levels whereas the $\mathrm{CON}$ group was performing significantly below their baseline values. This finding supports the concept of preparing the body prior to a stressful event such as TKA surgery. Enhancing functional ability preoperatively may lead to the reduction of activity limitations, less work disability, improved quality of life, and lower health care costs post operatively.

Hypotheses three was also evaluated by using the ascending stairs measure. The analysis indicated a significant effect of the time and group on ascending stair time. Analysis indicated that the CON group and PRE groups were significantly different between $\mathrm{T} 1$ and $\mathrm{T} 3, \mathrm{~T} 1$ and $\mathrm{T} 4$ also $\mathrm{T} 3$ and $\mathrm{T} 4$. The $\mathrm{CON}$ group performed significantly poorer between $\mathrm{T} 2$ and $\mathrm{T} 4$ although they trended back towards $\mathrm{T} 1$ levels from $\mathrm{T} 3$ to $\mathrm{T} 4$. The PRE group did not decline at the same level as the CON group over the duration of the study. I speculate that this is due to PRE group having benefited from the exercise intervention and seeing an increase in the ascending stairs time at $\mathrm{T} 2$. These findings also supports hypothesis three.

Again the PRE group's training directly involved the use of resistance bands being used during a free standing squat exercise to increase quadriceps functional ability and the inclusion of step training exercises lead to an improvement in the functional ability of ascending stairs. I believe this again demonstrates the specificity of training principle which shows up in the form of physiological responses and adaptations to exercise training that were specific to the type of exercise and muscle groups involved with the PRE participants. The differences between $\mathrm{T} 1$ and $\mathrm{T} 3, \mathrm{~T} 1$ and $\mathrm{T} 4$ observed in the CON group and not the PRE group is directly related to the training effects of the exercise intervention on the PRE groups ascending stairs times. 
Hypotheses three was again evaluated by examining the descending stairs variable. Analysis indicated a significant effect of the time and group on the descending stair time. The significant differences were found between the PRE group and CON group at T3. The PRE group's descending stairs times did decrease at T2 and the PRE group did remain consistently functionally better than the CON group's descending stairs times at $\mathrm{T} 2, \mathrm{~T} 3$, and $\mathrm{T} 4$. This indicates the efficacy of the intervention to favorably affect the functional ability of the PREs over the CONs in support of hypothesis three. This small decrease in time of the PRE group at T2 may not big large enough to demonstrate a statistically significant effect although this change seems enough to keep the PRE group performing better than the CON group. By performing the exercises in the intervention the PRE group exhibited improved function at $\mathrm{T} 2, \mathrm{~T} 3$, and $\mathrm{T} 4$, and they steadily maintained better descending stairs times over the CON group from $\mathrm{T} 2$ until the end of the study. Persons in the CON group who did not participate in the intervention experienced increases in the time to descend stairs.

Again the PRE group's training directly involved the use of resistance bands being used during a free standing squat exercise designed to improve quadriceps and gluteal muscle function. These muscles are the primary muscles involved in descending stairs. I believe these findings again demonstrates the specificity of training principle which dictates the form of physiological responses and adaptations to exercise training that were specific to the type of exercise and muscle groups involved with the PRE participant's performance in the descending stairs. 


\section{Hypothesis four}

The study used the SF-36 to address hypothesis four that OA (KOA) patients who completed an eight-week prehabilitation program prior to TKA surgery would report higher levels of general health-related quality of life three months following their TKA surgery compared to OA patients who do not complete a prehabilitation program prior to their TKA surgery.

The SF-36 is an evaluative scale designed as an indicator of health-related quality of life (HRQL) status. This survey can be used for specific populations (TKA patients with OA). This survey was used for comparing the health status of TKA patients with OA in this study to OA individuals in the general population. The eight subscales of the SF36 are combined into two summary scales, the physical component scale (PCS) and the mental component scale (MCS).

The PCS and MCS group mean scores were compared to mean scores of the 1998 General U.S population, norms for OA. The mean score norms for the General U.S population with $\mathrm{OA}$ is $\mathrm{PCS}=38.97(11.24)$ and $\mathrm{MCS}=46.35(12.27)$ as listed by Ware (2001). The summary report scores for the combined TKA patients in this study three months post surgery was at 40.22 (9.42) for PCS and MCS at 55.39 (9.12). Both of these scores were found not to be significantly higher than the scores for individuals with OA in the general U.S population. The higher scores for both PRE and CON groups could be related to their lower pain due to TKA surgery.

As seen in table 4.27 the PRE group was significantly different from the population norms in seven of the eight health status concepts while the CON group was not significantly different in any of the concepts. I believe these findings supports 
hypothesis four. I believe that the PRE group having better functional ability in all of the functional tasks than the CON group contributed to them having greater SF-36 scores three months post TKA.

\section{Conclusion}

The social cognitive theory (SCT) states that specific efficacy expectations affect behavior, motivational level, thought patterns, and emotional reactions in response to any situation. I looked at two types of efficacy expectations described within the SCT in this study: self-efficacy expectations and outcome expectations.

Even though SEE scores of the PRE group did not increase significantly they were maintained and trended upward and returned higher than their original baseline score while the CON groups' SEE scores decreased over the course of the study and appeared to be below their baseline scores at the end of the study. These findings support the concepts of the SCT. This maintenance and rise over time of the PRE group's SEE scores and the downward trend prior to and following TKA of the CON group's SEE scores, even though they were not found to be significant, is a cognitive response of the PRE group completing eight weeks of prehabilitation exercise and the CON group not experiencing the intervention. These findings can be explained by the exercise intervention where the PRE participants realized they could perform the exercises. I believe this previous exercise experience prior to TKA came to be of value to the PRE group, as they began to believe they could perform the exercises and saw results, they then took this past memory experience with them three months post TKA surgery in the form of a behavioral change perception.

The PRE group, during the eight weeks of prehabilitation, under the influence of 
the concepts of the SCT gained the knowledge and skills to perform a given behavior, in this case the behavior was exercise, which I speculate lead to an increase in their confidence in their ability to take action to overcome barriers. The data in this study indicates that the PRE group benifited from the exercise intervention and returned closer to their baseline functional levels in all of the five functional tasks which were assessed.This finding is consistant with previous studies that show the OA patient benifiting from exercise (Ettinger, et al., 1997; Rooks, et al., 2006b; Topp, et al., 2002). I believe since the PRE group had higher post surgical functional ability than the CON group, thus influenceing their recovery time after TKA surery, leading to higher PCS scores for the PRE group three months post TKA sugery. This earlier return to baseline levels directly lead to the PRE group reporting higher levels of general health-related quality of life three months post their surgery compared to the CON group who did not engage in pre-operative guided exercise. The CON group was found to be lower in their PCS score of 38.07 (9.31) when compared to the U.S general population with OA. I believe this was a result of the CON group not benefiting from influence of the concepts of the SCT, resulting in no carry over three months post TKA of any benefits of the exercise intervention. The lower PCS scores of the CON group is representative of them not recognizing an increase in their functionality abilities over the duration of the study. 


\section{$\underline{\text { Recommendations }}$}

This study indicates that the introduction of low to moderate resistance training can facilitate recovery of TKA surgical patients. The data in this study indicate that the PRE group benefited from the exercise intervention prior to their TKA and returned closer to their baseline functional levels in all of our functional tasks post TKA. I speculate since the PRE group had higher post surgical functional ability sooner than the CON group, thus influenceing their recovery time after TKA surgery directly lead to the PRE group having higher perceptions of their general quality of life three months post TKA. It is hypothesized that extended preoperative prehabilitation exercise programs may result in accelerated postoperative functional outcomes. Findings of this study and the prehabilitation exercise program show the value of initiating resistance exercise training before TKA surgery. This finding is consistent with previous research (Brown, et al., 2009; Topp \& Page, 2009; Topp, et al., 2009). Encouraging patients to begin resistance exercises, in a prehabilitation exercise program at the earliest possible date before TKA will be crucial in the recovery of their functional abilities once postoperative rehabilitation therapy is started. The weeks of the program could be extended to 12 to 24 weeks if the participant's scheduled surgery time for TKA makes it possible. I believe this extended time could result in greater functional improvements over the duration of the exercise program.

I realize that this current protocol leads to fewer demands on the participant's time commitment to the supervised exercise sessions but I feel it leads to less progression of improved functional ability. Just like the specificity of training principle, the principle of progression, I feel is just as important in the long term gains and improvements of the 
participants. The principle of progression deals with "the increase in the training volume, or overload, to stimulate further improvements" (Heyward, 2010, p. 48). Throughout the intervention program one must progressively increase the training volume, or overload, to stimulate further gains or improvements. The progression needs to be directed under the guidance of the professional trainer in order to have gradual gains. If the participants do too much, too soon it may cause injuries and this is a major reason why some individuals drop out of the exercise program (Heyward, 2010). Just as important, if the participants see no progress they too will drop out of the program. The SCT again can be used to guide this progression. According to Bandura, the likelihood that people will engage in a specific behavior, like an exercise program, depends on their self-efficacy or perception of their ability to perform the task. If the individuals see progress and determine they can be successful as a result, they are more likely to increase self-efficacy towards exercise and continue the behavior.

Another recommendation is that the participants be given sufficient advice from their health care providers about locally available OA- specific exercise facilities or programs tailored to the OA patient. Physical therapy programs along with professional gym programs need to be certified by the physician's staff and offered to the participants.

Participants stated they often did not receive good exercise advice from their physicians. Many physicians are now having patients go through pre surgery education classes; but the patient is often left with no specific guidance regarding exercise. The advice they said they most often received lacks the details and specifics on the type, frequency, intensity, and duration of exercise which would be appropriate for individuals with OA. Many participants stated they only were given a pamphlet or handout with 
exercise instructions without being given directions or referrals to facilities and/or professionals in the field that could direct and guide their exercise program. Doctors need to become aware of results from studies like this one so they can apply the concept of prehabilitation (pre-operative) exercise program when treating their patients. The results from this study show the functional differences between those individuals that participant in pre-operative exercise under the direction of trained professionals and those that do not.

\section{Theory application}

The conceptual framework for this study was provided by Bandura's social cognitive theory. This study focused on two sets of expectations: self-efficacy expectations which are individuals' beliefs in their capabilities to perform a course of action to attain a desired outcome, and outcome expectations, which are beliefs that a certain consequence will be produced by personal action. The SCT provides predictors and principles on how to "inform, enable, guide, and motivate people to adapt habits that promote health" (Bandura, 2004, p. 146). This study I believe shows that the use of the SCT while introducing the patient to exercise prior to TKA has shown to have long term (three months post TKA) benefits following their TKA. The SCT supports the positive effects of prehabilitation exercises in terms of SEE and OEE in increasing the patient's post exercise behavior.

In order to improve exercise activity in older adults, it is useful to consider selfefficacy expectations related to exercise because these beliefs influence motivation to exercise and actual exercise activity. Preoperative exercise interventions introduced to change exercise behavior prior to TKA may increase the patient's self-efficacy towards 
exercise participation and compliance and help accelerate the rate of the patient's postoperative recovery. I believe that this study was limited in size and did not produce the significant results I had hypothesized would occur with SEE and OEE. In this study the presence of instructors with knowledge of $\mathrm{OA}$ and the availability of individualized, tailored exercise prescription programs prior to TKA lead to the participant's behavior change in the form the PRE group reporting higher levels of general health-related quality of life three months post their surgery compared to the CON group who did not engage in pre-operative guided exercise.

\section{Future studies and limitations}

The outcomes of this study have revealed that preoperative exercise did not have as large of an effect on self - efficacy to exercise behavior that I had hypothesized. The study did however demonstrate that outcome expectations and functional ability pre surgery and post - surgical recovery was affected leading to higher perceptions of general health-related quality of life three months post their surgery.

Future studies may examine a larger group of participants to increase the statistical power of the analysis. More studies need to be done to determine if an pre-operative exercise intervention could influence a patient's: 1) length of rehabilitation, 2) lower cost of healthcare services, 3 ) improve activities of daily living (ADLs) 4) return to work time, 5) improve overall quality of life.

This study demonstrated the slight to mild effects of an eight-week program of prehabilitation. The findings indicated improved functioning within the PRE group which I believed carried over three months post TKA as increased PCS scores. Future studies may include exercise interventions that last longer, include more participants and focus 
on the intensity of exercise progression in order to increase the participant's gains in strength and functional abilities. I believe that this study has demonstrated the need for exercise interventions being introduced preoperatively with patients scheduled for a TKA as an intervention designed to facilitate early recovery from their surgery.

\section{$\underline{\text { Summary }}$}

The number of individuals undergoing TKA is expected to increase dramatically as the population ages. The patient's ability to return to activities of daily living (ADL) has personal, social and financial implications. This study has shown the patient's selfefficacy, expected exercise outcomes, and functional ability can be maintained or even improve his or her rate and level of recovery post TKA. I believe exercise interventions introduced preoperatively prior to TKA will increase the patient's self-efficacy towards exercise participation and help accelerate the rate of the patient's postoperative recovery. This study has shown if the TKA patients return back to their baseline levels sooner they are going to reach a higher level of general health-related quality of life following their TKA surgery.

Post surgical rehabilitation has been the focus of most of the literature to date with literature dealing directly with exercise prehabilitation prior to TKA surgery is scarce or missing from the literature. The findings of this study contribute to fill the gap in the literature showing the need for exercise prehabilitation prior to TKA surgery. Future investigations may want to focus on the relationships between $\mathrm{OA}$ and the public's general health status, which includes participation in regular exercise prior to and post TKA, furthering the understanding of the impact of OA within the U.S adult population. 


\section{REFERENCES}

Abdi, H. (2007). Bonferroni and Sidak corrections for multiple comparisons. Thousand Oaks, CA: SAGE.

ACSM (2009). Guidelines for exercise testing and prescription (8th ed.). Philadelphia, PA: Lippincott, Williams, \& Wilkins.

Ajzen, I., \& Driver, B. L. (1991). Prediction of leisure participation from behavioral, normative, and control beliefs: an application of the theory of planned behavior. Leisure Sciences, 13, 185-204.

Ajzen, I., \& Driver, B. L. (1992). Application of the theory of planned behavior to leisure choice Journal of Leisure AResearch, 24, 207-224.

American College of Sports, M. (2004). Physical activity programs and behavior counseling in older adult populations. Medicine \& Science in Sports \& Exercise, 36(11), 1997-2003.

Amin, S., Baker, K., Niu, J., Clancy, M., Goggins, J., Guermazi, A., et al. (2009). Quadriceps strength and the risk of cartilage loss and symptom progression in knee osteoarthritis. Arthritis \& Rheumatism, 60(1), 189-198.

Annesi, J. J., \& Annesi, J. J. (2004). Relationship of social cognitive theory factors to exercise maintenance in adults. Perceptual \& Motor Skills, 99(1), 142-148.

Bandura, A. (1977a). Self-efficacy: toward a unifying theory of behavioral change. Psychological Review, 84(2), 191-215.

Bandura, A. (1977b). Self-efficacy: toward a unifying theory of behavioral change. Psychological Review, 84(2), 191-215.

Bandura, A. (1986). Social Foundations of Thought and Action: A Social Cognitive Theory Englewood Cliffs, NJ. Prentice-Hall.

Bandura, A. (2004). Health promotion by social cognitive means. Health Education \& Behavior, 31(2), 143-164.

Bandura, A. (Ed.). (1997). Self-Efficacy the exercise of control. New York: W.H. Freeman Company.

Barbay, K., \& Barbay, K. (2009). Research evidence for the use of preoperative exercise in patients preparing for total hip or total knee arthroplasty. Orthopaedic Nursing, 28(3), 127-133.

Beaupre, L. A., Lier, D., Davies, D. M., Johnston, D. B., Beaupre, L. A., Lier, D., et al. (2004). The effect of a preoperative exercise and education program on functional recovery, health related quality of life, and health service utilization following primary total knee arthroplasty. Journal of Rheumatology, 3l(6), 1166-1173.

Brown, K., Kachelman, J., Swank, A., Quesada, P., Nyland, J., Malkani, A., \& Topp,R. (2009). Predictors of functional task performance among patients scheduled for total knee arthroplasty. Journal of Strength \& Conditioning Research, 23(2), 436443. 
Brown, K., Swank, A., Quesada, P., Nyland, J., Malkani, A., \& Topp, R. (2010). Prehabilitation versus usual care before total knee arthroplasty: A case report comparing outcomes within the same individual. Physiotherapy Theory And Practice, 26(6), 399-407.

Buckwalter, J. A., \& Martin, J. A. (2006). Osteoarthritis. Advanced Drug Delivery Reviews, 58(2), 150-167.

Buckwalter, J. A., Saltzman, C., \& Brown, T. (2004). The impact of osteoarthritis: implications for research. Clin.Orthop Relat Res(427 Suppl), S6-15.

Centers for Disease Control and Prevention (2001). Prevalence of disabilities and associated health conditions among adults-United States, 1999. MMWR Morbidity \& Mortality Weekly Report, 50(7), 120-125.

Centers for Disease Control and Prevention (2002). Prevalence of self-reported arthritis or chronic joint symptoms among adults-United States, 2001. MMWR - Morbidity \& Mortality Weekly Report, 51(42), 948-950.

Chow, S.-C., \& Lui, J.-P. (1998). Design and analysis of clinical trials: Concept and methodologies. New York, NY: Wiley-Interscience Publication, John Wiley and Sons.

Claessens, A. A., Schouten, J. S., van den Ouweland, F. A., \& Valkenburg, H. A. (1990). Do clinical findings associate with radiographic osteoarthritis of the knee? Annals of the Rheumatic Diseases, 49(10), 771-774.

Cotter, K. A., Sherman, A. M., Cotter, K. A., \& Sherman, A. M. (2008). Love hurts: the influence of social relations on exercise self-efficacy for older adults with osteoarthritis. Journal of Aging \& Physical Activity, 16(4), 465-483.

Cottrell, R., \& McKenzie, J. (2005). Health Promotion and Education Research Methods: using the five chapter thesis/dissertation model. London: Jones and Barlett.

Creamer, P. (2004a). Current perspectives on the clinical presentation of joint pain in human OA. Novartis Foundation Symposium, 260, 64-74.

Creamer, P. (2004b). Current perspectives on the clinical presentation of joint pain in human OA. Novartis Foundation Symposium, 260, 64-74; discussion 74-68.

Cress, M. E., Buchner, D. M., Prohaska, T., Rimmer, J., Brown, M., Macera, C., et al. (2005). Best practices for physical activity programs and behavior counseling in older adult populations. [Review]. Journal of Aging \& Physical Activity, 13(1), 61-74.

D'Lima, D. D., Colwell, C. W., Jr., Morris, B. A., Hardwick, M. E., \& Kozin, F. (1996). The effect of preoperative exercise on total knee replacement outcomes. Clinical Orthopaedics \& Related Research(326), 174-182.

DeFrances, C. J., \& Hall, M. J. (2004). 2002 National Hospital Discharge Survey. Adv $\operatorname{Data}(342), 1-29$.

Der Ananian, C., Wilcox, S., Saunders, R., Watkins, K., \& Evans, A. (2006). Factors that influence exercise among adults with arthritis in three activity levels. Preventing Chronic Disease, 3(3), A81. 
Deyle, G. D., Henderson, N. E., Matekel, R. L., Ryder, M. G., Garber, M. B., \& Allison, S. C. (2000). Effectiveness of manual physical therapy and exercise in osteoarthritis of the knee. . Annual of Internal Medicine, 132(3), 173-181.

DiClemente, C. C., Prochaska, J. O., Fairhurst, S. K., Velicer, W. F., Velasquez, M. M., \& Rossi, J. S. (1991). The process of smoking cessation: an analysis of precontemplation, contemplation, and preparation stages of change. Journal of Consulting \& Clinical Psychology, 59(2), 295-304.

Ditmyer, M. M., Topp, R., Pifer, M., Ditmyer, M. M., Topp, R., \& Pifer, M. (2002). Prehabilitation in preparation for orthopaedic surgery. Orthopaedic Nursing, 21(5), 43-51; quiz 52-44.

Ettinger, W. H., Burns, R., Messier, S. P., Applegate, W., Rejeski, W. J., Morgan, T., et al. (1997). A randomized trial comparing aerobic exercise and resistance exercise with a health education program in older adults with knee osteoarthritis. The Fitness Arthritis and Seniors Trial (FAST). JAMA, 277(1), 25-31.

Finch, E., Brooks, D., Stratford, P. W., \& Mayo, N. E. (2002). Physical Rehabilitation Outcomes Measures. A guide to Enhanced Clinical Decision Making (2nd ed.). Hamilton, Ontario: Lippincott, Williams \& Wilkins.

Fisher, N. M., Gresham, G. E., Abrams, M., Hicks, J., Horrigan, D., \& Pendergast, D. R. (1993). Quantitative effects of physical therapy on muscular and functional performance in subjects with osteoarthritis of the knees. Archives of Physical Medicine \& Rehabilitation, 74(8), 840-847.

Fisher, N. M., White, S. C., Yack, H. J., Smolinski, R. J., \& Pendergast, D. R. (1997). Muscle function and gait in patients with knee osteoarthritis before and after muscle rehabilitation. Disability \& Rehabilitation, 19(2), 47-55.

Fleck, S., \& Kraemer, W. J. (1997). Designing resistance training programs (2nd ed.). Champaign, IL: Human Kinetics Books.

Fletcher, J. S., \& Banasik, J. L. (2001). Exercise self-efficacy. Clinical Excellence for Nurse Practitioners, 5(3), 134-143.

Foundation, A. (2009). Osteoarthritis, what is it? Retrieved May 14, 2009, 2009, from $\mathrm{http} / / / \mathrm{www}$.arthritis.org/disease-center.php?disease_id=32

Gilbey, H. J., Ackland, T. R., Wang, A. W., Morton, A. R., Trouchet, T., Tapper, J., et al. (2003). Exercise improves early functional recovery after total hip arthroplasty. Clinical Orthopaedics \& Related Research(408), 193-200.

Glanz, K., \& Rimer, B. (2005). Theory at a Glance: A Guide for Health Promotion Practice.

Glanz, K., Rimer, B. K., \& Viswanth, K. (Eds.). (2008). Health Behavior and Health Education, Theory, Research, andPractice (Fourth ed.). San Francisco, CA: Jossey-Bass.

Government, U. (2000). Healthy People 2010: With Understanding and Improving Health and Objectives for Improving Health. from http://www.healthypeople.gov/data/midcourse/pdf/ExecutiveSummary.pdf.

Greaney, M. L., Riebe, D., Ewing Garber, C., Rossi, J. S., Lees, F. D., Burbank, P. A., et al. (2008). Long-term effects of a stage-based intervention for changing exercise intentions and behavior in older adults. Gerontologist, 48(3), 358-367. 
Grembowski, D., Patrick, D., Diehr, P., Durham, M., Beresford, S., Kay, E., et al. (1993). Self-efficacy and health behavior among older adults. Journal of Health \& Social Behavior, 34(2), 89-104.

Harnirattisai, T., \& Johnson, A. J. (2005). Effectiveness of a Behavioral Change Intervention in Thai Elders After Knee Replacement. Nursing Research, 54(2), 97-107.

Harnirattisai, T., \& Johnson, R. A. (2005). Effectiveness of a behavioral change intervention in Thai elders after knee replacement. Nursing Research, 54(2), 97 107.

Hausenblas, H. A., Nigg, C. R., Dannecker, E. A., Downs, D. S., Gardner, R. E., \& Fallon, E. A. (2001). A missing oiece of the transtheorectical model applied to exercise: Developement and Validation of the temptation to not exercise scale Psychology and Health, 16, 381-390.

Hawker, G. A., Guan, J., Croxford, R., Coyte, P. C., Glazier, R. H., Harvey, B. J., et al. (2006). A prospective population-based study of the predictors of undergoing total joint arthroplasty. Arthritis \& Rheumatism, 54(10), 3212-3220.

Hershkovitz, A., \& Brill, S. (2006). Get up and go-home. Aging, Clinical and Experimental Research, 18(4), 301-306.

Hershkovitz, A., Gottlieb, D., Beloosesky, Y., \& Brill, S. (2006). Assessing the potential for functional improvement of stroke patients attending a geriatric day hospital. Archives of Gerontology and Geriatrics, 43(2), 243-248.

Heyward, V. H. (2010). Advanced Fitness Assessment and Exercise Prescription (6 ed.). Champaign, IL: Human Kinetics.

Hootman, J. M., Macera, C. A., Ham, S. A., Helmick, C. G., \& Sniezek, J. E. (2003). Physical activity levels among the general US adult population and in adults with and without arthritis. Arthritis \& Rheumatism, 49(1), 129-135.

Hootman, J. M., Macera, C. A., Ham, S. A., Helmick, C. G., Sniezek, J. E., Hootman, J. M., et al. (2003). Physical activity levels among the general US adult population and in adults with and without arthritis. Arthritis \& Rheumatism, 49(1), 129-135.

Hughes, S. L., Seymour, R. B., Campbell, R., Pollak, N., Huber, G., Sharma, L., et al. (2004). Impact of the fit and strong intervention on older adults with osteoarthritis. Gerontologist, 44(2), 217-228.

Hurley, M. V. (1999). The role of muscle weakness in the pathogenesis of osteoarthritis. Rheumatic Diseases Clinics of North America, 25(2), 283-298.

Jaggers, J. R., Simpson, C. D., Frost, K. L., Quesada, P. M., Topp, R., Swank, A. M., et al. (2007). Prehabilitation before knee arthroplasty increases postsurgical function: a case study. Journal of Strength \& Conditioning Research, 21(2), 632634.

Johnson, S. S., Paiva, A. L., Cummins, C. O., Johnson, J. L., Dyment, S. J., Wright, J. A., et al. (2008). Transtheoretical model-based multiple behavior intervention for weight management: effectiveness on a population basis. Preventive Medicine, 46(3), 238-246.

Jones, C. J., Rikli, R. E., \& Beam, W. C. (1999). A 30-s chair-stand test as a measure of lower body strength in community-residing older adults. Research Quarterly for Exercise \& Sport, 70(2), 113-119. 
Jones, L. W., Sinclair, R. C., Rhodes, R. E., Courneya, K. S., Jones, L. W., Sinclair, R. C., et al. (2004). Promoting exercise behaviour: an integration of persuasion theories and the theory of planned behaviour. British Journal of Health Psychology, 9(Pt 4), 505-521.

Kachelman, J., Bibeau, W., Swank, A., Quesada, P., Nyland, J., Malkani, A., et al. (In review). Prehabilitation prior to knee arthroplasty increases strength and function. Journal of Rehabilitation Research and Development.

Katula, J. A., Sipe, M., Rejeski, W. J., Focht, B. C., Katula, J. A., Sipe, M., et al. (2006). Strength training in older adults: an empowering intervention. Medicine \& Science in Sports \& Exercise, 38(1), 106-111.

Kunzmann, U., Little, T., Smith, J., Kunzmann, U., Little, T., \& Smith, J. (2002). Perceiving control: a double-edged sword in old age. Journals of Gerontology Series B-Psychological Sciences \& Social Sciences, 57(6), P484-491.

Kurtz, S., Ong, K., Lau, E., Mowat, F., \& Halpern, M. (2007). Projections of primary and revision hip and knee arthroplasty in the United States from 2005 to 2030. J Bone Joint Surg Am, 89(4), 780-785.

Lachin, J. M. (2000). Statistical considerations in the intent-to-treat principle. Controlled Clinical Trials, 21(3), 167-189.

Lachman, M. E. (1986). Locus of control in aging research: a case for multidimensional and domain-specific assessment. Psychology \& Aging, 1(1), 34-40.

Lawrence, R. C., Felson, D. T., Helmick, C. G., Arnold, L. M., Choi, H., Deyo, R. A., et al. (2008). Estimates of the prevalence of arthritis and other rheumatic conditions in the United States. Part II. Arthritis \& Rheumatism, 58(1), 26-35.

Lethbridge-Cejku, M., Helmick, C. G., Popovic, J. R., Lethbridge-Cejku, M., Helmick, C. G., \& Popovic, J. R. (2003). Hospitalizations for arthritis and other rheumatic conditions: data from the 1997 National Hospital Discharge Survey. Medical Care, 41(12), 1367-1373.

Marcus, B. H., Eaton, C. A., Rossi, J. S., \& Harlow, L. L. (1994). Self-efficacy, decision making, and stages of change: An integrative model of physical exercise. Journal of Applied Social Psychology, 24, 489-509.

Marcus, B. H., Selby, V. C., Niaura, R. S., \& Rossi, J. S. (1992). Self-efficacy and the stages of exercise behavior change. Research Quarterly for Exercise \& Sport, 63(1), 60-66.

McAuley, E. (1993). Self-efficacy and the maintenance of exercise participation in older adults. Journal of Behavioral Medicine, 16(1), 103-113.

McAuley, E., Jerome, G. J., Marquez, D. X., Elavsky, S., Blissmer, B., McAuley, E., et al. (2003). Exercise self-efficacy in older adults: social, affective, and behavioral influences. Annals of Behavioral Medicine, 25(1), 1-7.

McDowell, I., \& Newell, C. (1996). Measuring Health: A Guide to Rating Scales and Questionaires (2nd ed.). New York, New York: Oxford University Press.

Messier, S. P., Loeser, R. F., Miller, G. D., Morgan, T. M., Rejeski, W. J., Sevick, M. A., et al. (2004). Exercise and dietary weight loss in overweight and obese older adults with knee osteoarthritis: the Arthritis, Diet, and Activity Promotion Trial. Arthritis \& Rheumatism, 50(5), 1501-1510. 
Minns Lowe, C. J., Barker, K. L., Dewey, M., Sackley, C. M., Minns Lowe, C. J., Barker, K. L., et al. (2007). Effectiveness of physiotherapy exercise after knee arthroplasty for osteoarthritis: systematic review and meta-analysis of randomised controlled trials. BMJ, 335(7624), 812.

Mizner, R. L., Petterson, S. C., Stevens, J. E., Axe, M. J., \& Snyder-Mackler, L. (2005). Preoperative quadriceps strength predicts functional ability one year after total knee arthroplasty. Journal of Rheumatology, 32(8), 1533-1539.

Model., H. B. (Ed.) (2002) Encyclopedia of Public Health.

Murphy, S. L., Strasburg, D. M., Lyden, A. K., Smith, D. M., Koliba, J. F., Dadabhoy, D. P., et al. (2008). Effects of activity strategy training on pain and physical activity in older adults with knee or hip osteoarthritis: a pilot study. Arthritis \& Rheumatism, 59(10), 1480-1487.

National Center for Chronic Disease Prevention and Health Promotion, C. (2007). Data and Statistics, Kentucky.

http://www.cdc.gov/arthritis/data_statistics/summary/ky.htm

Neupert, S. D., Lachman, M. E., Whitbourne, S. B., Neupert, S. D., Lachman, M. E., \& Whitbourne, S. B. (2009). Exercise self-efficacy and control beliefs: effects on exercise behavior after an exercise intervention for older adultsJournal of Aging \& Physical Activity, 17(1), 1-16.

Newsom (2006). Post Hoc Tests. Portland State University.

Nunnally, J. C., \& Bernstein, I. H. (1994). Psychometric theory (3rd ed.). New York, New York: McGraw- Hill.

O'Connor, M. I., \& Fehring, T. K. (2009). An outstanding scientific knee paper from the specialty societies. Journal of Bone \& Joint Surgery - American Volume, 91 Suppl $5,62-63$.

Osteoarthritis, A. C. o. R. S. o. (2000). Recommendations for the medical management of osteoarthritis of the hip and knee: 2000 update. American College of Rheumatology, Subcommittee on Osteoarthritis Guidelines. Arthritis \& Rheumatism, 43(9), 1905-1915.

Overall, J. E., \& Doyle, S. R. (1994). Estimating sample sizes for repeated measurement designs. Control Clin Trials, 15(2), 100-123.

Panel, O. (2005). Ottawa panel evidence-based clinical practice guidelines for therapeutic exercises and manual therapy in the management of osteoarthritis. Physical Therapy, 85(9), 907-971.

Petrella, R. J., \& Bartha, C. (2000). Home based exercise therapy for older patients with knee osteoarthritis: a randomized clinical trial. Journal of Rheumatology, 27(9), 2215-2221.

Petterson, S. C., Barrance, P., Buchanan, T., Binder-Macleod, S., Snyder-Mackler, L., Petterson, S. C., et al. (2008). Mechanisms underlying quadriceps weakness in knee osteoarthritis. Medicine \& Science in Sports \& Exercise, 40(3), 422-427.

Petterson, S. C., Mizner, R. L., Stevens, J. E., Raisis, L., Bodenstab, A., Newcomb, W., et al. (2009). Improved function from progressive strengthening interventions after total knee arthroplasty. Arthritis \& Rheumatism, 61(2), 174-183.

Podsiadlo, D., \& Richardson, S. (2000). The timed "Up \& Go": A test of basic functional mobility for frail elderly persons. Journal of the American Geriatric Society, 48(1), 104-105. 
Prevention, C. f. D. C. a. (2006). Prevalence of Doctor-Diagnosed Arthritis and ArthritisAttributable Activity Limitation --- United States, 2003--2005 MMWR - Morbidity \& Mortality Weekly Report, 55(40), 1089-1092.

Prochaska, J. O., \& Velicer, W. F. (1997). The transtheoretical model of health behavior change. American Journal of Health Promotion, 12(1), 38-48.

Prochasta, J. O., \& DiClemente, C. C. (1983). Stages and processes of self-change in smoking: Toward an integrative model of change. Journal of Consuling and Clinical Psychology, 5, 390-395.

Resnick, B., \& Jenkins, L. S. (2000). Testing the reliability and validity of the SelfEfficacy for Exercise scale. Nursing Research, 49(3), 154-159.

Resnick, B., Palmer, M. H., Jenkins, L. S., \& Spellbring, A. M. (2000). Path analysis of efficacy expectations and exercise behaviour in older adults. Journal of Advanced Nursing, 31(6), 1309-1315.

Resnick, B., \& Spellbring, A. M. (2000). Understanding what motivates older adults to exercise. Journal of Gerontological Nursing, 26(3), 34-42.

Resnick, B., Zimmerman, S., Orwig, D., Furstenberg, A. L., \& Magaziner, J. (2001). Model testing for reliability and validity of the Outcome Expectations for Exercise Scale. Nursing Research, 50(5), 293-299.

Resnick, B., Zimmerman, S. I., Orwig, D., Furstenberg, A. L., \& Magaziner, J. (2000). Outcome expectations for exercise scale: utility and psychometrics. Journals of Gerontology Series B-Psychological Sciences \& Social Sciences, 55(6), S352356.

Ries, M. D., Philbin, E. F., Groff, G. D., Sheesley, K. A., Richman, J. A., \& Lynch, F., Jr. (1996). Improvement in cardiovascular fitness after total knee arthroplasty. Journal of Bone \& Joint Surgery - American Volume, 78(11), 1696-1701.

Rikli, R., \& Jones, C. (1999). Development and validation of a functional fitness test for community-residing older adults. Journal of Aging and Physical Activity, 7(3), 129-161.

Rodgers, J. A., Garvin, K. L., Walker, C. W., Morford, D., Urban, J., \& Bedard, J. (1998). Preoperative physical therapy in primary total knee arthroplasty. Journal of Arthroplasty, 13(4), 414-421.

Rooks, D. S., Huang, J., Bierbaum, B. E., Bolus, S. A., Rubano, J., Connolly, C. E., et al. (2006a). Effect of preoperative exercise on measures of functional status in men and women undergoing total hip and knee arthroplasty. Arthritis Rheumatology, 55(5), 700-708.

Rooks, D. S., Huang, J., Bierbaum, B. E., Bolus, S. A., Rubano, J., Connolly, C. E., et al. (2006b). Effect of preoperative exercise on measures of functional status in men and women undergoing total hip and knee arthroplasty. Arthritis Rheumatology, 55(5), 700-708.

Rosenstock, I. M. (1974). Historical origins of the Health Belief Model. Health Education Monograms, 2, 328-335. 
Sacks, J. J., Helmick, C. G., Langmaid, G., Sacks, J. J., Helmick, C. G., \& Langmaid, G. (2004). Deaths from arthritis and other rheumatic conditions, United States, 19791998. Journal of Rheumatology, 31(9), 1823-1828.

Schiavo, R. (2007). Health Communication: from Theory to Practice (First ed.). San Francisco, CA: Jossey-Bass.

Shih, M., Hootman, J. M., Kruger, J., Helmick, C. G., Shih, M., Hootman, J. M., et al. (2006). Physical activity in men and women with arthritis National Health Interview Survey, 2002. American Journal of Preventive Medicine, 30(5), 385393.

Slemenda, C., Brandt, K. D., Heilman, D. K., Mazzuca, S., Braunstein, E. M., Katz, B. P., et al. (1997). Quadriceps weakness and osteoarthritis of the knee. Annals of Internal Medicine, 127(2), 97-104.

Somers, T. J., Keefe, F. J., Godiwala, N., \& Hoyer, G. H. (2009). Psychosocial factors and pain experience of osteoarthritis patients: new findings and new directions. Current Opinion in Rheumatology, 21, 501-506.

Sonstroem, R. J. (1988). Exercise Adherence (Dishman R K ed.). Champaign, IL: Human Kinetics.

Spencer, L., Adams, T. B., Malone, S., Roy, L., Yost, E., Spencer, L., et al. (2006). Applying the transtheoretical model to exercise: a systematic and comprehensive review of the literature. Health Promotion Practice, 7(4), 428-443.

Srikanth, V. K., Fryer, J. L., Zhai, G., Winzenberg, T. M., Hosmer, D., Jones, G., et al. (2005). A meta-analysis of sex differences prevalence, incidence and severity of osteoarthritis. [Meta-Analysis]. Osteoarthritis \& Cartilage, 13(9), 769-781.

Steinhardt, M. A., \& Dishman, R. K. (1989). Reliability and validity of expected outcomes and barriers for habitual physical activity. Journal of Occupational Medicine, 31(6), 536-546.

Stillwell, K. M., Forman, D., McElwain, D., Simpson, C., \& Garber, C. (1996). The 6 minute walk test for evaluation of functional capacity in elderly adults. Medicine \& Science in Sports \& Exercise, S152.

Topp, Woolley, S., Hornyak, J., Khuder, S., \& Kahaleh, B. (2002). The effect of dynamic versus isometric resistance training on pain and functioning among adults with osteoarthritis of the knee. Archives of Physical Medicine \& Rehabilitation, 83(9), 1187-1195.

Topp, R., Ditmyer, M., King, K., Doherty, K., \& Hornyak, J. (2002). The effect of bed rest and potential of prehabilitation on patients in the intensive care unit. $A A C N$ Clinical Issues, 13(2), 263-276.

Topp, R., Mikesky, A., Dayhoff, N. E., \& Holt, W. (1996). Effect of resistance training on strength, postural control, and gait velocity among older adults. Clin Nurs Res, $5(4), 407-427$.

Topp, R., Mikesky, A., \& Thompson, K. (1998). Determinants of four functional tasks among older adults: an exploratory regression analysis. $J$ Orthop Sports Phys Ther, 27(2), 144-153.

Topp, R., \& Page, P. (2009). Improve Function before knee replacement surgery. Functional $U, 7(2), 1-8$. 
Topp, R., Swank, A., Quesada, P., Nyland, J., Kachelman, J., \& Malkani, A. (2008, October). Predicting functional ability following total knee replacement. Paper presented at the Council for the Advancement of Nursing Science 2008 National State of the Science Congress in Nursing Research, Washington, D.C.

Topp, R., Swank, A., Quesada, P., Nyland, J., \& Malkani, A. (2008, March). The effect of prehabilitation on leg strength and performance of functional tasks prior to TKA. Paper presented at the Midwest Nursing Research Society Annual Conference, Indianapolis, $\mathbb{N}$.

Topp, R., Swank, A., Quesada, P., Nyland, J., \& Malkani, A. (2009a). The effect of prehabilitaion on functional ability and pain prior to and following TKA. Paper presented at the Midwest Nursing Research Society Annual Conference.

Topp, R., Swank, A., Quesada, P., Nyland, J., \& Malkani, A. (2009b). The Effect of Prehabilitation Exercise on Strength and Functioning After Total Knee Arthroplasty. American Academy of Physical Medicine and Rehabilitation, 1, 729-735.

Topp, R., Swank, A. M., Quesada, P. M., Nyland, J., \& Malkani, A. (2009). The Effect of Prehabilitation Exercise on Strength and Functioning After Total Knee Arthroplasty. American Academy of Physical Medicine and Rehabilitation, 1, 729-735.

Topp, R., Woolley, S., Hornyak, J., Khuder, S., \& Kahaleh, B. (2002). The effect of dynamic versus isometric resistance training on pain and functioning among adults with osteoarthritis of the knee. Archives of Physical Medicine \& Rehabilitation, 83(9), 1187-1195.

Topp, R., Woolley, S., Pifer, M., Khuder, S., Hornyak, J., \& Kahaleh, B. (2001, March). The effect of strength training on pain during functioning among patients with $O A$ of the knee. Paper presented at the Midwest Nursing Research Society's Annual Conference, Cleveland, $\mathrm{OH}$

Ware, J., \& Kosinski, M. (2001). SF-36 Physical \& Mental Health Summary Scales: A Manual for Users of Version 1. (Second ed.). Lincoln, RI: QualityMetric Incorporated.

Wilcox, S., Der Ananian, C., Abbott, J., Ramsey, C., \& Sharp, P. A. (2006). Perceived exercise barriers, enablers, and benifits among exercising and nonexercising adults with arthritis: results from a qualitative study. Arthritis \& Rheumatism, 55(4), 616-627.

Wilcox, S., Der Ananian, C., Abbott, J., Vrazel, J., Ramsey, C., Sharpe, P. A., et al. (2006). Perceived exercise barriers, enablers, and benefits among exercising and nonexercising adults with arthritis: results from a qualitative study. Arthritis \& Rheumatism, 55(4), 616-627. 


\section{APPENDICES}
A. Informed Consent
B. Prehabilitation Intervention Booklet
C. Exercise Log data recording sheet
D. ACSM Exclusion Criteria
E. Demographic Questionnaire
F. Medical Outcomes Study SF-36 form
G. VAS for Pain Assessment during Functional Tasks
H. Medication Questionnaire to be collected at T1, T2, T3 \& T4
I. The Self-Efficacy Exercise (SEE) scale
J. Outcome Expectations for Exercise Scale (OEE) 


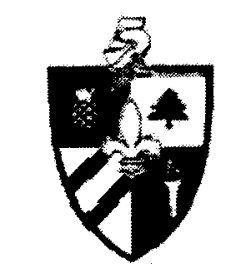

BELLARMINE

UNIVERSITY

February 3, 2010

Tony Brosky, Jr. PT, MS. SCS

Physical Therapy Program

Bellarmine University

2001 Newburg Road

Louisville, KY 40205

Re: IRB \#0409-2, Brosky (PI) Effects of pre-habilitation on early rehabilitation of patients

following total knee arthroplasty (amendment)

Professor Brosky,

Two amendments to the above study and its protocol have been reviewed by a member of the IRB. The first amendment adds Professor Kent Brown as a co-Principle Investigator, and, secondly, study participants will now complete the SF 36 Health Survey Form as part the protocol. The informed consent has been modified to reflect these changes. These amendments have been noted in our records. Your study review period now extends to February 2, 2011. If this study is to be ongoing at that time, please complete the Project Report/Continuation form one month before the end of the review period, or, when the study is completed, submit the Termination Form. These forms are found at http://cas.bellarmine.edu/chemistry/irbhuman1.htm

Best of luck with this ongoing project!

Jerome Walker

Chair, Bellarmine University IRB 


\section{APPENDIX A}

\section{Effects of Pre-habilitation on Early Rehabilitation of Total Knee Arthroplasty Subject Informed Consent}

\section{Introduction and Background Information}

You are invited to participate in a research study. The study is being conducted by Joseph A. Brosky, Jr., PT, MS, SCS, Kent Brown PhDc, MS, CSCS and Robert Topp, PhD, RN. The study is sponsored by Bellarmine University, the University of Louisville, Norton Audubon Hospital and the Hygenic Corporation. The study will take place at Bellarmine University Physical Therapy Service Learning Clinic (2120 Newburg Road, BOB 200). Approximately 40 subjects will be invited to participate. Your participation in this study will last for approximately 8-12 weeks.

\section{Purpose}

The purpose of this research study is to determine the benefits of an 8-week program of exercises performed before total knee joint (TKA) surgery (known as "pre-habilitation"). The study wants to determine if these pre-habilitation exercises can improve your exercise self-efficacy, outcome expectations for exercise, and ability to complete functional tasks like walking, going up/down stairs, and standing up/sitting down from a chair. The study also wants to determine if prehabilitation exercises have any effect on your level of knee pain, your knee strength and range of motion. And finally the study wants to determine if pre-habilitation exercises have any effect on the length of time you spend in the hospital and the number of outpatient rehabilitation sessions needed following total knee replacement.

\section{Procedures}

In this study, once you have met with your surgeon and scheduled your surgery and agreed to participate, you will be asked to provide information about your past medical history and complete a standardized survey about your knee pain, stiffness, and physical activities (WOMAC-Western Ontario and McMaster Universities Osteoarthritis Index) and about your perceptions and attitudes towards exercise (Self Efficacy to Exercise/Outcome Expectation for Exercise and SF 36 Health Survey). You are free to decline to answer any questions that make you uncomfortable. You will be asked to perform normal everyday activities that involve walking for 6 minutes, getting up from a chair-walking 10 feet-then turning around and sitting back down, walking up and down a flight of stairs, and standing up and sitting down from a chair. The degree to which you can bend and straighten your knee will be measured with a "ruler" that measures joint motion, and your knee strength will be measured by your ability to straighten and bend your knee against a padded device that measures force. Performance of these measures will occur on 4 occasions: approximately 8 weeks and 1 week before your surgery, and at 1 week and 2 weeks after your surgery. All participants will be randomly placed into either a control group (testing only) or a pre-habilitation group (perform exercises) when they choose to enter into the study. If you are assigned to the pre-habilitation group you will receive an illustrated exercise booklet. You will be required to keep track of exercises when you perform them. You will be asked to perform the exercise program 3 times a week, but only one of these 3 weekly sessions will be required to be performed at the Bellarmine University Physical Therapy Laboratory. 
The other two exercise sessions can be performed at home each week. It is estimated that it will take approximately one hour to perform each of the 4 testing and weekly supervised exercise sessions.

\section{Potential Risks}

There are risks associated with this research study which may include muscular soreness and swelling following the testing sessions and/or exercise sessions. If muscle soreness or swelling occurs, you will be instructed in procedures to minimize the soreness and swelling. Some of the exercises involve the use of elastic tubing which contains latex. If you have a known or suspected allergy to latex you should notify the investigators immediately and realize this may exclude you from the study.

\section{Benefits}

The possible benefits of this study include instruction and supervision of a rehabilitation program involving common exercises used with patients with knee osteoarthritis or following knee joint replacement surgery. The exercise program may be beneficial to you by assisting in your recovery from the surgery. The information collected may not benefit you directly and may be helpful to others who have knee osteoarthritis or knee joint replacement surgery.

\section{Injury}

No money has been set aside for a potential injury. If you believe you have sustained an injury as a direct result of participation in this study you should contact Professor Joseph A. Brosky, Jr. (502) 452-8375, Kent Brown (502) 452-8391 or Dr. Robert Topp (502) 852-8510. You may be responsible for covering any injury-related costs or your personal health insurance may be used to cover costs for such an event. You may contact your health insurance company to determine if your insurance company provides coverage for such injuries. In a case of serious injury, 911 will be called.

\section{Compensation}

You will receive $\$ 10$ for each of the first three data collection sessions you complete (T1baseline, T2-1 week before surgery and T3-1 week after surgery) and $\$ 20$ upon completion of the final data collection session (T4-2 weeks after surgery) for a total of $\$ 50$ for completing all data collection sessions.

\section{Confidentiality}

Although absolute confidentiality cannot be guaranteed, confidentiality will be protected to the extent permitted by law. The study sponsors, the Institutional Review Board, or other appropriate agencies may inspect your research records. Should the data collected in this research study be published, your identity will not be revealed. Results of this research study, if published will be reported in aggregate and your identity will not be revealed. Financial personnel may need to be notified of your participation to process payment. 


\section{Voluntary Participation}

Your participation in this research study is voluntary. You are free to refuse to participate or withdraw your consent at any time without incurring any penalty or losing benefit to which you are otherwise entitled.

\section{Research Subject's Rights and Contact Persons}

You acknowledge that all your present questions have been answered in language you can understand. If you have any future questions about the study or would like to withdraw from the study, please contact Professor Kent Brown. (502) 452-8391, Professor Joseph A. Brosky, Jr. (502) 452-8375, or Dr. Robert Topp (502) 852-8510. If you have any questions about your rights as a research subject, you may call the Institutional Review Board (502-452-8219). You will be given the opportunity to discuss any questions about your rights as a research subject, in confidence, with a member of the Board. This is an independent committee composed of members of the University community and lay members of the community not connected with this Institution. The Board has reviewed this study.

\section{Consent}

You have discussed the above information and hereby consent to voluntarily participate in this study. You have been given a signed copy of this informed consent form.

Signature of Subject

Date Signed

Signature of Investigator

Date Signed

Signature of Person Explaining if other than Investigator

Date Signed 


\section{APPENDIX B \\ Prehabilitation Intervention Booklet}

Training Book

Introduction

This booklet is intended as a guide to help you with your exercise program. The exercise guidelines outline the requirements necessary for you to follow throughout the next 8 weeks. Illustrations and easy-to-read instructions provide you with the essential information to assist you in your program. Finally, weekly log sheets are provided for each of the 8 weeks in your program. You are required to turn in your log sheets each week, therefore it is important to keep current with this information.

Should you have any questions regarding any of the information provided in this booklet, please contact:

Kent Brown: Office \# 502-452-8391

$$
\text { Cell \# 502-523-4107 }
$$

Email:kbrown@bellarmine.edu

Thank you and good luck! 


\section{Exercise Guidelines}

In order to ensure complete compliance with the study protocol, please follow the exercise guidelines listed below. Any deviation from these guidelines can affect the results of the study. We appreciate your cooperation.

1.Exercise Sessions: You are expected to perform this exercise program three nonconsecutive days per week (i.e., Monday-Wednesday-Friday, or Tuesday-ThursdaySaturday). You are invited to participate in one of your three weekly exercise sessions with an exercise leader at Bellarmine University. Parking will be provided for you to attend this exercise session at Norton Hospital.

2.Weekly log sheets: Weekly log sheets must be completed, and submitted (either in person or by mail) to the study office at the end of each week. It is important to accurately record your exercise sessions so you can get the maximum benefit from the exercises you complete. Weekly log sheets are provided with the prescribed number of repetitions designated for that exercise session for your convenience. (See the Log Sheet Section of this booklet.)

3.Warm-up: Prior to each exercise session, it is important for you to properly warm-up in order to prevent injury and to get the most from the exercise session. Follow the warm-up exercises provided in the Exercise Section of the booklet.

4. Order of Exercises: Perform the exercises in the order shown in this booklet. The exercise order is also listed on each weekly log sheet. This will help ensure consistency with the study protocols. In most cases, the exercises can be performed while standing or sitting. If you are not able to perform a specific exercise, even with the modifications provided, please make note on the log sheet.

5.Level of resistance using the Thera-band ${ }^{\mathrm{TM}}$ exercise bands: You will be provided with several colors of Thera-band ${ }^{\mathrm{TM}}$. Each color designates a different level of resistance (see chart below). In the beginning, choose a lower level of resistance and attempt to complete 8 repetitions of one of the exercises. You might find that you need a different color for the various exercises. If you can easily complete more than 8 repetitions with that color, then you should move to the next higher level of resistance until you find a color in which you can complete 8 repetitions. Maintain that level (color) until you find that you can move above the prescribed number of repetitions for that week. Then you can move to the next level (color). 
For the purposes of this study...

a. The correct level of resistance is defined as being able to perform the prescribed number of sets and repetitions with full range of motion and in proper body alignment.

b. A level of resistance that is too difficult is defined as not being able to perform the prescribed number of sets and repetitions with full range of motion and in proper body alignment or without stopping.

c. A level of resistance that is too easy is defined as being able to perform more the prescribed number of sets and repetitions with full range of motion and in proper body alignment.

\begin{tabular}{|c|c|c|}
\hline Color of Thera-band $^{\mathrm{TM}}$ & \multicolumn{2}{|c|}{ Level of Resistance } \\
\hline Yellow & Thin & Lightest \\
Red & Medium & \\
Green & Heavy & \\
Blue & Extra Heavy & \\
Black & Special Heavy & \\
Silver & Super Heavy & \\
Gold & Maximum & Heaviest \\
\hline
\end{tabular}


6. Step training: You can perform your step training on the bottom step of your stairway at home. To complete this step training you will be asked to step up and down the bottom step four different ways; going forward, going backward, side stepping from the left, and side stepping from the right. The height of the steps may need to be modified for each of the exercises, but please record the height of the steps performed on each of the four different ways (e.g. forward, backward, right, and left). Please use the stairway banister to keep your balance during these exercises.

7. Flexibility training: After performing your resistance and step exercises, make sure you do your flexibility exercises. They are provided at the end of this booklet. These stretches should be held to mild tension for about 20 seconds. Relax and then repeat each stretch before moving to the next flexibility exercise.

8. Questions: Should you have any questions or concerns, contact the study office at (502) 272-8391. 


\section{Warm-up Exercises}

1. Marching in place: This can be performed standing or seated. If standing, stay in one spot, walk in place moving your arms back and forth at a leisurely pace. If seated, alternate lifting legs off floor as if marching, while moving your arms back and forth at a leisurely pace. Perform for approximately 3 minutes.

2. Arm circles: This can be performed standing or seated. Slowly lift both arms from your sides until parallel to the floor. Begin moving arms in small circular motions as if drawing circles on the walls. You can make the circles bigger as you continue. Perform 10 circles in each direction.

3. Forearm lifts: This can be performed standing or seated. With your arms hanging by your side, slowly alternate bending your arm at the elbow bringing your hand up as if to touch the front of your shoulder. Perform 10 with each arm.

\section{Resistance Training Exercises with Thera-band ${ }^{\mathrm{TM}}$}

The following section contains the resistance exercises that you will be performing in your exercise program. The exercises should be completed in the following order:

\section{Name and order of exercises}

Squats

Toe Raises (plantar flexion)

Gas and Clutch (dorsi flexion)

Hamstring Curls

Biceps Curls

Triceps Pulls

Chest Press

Seated Row 


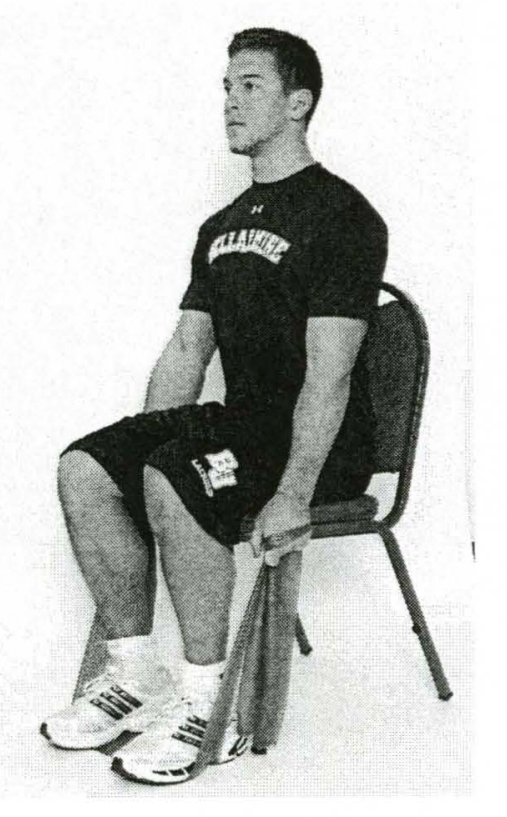

\section{Exercise \#1: Squat}

The chair squat is an excellent exercise to strengthen the quadriceps and entire leg. It's also a functional exercise to help improve mobility.

Begin with center of band under feet. Grasp ends of bands with hands by sides. Keep tension in the band with elbows straight. Keeping your elbows straight, slowly bend your knees while leaning forward slightly at the hips. Slowly return to starting position.

TIP: Keep your back straight.

\section{Exercise \#2: Toe Raises}

This exercise helps strengthen your calf muscles in the lower leg. It's also a good balance exercise.

Place the middle of the band under the balls of both feet. Grasp the ends of the band at your hips. Keeping your elbows straight, raise your heels as far as you can. 


\section{Exercise \#3: Gas and Clutch}

Begin with loop around the foot. Bring the loop under and around the opposite foot, grasping the end at waist level. Pull your foot upward against the band. Hold and slowly return.

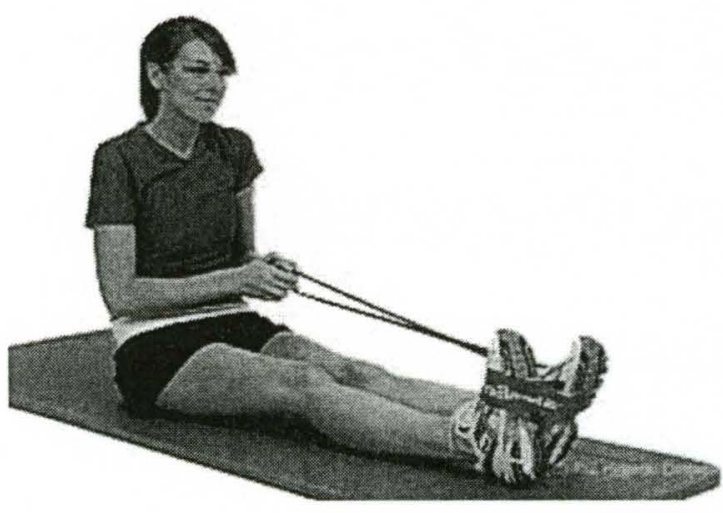

Exercise \#4: Hamstring Curls

Stabilize one end of a short band under the foot. Loop the other end around your ankle. Bend your knee, pulling your foot up against the band. Be sure to maintain an upright trunk. Hold and slowly return.

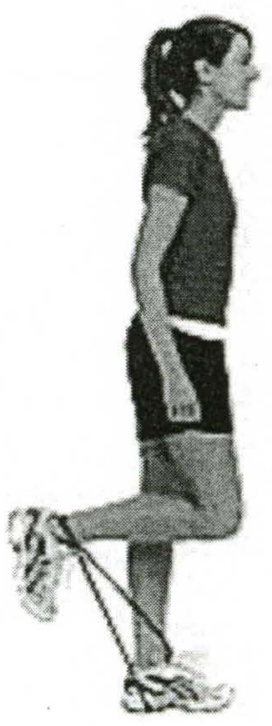




\section{Exercise \#5: Hip Kick Backs}

Loop the band around your ankle, and stabilize the other end of the band to a stationary object near the floor. Stand with side closest to attachment with non-exercising leg. Keep your knees straight and kick outward. Keep your back straight, and avoid leaning or bending over. Hold and slowly return.

\section{Exercise \#6 Hip Side Kicks}

Loop the band around your ankle, and stabilize the other end of the band to a stationary object near the floor. Stand with side closest to attachment with nonexercising leg. Keep your knees straight and kick outward. Keep your back straight, and avoid leaning or bending over. Hold and slowly return. 


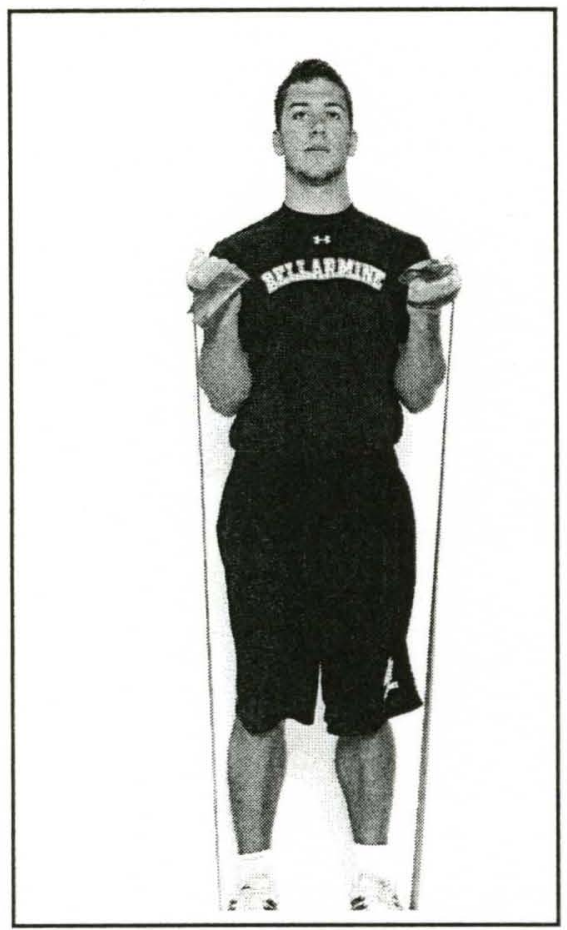

\section{Exercise \#7: Biceps Curls}

Wrap the middle of the band around both feet and grasp each end of the band with palms facing forward. Keep elbows at your side. Keeping wrists straight, bend elbow, bringing your hands to shoulders. Slowly return to the starting position.

TIP: Keep your back straight! Don't slouch or lean forward.

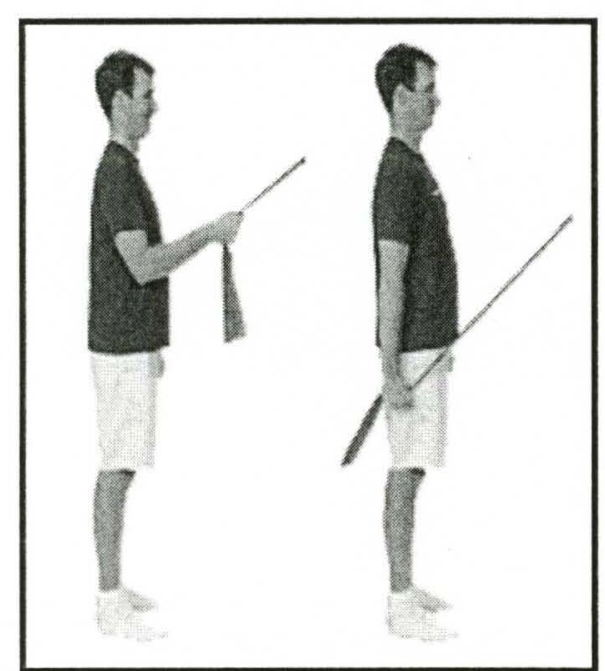

Exercise \#8: Triceps Pull

Strengthens the back of the arm.

Securely attach one end of the band with a Door Anchor or Assist. Grasp the end of the band and take up the slack. Keep your elbow by your side as you extend your elbow. Hold and slowly return. Keep your back straight. 


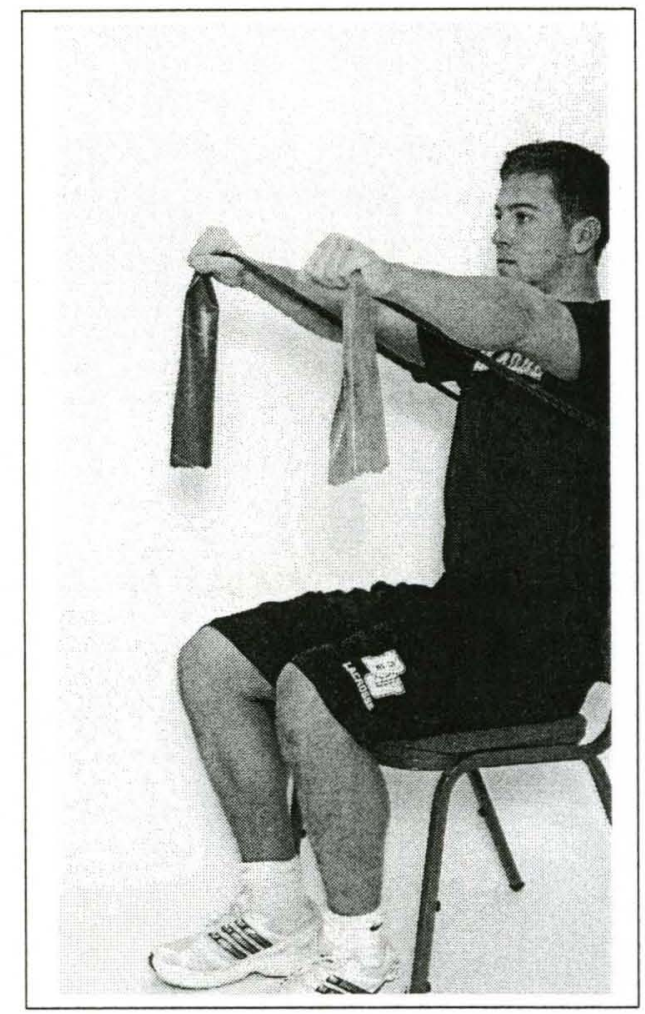

\section{Exercise \#9: Chest Press}

The Bench Press strengthens the front part of the shoulder and triceps.

Begin with band wrapped around your upper back. Grasp both ends of band with elbows bent and palms facing inward. Push band forward, extending your elbows to shoulder level. Slowly return to starting position.

TIP: Keep your back and neck straight. Don't shrug your shoulders. Don't hold your breath.

\section{Exercise \#10: Seated Row}

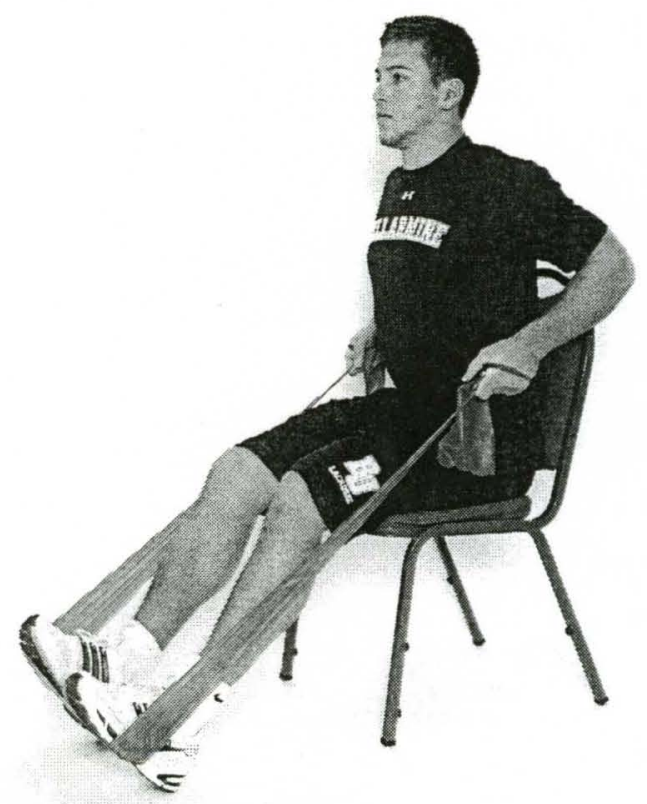

The Seated Row strengthens the upper back.

Extend your legs and wrap middle of band around feet. Be sure band is secure around feet and won't slip. Grasp both ends of band with elbows straight. Pull band upward and back, bending elbows. Slowly return to starting position.

TIP: Keep your knees and back straight. 


\section{Step Exercises}

General instructions: Use the bottom step of a stairway in your home. Use the stairway banister to keep your balance but NOT to support your weight. At first, complete each of the four step exercises slowly until you are comfortable with the motion.

\section{Step Exercise \#1: Step Up, Step Down Facing the Stairs}

Step up with the right leg followed by the left leg. Step down with the right leg followed by the left leg. This is one repetition. Repeat to your designated number of repetitions.
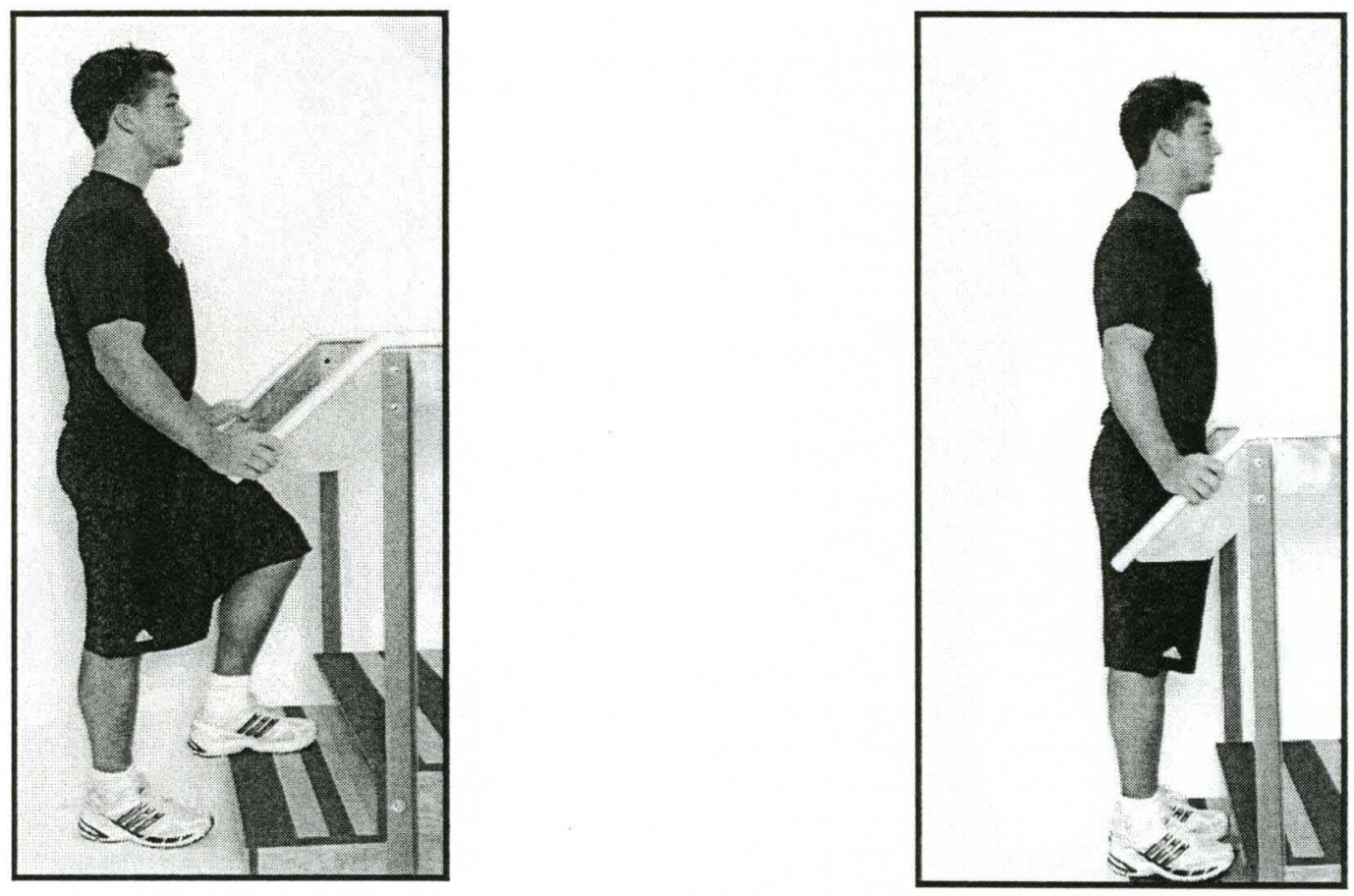
Step Exercise \#2 Step Up. Step Down with Right Side to the Stairs

With your right shoulder facing the stairs step up with the right leg followed by the left leg. Step down with the left leg followed by the right leg. This is one repetition. Repeat to your designated number of repetitions.
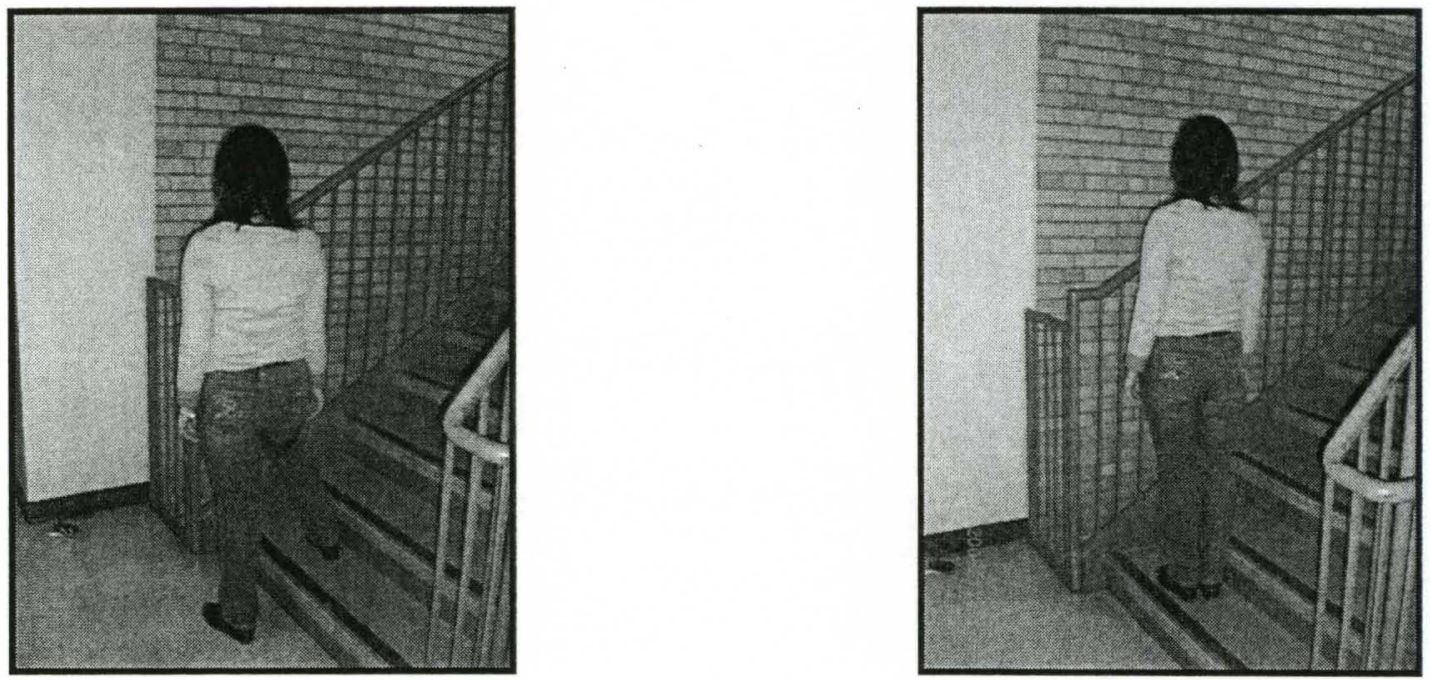

Step Exercise \#3 Step Up, Step Down with Left Side to the Stairs

With your left shoulder facing the stairs step up with the left leg followed by the right leg. Step down with the right leg followed by the left leg. This is one repetition. Repeat to your designated number of repetitions.
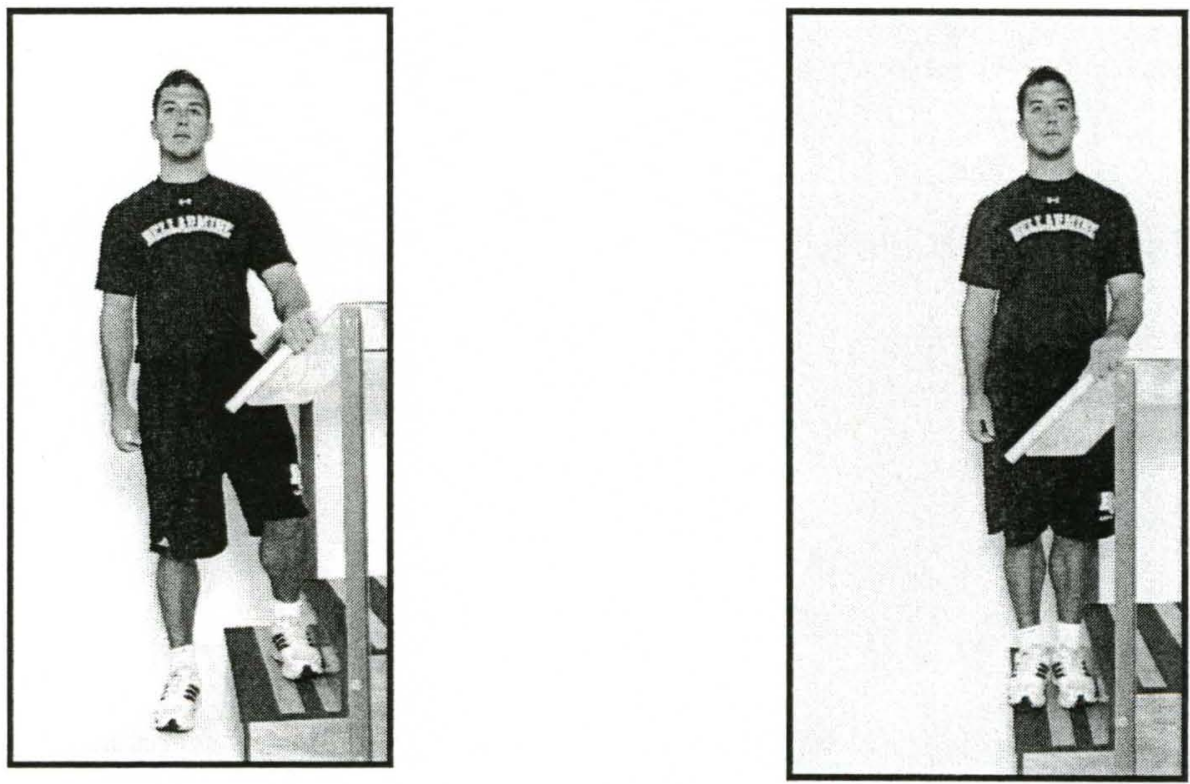


\section{Flexibility Exercises}

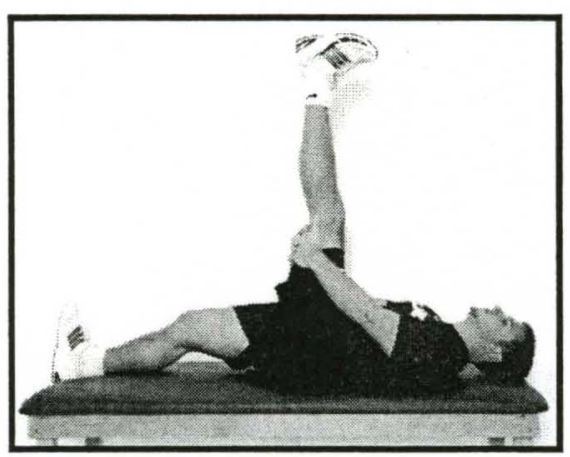

Flexibility Exercise \#1: Hamstring Stretch

1.

as shown

Lie on back holding leg with hands

2. Keep the opposite knee bent

3. Straighten the knee as far as you can and pull toward your nose

4. Hold 20-30 seconds. Perform 2 reps.

Repeat with opposite leg

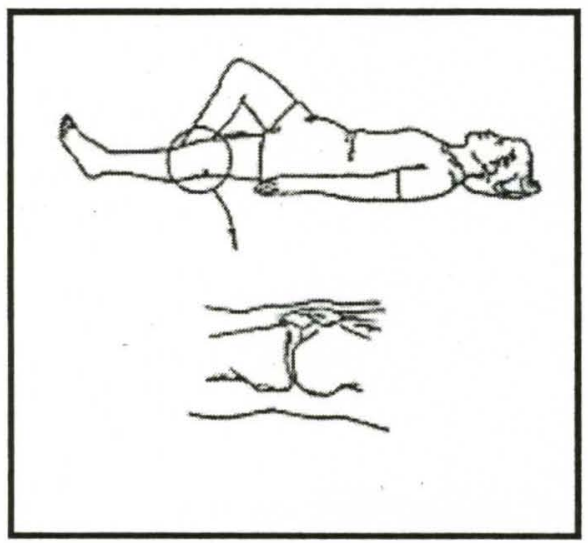

Flexibility Exercise \#2: Quadriceps Set

1.Sit or lie on your back with your leg straight

2.Press the back of your knee downward

3. This will tighten the muscle on top of your thigh and move your kneecap as shown

4.Hold for 10 seconds.

5.Repeat with opposite leg 5 reps each.

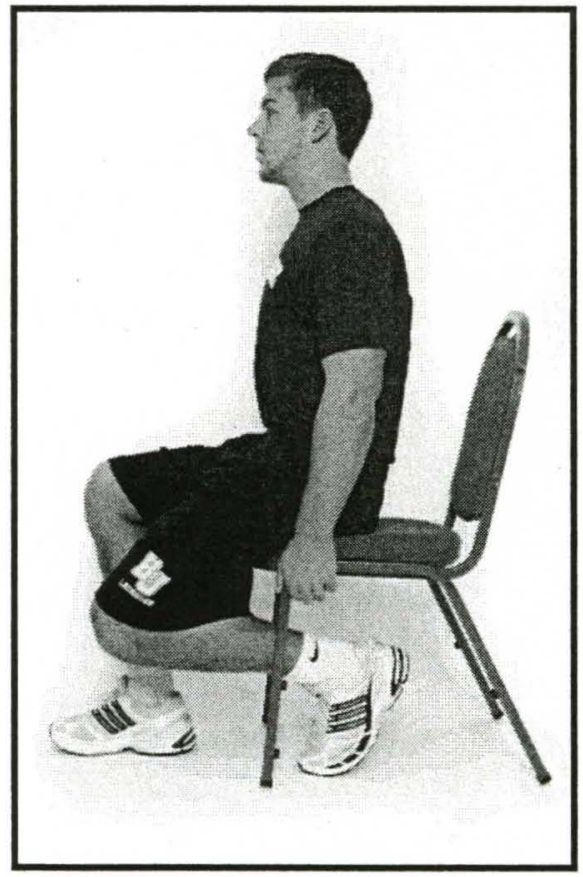

Flexibility Exercise \#3: Knee Flexion

1. Sit in a chair with your foot close to the base of the chair

2. Scoot forward toward edge of the chair as far as you can to bend your knee

3. Hold for 20 seconds. Perform 2 reps.

4. Repeat with opposite leg 


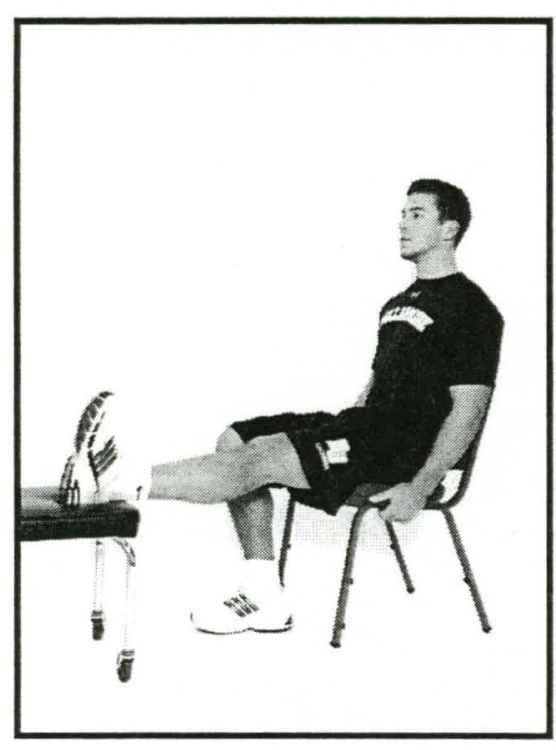

Flexibility Exercise \#4: Knee Extension Stretch

1. Sit with leg propped as shown

2. Straighten the knee of the propped

leg as far as possible

3. Hold for $20-30$ seconds, 2 reps.

4. Repeat with opposite leg

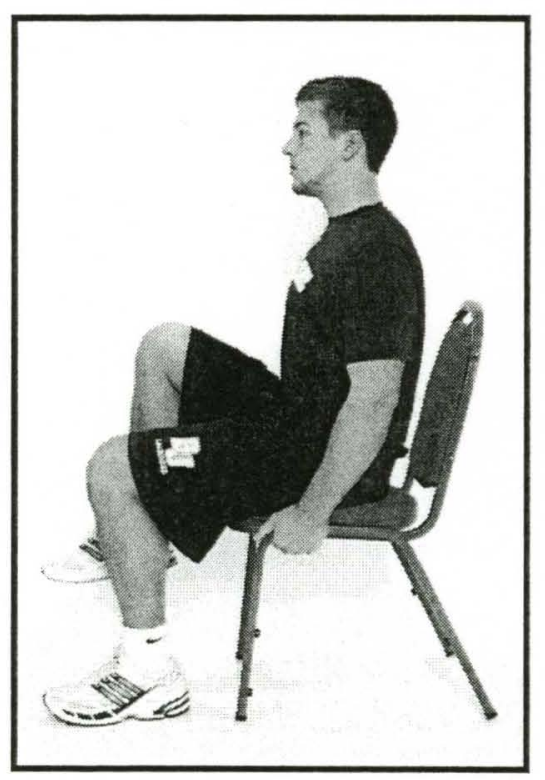

Flexibility Exercise \#5: Hip Stretch

1. Sit in a chair with knees bent as shown

2. Bend hip to lift foot off floor and pull your thigh to your chest while increasing the bend in your knee.

3. Hold 1-2 seconds. Repeat 20 reps.

4. 4.Repeat with opposite leg

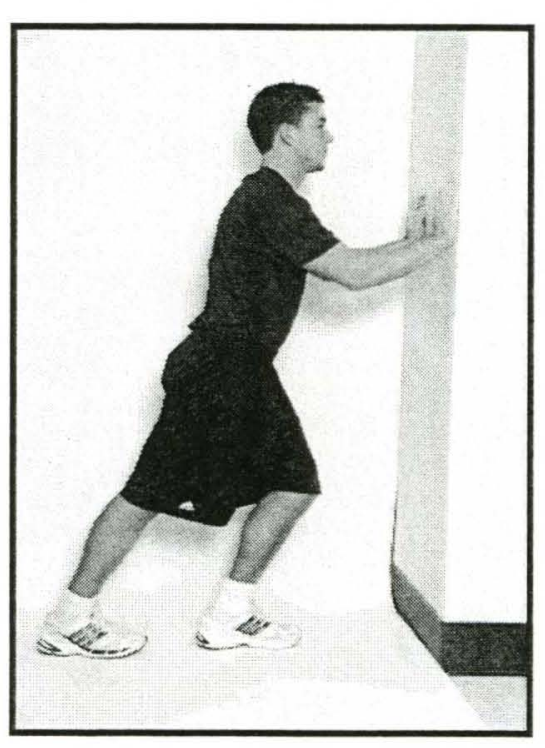

\section{Flexibility Exercise \#6: Calf Stretch}

1. Position your body in front of a wall as shown with your left leg about $2 \mathrm{ft}$ from the wall. Place your right leg about $1 \mathrm{ft}$ behind your left foot.

2. Point toes directly toward wall and hold the heels down on the floor

3. Lean into wall as shown so that you feel a stretch in your calf

4. Hold for 20 seconds. Perform 2 reps.

5. Repeat with opposite leg 


\section{Don't Forget to Cool Down!}

1. Marching in place: This can be performed standing or seated. If standing, stay in one spot, walk in place moving your arms back and forth at a leisurely pace. If seated, alternate lifting legs off floor as if marching, while moving your arms back and forth at a leisurely pace. Perform for approximately 3 minutes.

2. Arm circles: This can be performed standing or seated. Slowly lift both arms from your sides until parallel to the floor. Begin moving arms in small circular motions as if drawing circles on the walls. You can make the circles bigger as you continue. Perform 10 circles in each direction.

3. Forearm lifts: This can be performed standing or seated. With your arms hanging by your side, slowly alternate bending your arm at the elbow bringing your hand up as if to touch the front of your shoulder. Perform 10 with each arm. 


\section{APPENDIX $\mathrm{C}$}

WEEKLY LOG SHEET-Data of Rehabilitation exercise

Week \#

Subject:

\begin{tabular}{|c|c|c|c|c|c|c|c|c|}
\hline $\begin{array}{l}\text { Name of } \\
\text { Exercise }\end{array}$ & \multicolumn{2}{|c|}{$\begin{array}{l}\text { \# prescribed } \\
\text { of sets }(\mathrm{S}) \\
\text { and } \\
\text { repetitions } \\
\text { (R) }\end{array}$} & \multicolumn{2}{|c|}{$\begin{array}{l}\text { First workout } \\
\text { Date: }\end{array}$} & \multicolumn{2}{|c|}{$\begin{array}{l}\text { Second workout } \\
\text { Date: }\end{array}$} & \multicolumn{2}{|c|}{$\begin{array}{l}\text { Third Workout } \\
\text { Date: }\end{array}$} \\
\hline \multicolumn{9}{|c|}{ RESISTANCE EXERCISES } \\
\hline & Sets & Reps & $\# \mathrm{~S} \& \mathrm{R}$ & Color & $\# S \& R$ & Color & \#S \& R & $\begin{array}{c}\text { Colo } \\
\mathrm{r}\end{array}$ \\
\hline Squat & 1 & 10 & & & & & & \\
\hline Toe Raises & 1 & 10 & & & & & & \\
\hline Gas \& Clutch & 1 & 10 & & & & & & \\
\hline Hamstring Curls & 1 & 10 & & & & & & \\
\hline Hip Kick Backs & 1 & 10 & & & & & & \\
\hline Hip Side Raises & 1 & 10 & & & & & & \\
\hline Biceps Curls & 1 & 10 & & & & & & \\
\hline Triceps Pulls & 1 & 10 & & & & & & \\
\hline Chest Press & 1 & 10 & & & & & & \\
\hline Seated Row & 1 & 10 & & & & & & \\
\hline \multicolumn{9}{|c|}{ STEP EXERCISES } \\
\hline & Sets & Reps & S/R: (Ht: & in.) & $\mathrm{S} / \mathrm{R}:(\mathrm{Ht}$ : & in.) & $(\mathrm{Ht}:$ & in.) \\
\hline $\begin{array}{l}\text { Up/Down the } \\
\text { Step Going } \\
\text { Forward }\end{array}$ & 1 & 8 & & & & & & \\
\hline $\begin{array}{l}\text { Up/Down } \\
\text { Starting from } \\
\text { the Right }\end{array}$ & 1 & 8 & & & & & & \\
\hline
\end{tabular}




\begin{tabular}{|l|c|c|c|c|c|c|c|c|c|}
\hline $\begin{array}{c}\text { Up/Down } \\
\text { Starting from } \\
\text { the Left }\end{array}$ & 1 & 8 & \multicolumn{3}{|l|}{} & & & \\
\hline \multicolumn{7}{|c|}{ FLEXIBILITY EXERCISES } \\
\hline & S/R & Sec. & S/R & Sec. & S/R & Sec. & Sets & S/R \\
\hline $\begin{array}{l}\text { Hamstring } \\
\text { Stretch }\end{array}$ & 2 & 20 & & & & & & \\
\hline Quadriceps Set & 5 & 10 & & & & & & \\
\hline $\begin{array}{l}\text { Knee Flexion } \\
\text { Bends }\end{array}$ & 2 & 20 & & & & & & \\
\hline Heel Props & 2 & 20 & & & & & & \\
\hline Hip Flexion & 2 & 20 & & & & & & \\
\hline Calf Stretch & 2 & 20 & & & & & & \\
\hline
\end{tabular}




\section{APPENDIX D}

\section{Exclusion Criteria}

Criteria to exclude subjects from starting or continuing in the exercise protocol (modified from ACSM, 2009)

1. Symptomatic $\mathrm{CAD}$ as evidence by uncontrollable angina, or a diagnosed MI within the past 1 year.

2. Presence or history of cardiac dysrhythamias requiring therapy including uncontrolled ventricular arrhythmia, $>6$ PVC per minute, ventricular fibrillation, flutter, standstill, tachycardia, supraventricular tachycardia, idioventricular rhythms, atrial flutter or fibrillation, and $2^{\text {nd }}$ or $3^{\text {rd }}$ degree heart block.

3. Documented Chronic Heart Failure (CHF) as evidence of an $\mathrm{S} 3$ at rest or exercise, rales after exercise, or a documented medical history of CHF.

4. Severe aortic stenosis demonstrated by syncope and angina, or severe left ventricular hypertrophy with $\mathrm{S}$-T segment or $T$ wave changes on $E K G$.

5. Suspected or known dissecting aneurysm or history of ventricular aneurysm.

6. Acute myocarditis, pericarditis, subacute endocarditis, or acute Rheumatic fever.

7. Systemic or pulmonary emboli with the past 3 months.

8. Acute thrombophlebitis or intracardiac thrombi.

9. A recent significant change in the resting EKG.

10. Uncontrolled hypertension (diastolic $>100$, or systolic $>175$ at rest)

11. Peripheral vascular disease severe enough to prevent moderate intensity walking for 30 minutes.

12. COPD severe enough to prevent moderate intensity exercise for 10 minutes.

13. A history of cerebrovascular disease, which has result in permanent mental or physical disability.

14. Other chronic disease, which contraindicates moderate intensity exercise for 10 minutes including but not, limited to vascular disease, cancer, and severe renal or hepatic disease.

15. Any condition which requires the subject to take anti-anginal medications, lithium, tricyclic antidepressants, phenothiazides, and MAO inhibitors.

16. Younger than 40 years of age.

17. Unable to read and/or understand English.

18. Unable to agree to participate in the research protocol for 10 weeks.

19. Known or suspected latex allergy. 


\section{APPENDIX E}

\section{Demographic Questionnaire}

First Name:

Last Name:

Date:
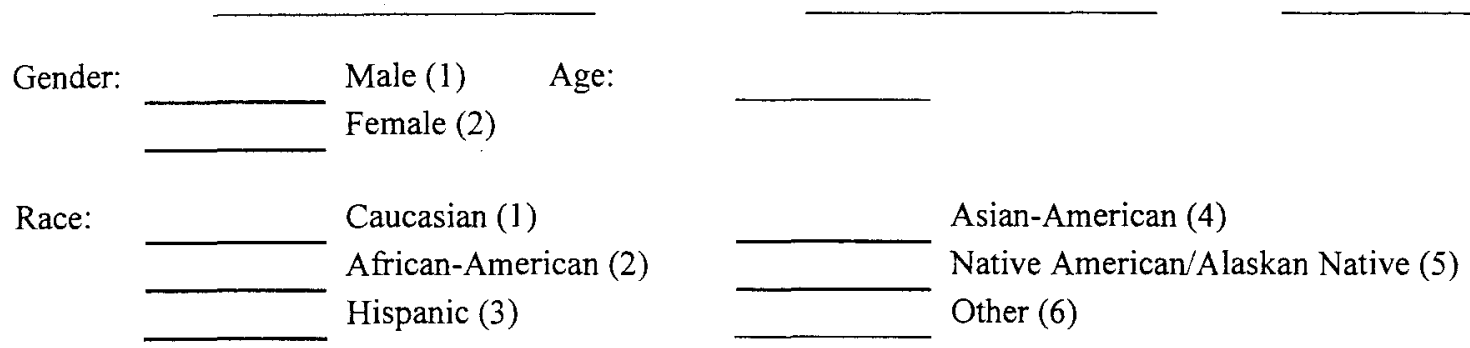

If you are a female, are you currently taking hormone replacement therapy?

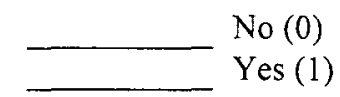

If YES, please indicate: Name of medication: Dose taken:

How frequently do you take this dose?

Date of Total Knee Replacement Surgery:

(Day/Month/Year)

Which knee is being replaced?

RIGHT (0)

LEFT (1)

BOTH (2)

Is this your first total knee replacement surgery?

No $(0)$

Yes (1)

If $\mathrm{NO}$, when did your previous total knee replacement surgery occur?

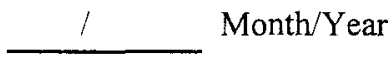

Do you have any chronic health problems?

No (0)

Yes (1)

If YES, please list/describe below:

Date Diagnosed

Type of Problem by a Physician
Current Treatment 


\section{Please continue to the next page}

Do you have any other orthopedic / health-related issue(s) that affect your lower extremity functioning (ex. lumbar stenosis, scoliosis, history of hip arthritis or hip replacement, ankle/foot problems, etc.)? Please describe / list:

Who is your private physician?

Name Address

Telephone Number

Are you currently:

(please check one)

Married (1)

Widowed (2)

Divorced (3)

Single (never married) (4)

Living with someone as if married (5)

What was the highest grade you complete in school?

What is your approximate family income

Including wages, disability payment, retirement

Income and welfare?

$\$ 0-\$ 10,000$

$\$ 10,001-\$ 20,000$

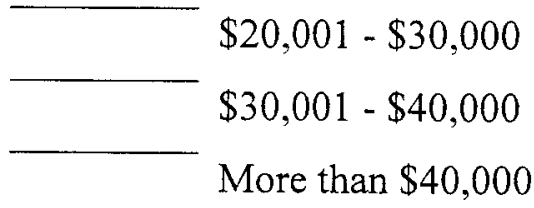




\section{APPENDIX F}

SF-36v2 standard

Your Health and Well-Being

This survey asks for your views about your health. This information will help keep track of how you feel and how well you are able to do your usual activities. Thank you for completing this survey!

For each of the following questions, please mark an $\bigotimes$ in the one box that best describes your answer.

1. In general, would you say your health is:

\begin{tabular}{|ccccc|}
\hline Excellent & $\begin{array}{c}\text { Very } \\
\text { good }\end{array}$ & Good & Fair & Poor \\
$\square 1$ & $\nabla$ & $\nabla$ & $\nabla$ & $\nabla$ \\
$\square$ & $\square 2$ & $\square 3$ & $\square 4$ & $\square 5$
\end{tabular}

2. Compared to one year ago, how would you rate your health in general now?

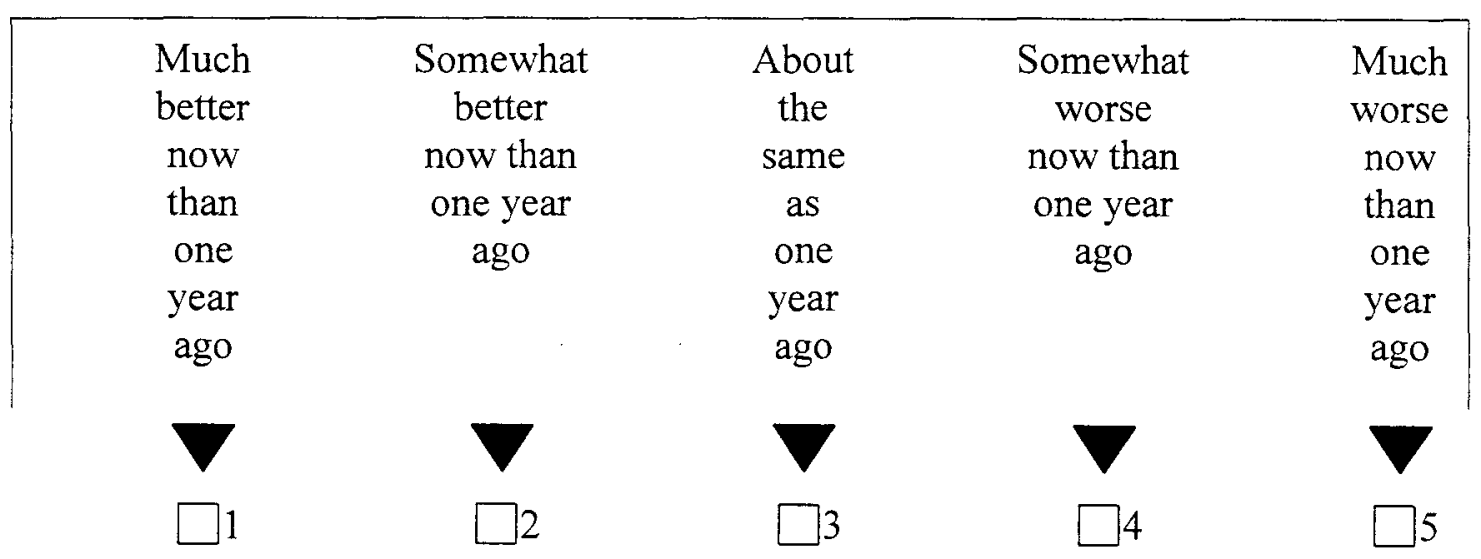


3.The following questions are about activities you might do during a typical day. Does your health now limit you in these activities? If so, how much?

\begin{tabular}{|ccc|}
\hline Yes, & Yes, & No, not \\
limited & limited & limited \\
a lot & a little & at all \\
$\nabla$ & $\nabla$ & $\nabla$
\end{tabular}

a Vigorous activities, such as running, lifting heavy objects, participating in strenuous sports

b Moderate activities, such as moving a table, pushing a vacuum cleaner, bowling, or playing golf.

c Lifting or carrying groceries. $\square 1$ $\square 2$ $\square 3$

d Climbing several flights of stairs

e Climbing one flight of stairs

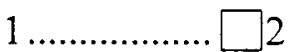

f Bending, kneeling, or stooping...

g Walking more than a mile

h Walking several hundred yards

i Walking one hundred yards.<smiles>C1CCC1</smiles>
$\square 3$

j Bathing or dressing yourself $\square 2$ $\square 3$ 
3. During the past 4 weeks, how much of the time have you had any of the following problems with your work or other regular daily activities as a result of your physical health?

a Cut down on the amount of time you spent on work or other activities

$\begin{gathered}\text { All of Most of Some of A little } \\ \text { the time the time the time one }\end{gathered}$
of the
the time

b Accomplished less than you would like

c Were limited in the kind of work or other activities

d Had difficulty performing the work or other activities (for example, it took extra effort)

4. During the past 4 weeks, how much of the time have you had any of the following problems with your work or other regular daily activities as a result of any emotional problems (such as feeling depressed or anxious)?

$\begin{array}{cccc}\text { All of } & \text { Most of Some of A little } & \text { None of } \\ \text { the time the time the time of the } & \text { the time } \\ \text { time }\end{array}$

a Cut down on the amount of time you spent on work or other activities

$\square 1$

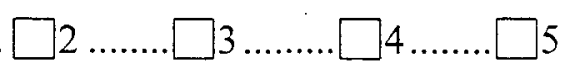

b Accomplished less than you would like

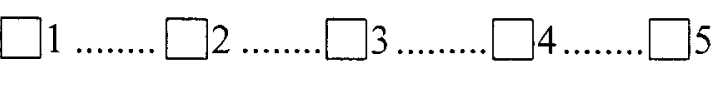

c Did work or other activities less carefully than usual. 
6. During the past 4 weeks, to what extent has your physical health or emotional problems interfered with your normal social activities with family, friends, neighbors, or groups?

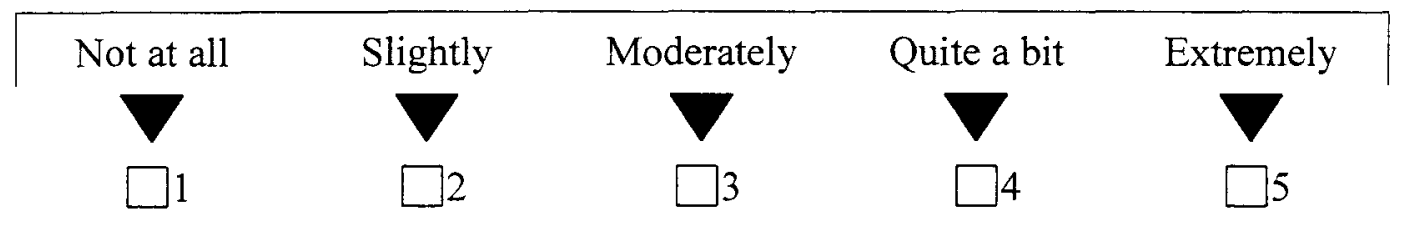

7. How much bodily pain have you had during the past 4 weeks?

\begin{tabular}{|cccccc|}
\hline None & Very mild & Mild & Moderate & Severe & Very Severe \\
$\square 1$ & $\nabla$ & $\nabla$ & $\nabla$ & $\nabla$ & $\nabla$ \\
$\square$ & $\square 2$ & $\square 3$ & $\square 4$ & $\square 5$ & $\square 6$
\end{tabular}

8. During the past 4 weeks, how much did pain interfere with your normal work (including both work outside the home and housework)?

\begin{tabular}{|ccccc|}
\hline Not at all & A little bit & Moderately & Quite a bit & Extremely \\
$\square 1$ & $\nabla$ & $\nabla$ & $\nabla$ & $\nabla$ \\
\hline 2 & $\square 2$ & $\square 3$ & $\square 4$ & $\square 5$
\end{tabular}


9. These questions are about how you feel and how things have been with you during the past 4 weeks. For each question, please give the one answer that comes closest to the way you have been feeling. How much of the time during the past 4 weeks...

$\begin{gathered}\text { All of Most of Some of A little None of } \\ \text { the time the time the time of the the time } \\ \text { time }\end{gathered}$

a Did you feel full of life?

b Have you been very nervous?

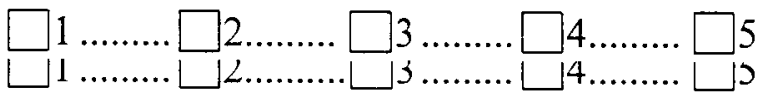

c Have you felt so down in the dumps that nothing could cheer you up?<smiles>c1cc(C2CCC(C3CCC3)C2)ccc1C1CCCC1</smiles>

d Have you felt calm and peaceful?

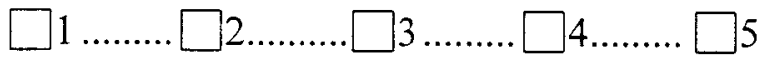

e Did you have a lot of energy?

f Have you felt downhearted and depressed?

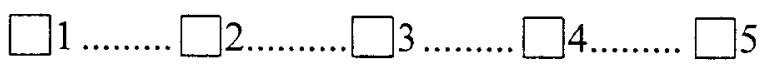

g Did you feel worn out?

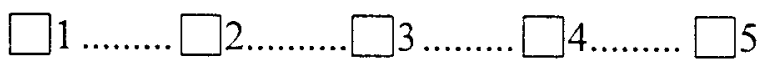

h Have you been happy?

i Did you feel tired?

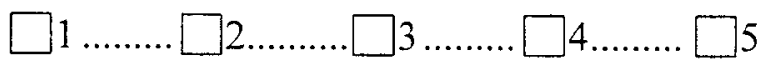

10. During the past 4 weeks, how much of the time has your physical health or emotional problems interfered with your social activities (like visiting friends, relatives, etc.)?

\begin{tabular}{|ccccc|}
\hline $\begin{array}{c}\text { All of the } \\
\text { time }\end{array}$ & $\begin{array}{c}\text { Most of the } \\
\text { time }\end{array}$ & $\begin{array}{c}\text { Some of the } \\
\text { time }\end{array}$ & $\begin{array}{c}\text { A little of the } \\
\text { time }\end{array}$ & $\begin{array}{c}\text { None of the } \\
\text { time }\end{array}$ \\
$\square 1$ & $\square 2$ & $\square 3$ & $\square 4$ & $\square 5$
\end{tabular}


11. How TRUE or FALSE is each of the following statements for you?

\begin{tabular}{|ccccc}
\hline $\begin{array}{c}\text { Definitely } \\
\text { true }\end{array}$ & $\begin{array}{c}\text { Mostly } \\
\text { true }\end{array}$ & $\begin{array}{c}\text { Don't } \\
\text { know }\end{array}$ & $\begin{array}{c}\text { Mostly } \\
\text { false }\end{array}$ & $\begin{array}{c}\text { Definitel } \\
\text { false }\end{array}$ \\
$\nabla$ & $\nabla$ & $\nabla$ & $\nabla$ & $\nabla$
\end{tabular}

a I seem to get sick a little easier than other people

b I am as healthy as anybody I know

....... $\square 1$

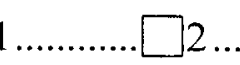

$\square 3$

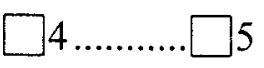

c I expect my health to get worse

$\square 1$

$\square 2$

$\square 3$

$\square 4 \ldots \ldots \ldots$

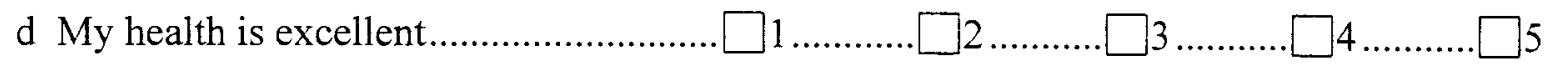

THANK YOU FOR COMPLETING THESE QUESTIONS! 


\section{APPENDIX G}

\section{Visual Analog Scale (VAS) for rating pain during the functional tasks}

Distance Covered in a 6-Minute Walk

Distance:

How much pain did you have in your affected knee which will be or was replaced?

No Pain

Extreme Pain

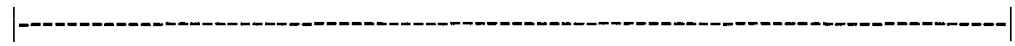

Timed Up and Go Test

Time:

How much pain did you have in your affected knee which will be or was replaced?

No Pain Extreme Pain

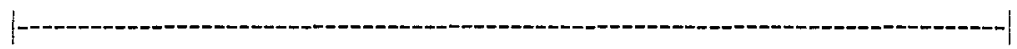

Number of Times Up From a Chair in 30 seconds

Times:

How much pain did you have in your affected knee which will be or was replaced?

No Pain

Extreme Pain

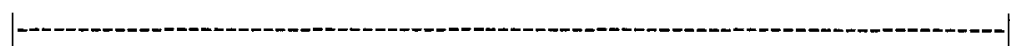

Ascending Stairs

Time:

How much pain did you have in your affected knee which will be or was replaced?

No Pain

Extreme Pain

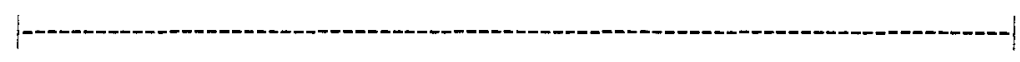

Descending Stairs

Time:

How much pain did you have in your affected knee which will be or was replaced?

No Pain

Extreme Pain

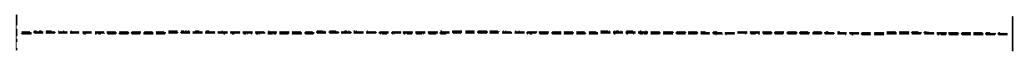


Height:

in. Weight:

\section{Grip Strength:}

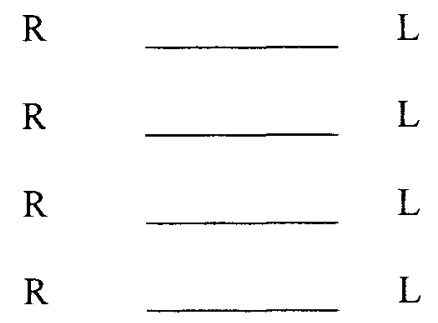

AROM: (Involved: RIGHT or LEFT )

Supine Active Flexion:

$\mathrm{R}$

$\mathrm{L}$

Supine Passive Extension:

$\mathrm{R}$

L

Seated Active Extension

Manual Muscle Test:

$\mathrm{R}$

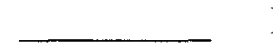

L

AVERAGE(lbs.)

lbs.

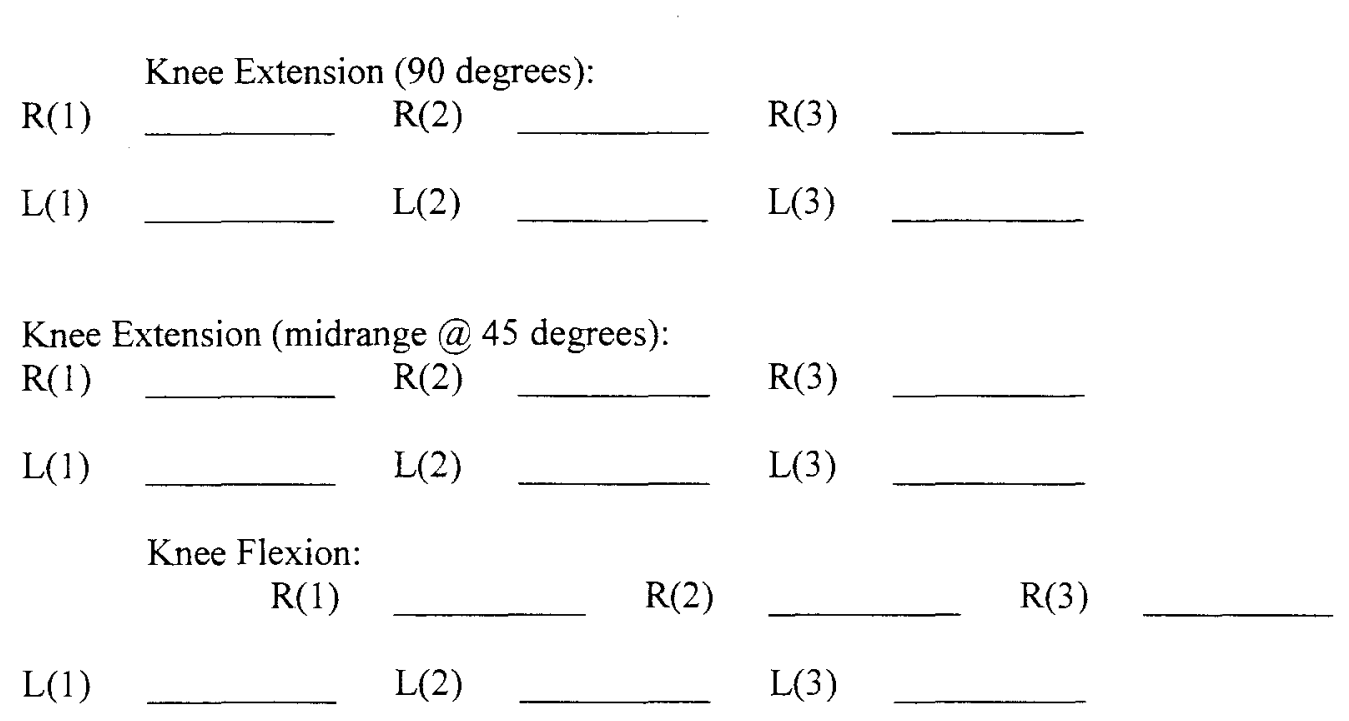

QUALITATIVE/OBSERVATIONAL COMMENTS (e.g. gait characteristics, deformity, SOB, effort, etc.) : 


\section{APPENDIX H}

\section{$\underline{\text { Medication Questionnaire }}$}

Please recall the number, dose and type of all medication(s) you consumed to control your knee pain yesterday. Provide information for all prescribed and over-thecounter medications you took yesterday. (Do not include vitamin supplements, we will ask about them next!)

\begin{tabular}{|c|c|c|c|}
\hline Name of Medication & Dosage & Frequency & Reason for taking \\
\hline Eg. Aspirin & $325 \mathrm{mg}$ (1 pill) & $2 x$ per day & arthritis pain \\
\hline & & & \\
\hline & & & \\
\hline & & & \\
\hline & & & \\
\hline & & & \\
\hline & & & \\
\hline & & & \\
\hline & & & \\
\hline
\end{tabular}

Please provide the following information for all vitamins and/or mineral supplements you took yesterday.

\begin{tabular}{|lllll}
\hline Name of Vitamin/Supplement & Dosage & Frequency & Reason for taking \\
\hline Eg. Glucosamine & - & $-200 \mathrm{mg}$ & -1 per day & Joint health \\
\hline & - & - & - & - \\
\hline
\end{tabular}




\section{APPENDIX I}

The Self-Efficacy Exercise (SEE) scale

CLIENT's NAME

DATE

T -

How confident are you right now that you could exercise 3 times per week for 20 minutes if:

1. The weather was bothering you

$\begin{array}{lllllllllll}0 & 1 & 2 & 3 & 4 & 5 & 6 & 7 & 8 & 9 & 10\end{array}$

2. You were bored by the program or activity

$\begin{array}{lllllllllll}0 & 1 & 2 & 3 & 4 & 5 & 6 & 7 & 8 & 9 & 10\end{array}$

3. You felt pain when exercising

$\begin{array}{lllllllllll}0 & 1 & 2 & 3 & 4 & 5 & 6 & 7 & 8 & 9 & 10\end{array}$

4. You had to exercise alone

$\begin{array}{lllllllllll}0 & 1 & 2 & 3 & 4 & 5 & 6 & 7 & 8 & 9 & 10\end{array}$

5. You did not enjoy it

$\begin{array}{lllllllllll}0 & 1 & 2 & 3 & 4 & 5 & 6 & 7 & 8 & 9 & 10\end{array}$

6. You were too busy with other activities

$\begin{array}{lllllllllll}0 & 1 & 2 & 3 & 4 & 5 & 6 & 7 & 8 & 9 & 10\end{array}$

7. You felt tired

$\begin{array}{lllllllllll}0 & 1 & 2 & 3 & 4 & 5 & 6 & 7 & 8 & 9 & 10\end{array}$

8. You felt stressed

$\begin{array}{lllllllllll}0 & 1 & 2 & 3 & 4 & 5 & 6 & 7 & 8 & 9 & 10\end{array}$

9. You felt depressed

$\begin{array}{lllllllllll}0 & 1 & 2 & 3 & 4 & 5 & 6 & 7 & 8 & 9 & 10\end{array}$

Interviewer Name

(Resnick, et al., 2001) 
CLIENT'S NAME

DATE

T -

\section{Outcome Expectations for Exercise Scale (OEE)}

The OEE is a 9-item measure specifically focusing on the perceived consequences of exercise for older adults. To complete the OEE scale the participant is asked to listen to a statement about exercise and then check (1) to strongly agree, (2) agree, (3) neither agree nor disagree, (4) disagree, or (5) strongly disagree with the stated outcomes or benefits of exercising, which relate to both physical and mental health. The following 9 statements are included:

1. Makes me feel better physically

(1) ___ strongly agree

(2) agree

(3) n__ neither agree nor disagree

(4) disagree

(5) __ strongly disagree

2. Makes my mood better in general

(1) __ strongly agree

(2) __ agree

(3) neither agree nor disagree

(4) disagree

(5) __ strongly disagree

3. Helps me feel less tired

(1) __ strongly agree

(2) _ agree

(3) __ neither agree nor disagree

(4) — disagree

(5) __ strongly disagree

4. Makes my muscles stronger

(1) __ strongly agree

(2) _ agree

(3) n_ neither agree nor disagree

(4) disagree

(5) ___ strongly disagree 
5. Is an activity I enjoy doing
(1) strongly agree
(2) agree
(3) neither agree nor disagree
(4) _ disagree
(5) ___ strongly disagree

6. Gives me a sense of personal accomplishment
(1)
(2) agree
(3) neither agree nor disagree
(4) _ disagree
(5) __ strongly disagree

7. Makes me more alert mentally
(1)
(2) strongly agree
agree
(3) ___ neither agree nor disagree
(4) disagree
(5) __ strongly disagree

8. Improves my endurance in performing my daily activities
(1) strongly agree
(2) __ agree
(3) ___ neither agree nor disagree
(4) ___ disagree
(5) ___ strongly disagree

9. Helps to strengthen my bones.
(1) strongly agree
(2) __ agree
(3) __ neither agree nor disagree
(4) disagree
(5) __ strongly disagree

Interviewer's Name

(Resnick, et al., 2001) 


\section{GLOSSARY}

\section{Operational Terms}

Prehabilitation is the concept of preparing the body prior to a stressful event such as TKA surgery. This is done by enhancing knee strength and the ability to complete functional tasks of TKA patients preoperatively through exercise interventions introduced prior to their TKA.

Total Knee Arthroplasty (TKA) involves removal of the knee joint affected by $\mathrm{OA}$ and the placement of a prosthetic device, commonly involving prolonged rehabilitation (DeFrances \& Hall, 2004; Hawker, et al., 2006).

Elective is the term used when TKA surgery is performed by choice. One of the benefits of elective surgery is the time it allows for optimal preparation (including Prehabilitation) of the patient.

Primary surgery is original surgery, not a revision or the correction of a previous surgery.

Unilateral means done on one side.

Self-Efficacy is a person's belief in his or her ability to succeed in a particular situation or in obtaining a goal (A Bandura, 1997).

Self-efficacy expectations are the individual's beliefs in his or her capabilities to perform a specific behavior. 
Outcome expectations are the beliefs that carrying out a specific behavior will lead to a desired outcome. An outcome expectation might be what the individual perceives to be the benefits of exercise (e.g., improving muscle strength, living longer, losing weight, or feeling good in general) (Resnick, et al., 2001).

The 6 -minute walk distance test will be measured by the distanced traveled over a 30 meter track within 6 minutes. This measures exercise capacity.

Functional ability in Activities of Daily Living (ADL) is often measured by way of functional tasks. Functional tasks include any physical activity that simulates a practical task contributing to independent functioning including walking, rising from a chair, or negotiating stairs.

The Timed get up and go test (TUG) measures the time it takes a subject to rise from an armed chair, walk three meters, turn and return to a sitting position in the same chair.

Ascend/descend 10 stairs (ST) will be used to assess the subject's ability to ascend and descend a flight of 19 standard 7-inch stairs.

Sit-to-stand in 30 seconds will be employed to determine the subject's capacity to rise repeatedly from a chair over a 30-second period of time.

Knee strength will be assessed by the number of straight leg raises the subject can perform from a reclining position in 30 seconds.

$\underline{\text { Knee Range of Motion. Unassisted extension and flexion flexibility of both knees }}$ will also be assessed while the subject is seated on an examination table with legs dangling free from the floor. 
Adherence with the prehabilitation treatment will be monitored through exercise logs completed by each subject following each session of prehabilitation exercise and will be monitored weekly by the staff member conducting the supervised exercise session. 


\title{
CURRICULUM VITAE
}

\author{
Anthony Kent Brown \\ 3503 Hardwood Forest Drive \\ Louisville, KY. 40214 \\ (502) 523-4107 \\ kbrown@bellarmine.edu
}

\section{Academic Degrees}

\section{University of Louisville Louisville, $\mathrm{KY}$}

PhD. The School of Public Health and Information

Sciences. December, 2010

\section{University of Louisville Louisville, $\mathrm{KY}$}

M.S. in Exercise Physiology

Clinical Coursework: Applied Exercise Physiology; Lab Methods

in Exercise Physiology; Human Physiology; Applied Statistics;

Principles in Exercise Testing and Prescription; Physiology of

Exercise; Advanced Topics; Seminar in Exercise Physiology.

Health and Wellness/ Nutrition

\section{University of Louisville Louisville, KY}

B.S. in Health and Human Performance

Concentration in Exercise Science and Sports Medicine

Minor...Sport Administration

\section{Professional Experience}

Bellarmine University August, 2009- Present

Chair, Exercise Science Department

Assistant Professor

University of Louisville 2003 - July, 2009

Instructor, Health and Sports Sciences (HSS),

School of Education

Teach assigned classes and laboratory sections:

EXP 501; Applied Exercise Physiology

HSS 386; Structure in the Movement

Sciences A\&PI 
HSS 390 Function in the Movement

Sciences A\&PII

HSS 387; Kinesiology/Biomechanics, study of human movement

HSS 394; Introduction to Exercise Science

HSS 486; Introduction to Advanced Exercise Physiology

HSS 395; Personal Trainer Workshop

HSS 202; Human Anatomy and Physiology - Lab Biology

HSS 184; Healthy Lifestyles/Wellness Activity Classes

Nutrition Classes

Academic Advisor: HSS Department: a-m junior and senior ESS majors (225 students)

Elizabethtown Community \& Technical College

Adjunct Instructor - Biology 130, 139 (A \& P I \& II with Lab)

Jefferson Community \& Technical College

Adjunct Instructor - presently teaching Biology $137 \& 139$ (A \& P I \& II with Lab)

\section{Indiana Wesleyan University}

Adjunct Instructor - Concepts of Health and Wellness PHE 140

World Instructor Training Schools (WITS)

Instructor- Personal Training

\section{University of Louisville Louisville, KY}

Campus Health Initiative Jan. 2005-August 2005

Fitness Coordinator/Personal Trainer

- Health \& Fitness Assessments based on ACSM Guidelines

- Supervise student interns

- Direct Independent Study 
Graduate Teaching Assistant (GTA) Aug.03-Jan. 2005

Responsible for the instruction of college level activity classes each semester; weight training; human nutrition; physical fitness and conditioning, and fitness walking.

Responsible for the development and execution of the syllabus for these classes.

Teaching members of the PACT program (Program designed for the mentally challenged).

Assisting in the University of Louisville Exercise Physiology lab with research projects

Responsible for tutoring student athletes

\section{Exercise Physiology/Internship Louisville, KY}

Cardiovascular Associates (cardiac rehab) summer 2003

Provided strength and stress testing for cardiac patients

Develop exercise prescriptions for patients

Responsible for taking pts blood pressure prior to, during, and after exercise

Completed progress reports at cessation of rehabilitation program

Provided dietary and nutrition counseling to patients

Performed entry/exit stress tests for cardiac patients

Personal Trainer, Certified Strength and Conditioning Specialist (NSCA)

Member of the American College Sports Medicine (ACSM)

\section{Louisville Gas \& Electric Co. Louisville, KY}

Operator / Supervisor 07/1977-04/2001 retired Supervised 20 employees

Designed work-study materials for new employees

Developed Wellness Department at LG\&E

Maintained CPR and First Aid Standards as per OSHA 
Active member of the Safety Committee

\section{Honors \& Activities}

Awarded the 2010 Bellarmine Faculty Development Award Bellarmine University: Academic sponsor of Exer Science Club Bellarmine University: Undergraduate Affairs Committee Presently a National Strength and Conditioning Association(Certified Strength and Conditioning Specialist certified) and American College of Sports Medicine member University of Louisville Dean's Scholar (4.0 GPA) University of Louisville Dean's List (3.5 GPA) National Physique Committee (NPC) State Chair, 1990-2002

National NPC Bodybuilding Judge 1990-present 1986 KY Bodybuilding Champion

National Bodybuilding Competitor, 1987-1990 (Won Mid-USA title)

Prairie Village League Vice-President for 4 years, administered budget of approx. $\$ 100,000$ yearly CPR certified by American Heart Association (Current) Student Mentor award multiple times Awarded Faculty Favorite by U of L student body $>10$ times Honorary Faculty Guest Coach Men's \& women's Basketball

Presented to local organizations with talks on the benefits of strength training, physical fitness, wellness and nutrition, Risks of Child and Adult Obesity.

Presented at University of Louisville and Bellarmine University programs for Freshman Orientation into Exercise Science Programs. 


\section{Current Research}

Manuscript (published) with the Journal of Strength and Conditioning Research.

Brown, K., Kachelman, J., Swank, A., Quesada, P., Nyland, J., Malkani, A., Topp, R. (2009). Predictors of functional task performance among patients scheduled for total knee arthroplasty. Journal of Strength \& Conditioning Research, 23(2), 436-443.

Manuscript (published) with the Functional U Journal, a publication of the International Council on Active Aging (ICAA).

Joe Kachelman, Kent Brown, M.S., Robert Topp, RN, PhD. Exercise Programming for Individuals using Ambulatory Assistive Devices. Functional U. ICAA Research Review: July 2008, Volume 8, No. 26

Manuscript (Published) with Lower Extremity Review.

Brown, K., J. A. Brosky, D. Pariser, R. Topp. (March 2010). Preoperative Exercise Boosts Total Knee Arthroplasty (TKA) Outcomes. Lower Extremity Review. 2 (1), 53 61.

Manuscript (published) with Physiotherapy Theory and Practice: An International Journal of Physiotherapy

Brown, K., A. M. Swank, , P.M. Quesada, J. Nyland, A. Malkani, R. Topp. (August, 2010).

Prehabilitation vs. Usual Care before Knee Arthroplasty: A case report comparing outcomes within the same individual. Physiotherapy Theory and Practice: An International Journal of Physiotherapy. 26(6): 399- 410.

\section{Abstract presentations:}

Joseph Brosky, Margaret Finley, Robert Topp, Clyde Killian, Dave Pariser, Kent Brown, Gary Bloemer, Zack Stearns. Effects of a Partially Supervised Prehabilitation Exercise Program on Functional Performance Tasks before and After Total Knee Arthroplasty. American Physical Therapy Association (APTA). Combined Sections Meeting 2011 in New Orleans, LA. February 9-12, 2011.

Kent Brown, PhDc, M.S., Joseph A Brosky, PT, MS, SCS., David Pariser, PT, PhD. Gary F Bloemer, MD., Zack R Sterns, MD., Robert Topp, RN, PhD., Ann Swank, PhD., FACSM. Effects of Pre-habilitation on Early Functioning Following Total Knee Arthroplasty. American College of Sports Medicine National Conference. June 1-5, 2010. Baltimore, Maryland. 
R. Topp, J.A. Brosky Jr. K. Brown \& D. Parsier (2009) Effects of Prehabilitation on Early Rehabilitation of Patients Following Total Knee Arthroplasty. TheraBand Research Advisory Council, Cancun, Mexico, July 23-30, 2009.

Brown, K., A. M. Swank, R. Topp, P. .M Quesada, J. Kackelman, J. Nyland, A. Malkani. Prehabilitation vs. Usual Care before Knee Arthroplasty: A case study comparing outcomes within the same individual. American College of Sports Medicine National Conference. Oral presentation. May 27-30, 2009. Seattle, Washington.

Kent Brown, Ann M Swank, Robert Topp, Joe Kachelman, Peter M Quesada, John Nyland, Arthur Malkani, Effects of an 8 week prehabilitation program on strength among patients scheduled for total knee arthroplasty. Research Louisville 2008 Louisville, KY. October 21, 2008.

Kent Brown, Joe Kachelman, Ann M Swank, Peter M Quesada, John Nyland, Arthur Malkani, Robert Topp, Effects of an 8 week prehabilitation program on strength among patients scheduled for total knee arthroplasty. NSCA national Conference: July 8-12, 2008. Las Vegas, NV.

Kent Brown, M.S., Ann M Swank, PhD, FACSM, Robert Topp, RN, PhD, Peter M Quesada, PhD, Joe Kackelman, John Nyland, PT, EdD, FACSM, Arthur Malkani, MD. Predictors of functional ability among patients scheduled for total knee arthroplasty. American College of Sports Medicine National Conference. May 2831, 2008. Indianapolis, Indiana

Kent Brown, Joe Kachelman, Ann M Swank, PhD, Peter M Quesada, PhD, John Nyland, $\mathrm{PT}, \mathrm{PhD}$, Arthur Malkani, MD, Robert Topp, RN, PhD. Predictors of functional ability among patients scheduled for total knee arthroplasty. Research Louisville 2007!, Louisville, KY. October 16-19, 2007.

Naeger, C.W., Brown, K., Swank, A.M., Quesada, P.M., Nyland, J., Durham, M.P. \& Topp, R. Eight Weeks Pre-habilitation Increases Functional Performance: Casecontrol Comparison of Two Patients with Total Knee Arthroplasty. ACSM National Convention, Nashville, TN. May 25-June3, 2005.

Kent Adams, PhD. CSCS., Kent Brown, M.S., Current Research being performed (2004) abstract submitted to ACSM on Metabolic Comparison Between a One-And Two Handed Identical Lifting Task. 


\section{Professional References:}

Dr. Bryant Stamford, Professor

Hanover College Indiana

Phone: (812) 866-7236

stamford@hanover.edu

Dr. Robert Topp

University of Louisville

School of Nursing

Shirley Powers Endowed Chair for Research

Professor \& Distinguished University Scholar

Phone: (502) 852-8510

robert.topp@ louisville.edu

Ann Swank. PhD

Professor and Director

Exercise Physiology Lab

College of Education \& Human Development

Crawford Gym

University of Louisville, Louisville, $\mathrm{KY}$

Phone: (502) 852-8351

FAX: (502) 852-4534

swank@louisville.edu

Dr. Scott LaJoie

School of Public Health and Information Science

Department of Health Promotion and Behavioral Sciences

University of Louisville

Phone : 502-852- 1879

ASLAJO01@louisville.edu

Dr. Dean Jacks

School of Education, HSS Department

Department Director

Phone (502) 852-5050

FAX: (502) 852-4534

dejack02@gwise.louisville.edu 